University of Tennessee Health Science Center

UTHSC Digital Commons

\title{
Examining the Associations between Depressive Symptoms, Body Mass Index, and Physical Activity Self-Efficacy in African American Mother-Child Dyads
}

Y'Esha Vonyae Williams

University of Tennessee Health Science Center

Follow this and additional works at: https://dc.uthsc.edu/dissertations

Part of the Psychiatric and Mental Health Nursing Commons, and the Psychiatry and Psychology Commons

\section{Recommended Citation}

Williams, Y'Esha Vonyae (http://orcid.org/0000-0003-0917-4069), "Examining the Associations between Depressive Symptoms, Body Mass Index, and Physical Activity Self-Efficacy in African American MotherChild Dyads" (2016). Theses and Dissertations (ETD). Paper 416. http://dx.doi.org/10.21007/ etd.cghs.2016.0418. 


\title{
Examining the Associations between Depressive Symptoms, Body Mass Index, and Physical Activity Self-Efficacy in African American Mother-Child Dyads
}

\begin{abstract}
In recent decades the prevalence of childhood and adult depression and obesity has increased worldwide. Multiple factors influence the onset of both depression and obesity. Individual manifestations of depressive symptomatology and health-related problems associated with obesity vary; however, genetics and environmental and psychological factors have been implicated as correlates. Consequently, both disorders can ultimately interfere with individuals' activities of daily living and decrease their quality of life. African American women are known to have a higher prevalence of obesity and more severe depressive symptoms in comparison to Caucasian women. Likewise, African American children are more obese and experience many factors that influence the onset of depressive symptoms. With increases in the prevalence of childhood obesity and diagnoses of mood disorders in youth, analyzing the family's influence on these outcomes has become increasingly important. The purpose of this correlational study was to examine the associations among child depressive symptoms, body mass index (BMI) Z-scores, and physical activity self-efficacy and maternal depressive symptoms and BMI in African American mother-child dyads. A community sample of 65 African American mother-child dyads was recruited. Data were collected on height and weight to estimate BMI and self-report questionnaires were used to assess depressive symptoms among participating mothers and their children. Additional information on physical activity self-efficacy was collected from each child. Pearson product moment correlation coefficients were estimated to determine associations between variables that were sampled from underlying normal distributions. Spearman correlation coefficients were estimated to assess correlates of maternal BMI because data from this variable did not reflect sampling from a normal distribution. Results indicated positive correlations between children's depressive symptoms and their BMI Z-scores and their mothers' depressive symptoms. More depressive symptoms in children were related to having a higher BMI Zscore and a mother with more depressive symptoms. Results also indicated important correlations for the children's physical activity self-efficacy with their depressive symptoms, their BMI Z-scores, and maternal depressive symptoms. Although several associations were found between the children's physical activity self-efficacy and their depressive symptoms, BMI Z-scores, and maternal depressive symptoms, researchers should cautiously rely on self-reports of physical activity self-efficacy from younger children given that some children had difficulty understanding the self-efficacy measure. Findings suggest that the associations between depressive symptoms, BMI, and physical activity self-efficacy in African American mother-child dyads merit additional examination as such research studies may inform future approaches to prevent and treat obesity and depression in this population.
\end{abstract}

\section{Document Type}

Dissertation

\section{Degree Name}

Doctor of Philosophy (PhD)

\section{Program}

Nursing Science

Research Advisor

Carolyn J. Graff, Ph.D.

Keywords

African American, Depression, Obesity, Physical Activity, Self-Efficacy 


\section{Subject Categories}

Medicine and Health Sciences | Nursing | Psychiatric and Mental Health Nursing | Psychiatry and Psychology 
Examining the Associations between Depressive Symptoms, Body Mass Index, and Physical Activity Self-Efficacy in African American Mother-Child Dyads

\author{
A Dissertation \\ Presented for \\ The Graduate Studies Council \\ The University of Tennessee \\ Health Science Center
}

\author{
In Partial Fulfillment \\ Of the Requirements for the Degree \\ Doctor of Philosophy \\ From The University of Tennessee
}

By

Y'Esha Vonyae Williams

December 2016 
Copyright (C) 2016 by Y'Esha Williams. All rights reserved. 


\section{DEDICATION}

I dedicate this dissertation to my daughters Zyaa and Imerie.

I love you both beyond measure. 


\section{ACKNOWLEDGEMENTS}

I would like to acknowledge and show my appreciation to Dr. Patricia Cowan for initially accepting me as her graduate student in 2012. Under your mentorship and guidance I have acquired positive work ethics, I have accomplished many goals, and I was afforded many opportunities to engage in teaching and research activities. Your hard work does not go unnoticed and I aspire to follow in your footsteps.

I would like to also like to acknowledge the members of my committee Dr. Elizabeth Tolley, Dr. Mona Wicks, and Dr. Marion Hare for your continued support, your input, and all the time and effort that you have provided.

Lastly, I would like to acknowledge and thank Dr. Carolyn Graff for accepting the position as my committee chair in the Fall term of 2015. Your leadership, patience, and continued involvement in my dissertation process have been very essential in the completion of my project and I am forever grateful. 


\begin{abstract}
In recent decades the prevalence of childhood and adult depression and obesity has increased worldwide. Multiple factors influence the onset of both depression and obesity. Individual manifestations of depressive symptomatology and health-related problems associated with obesity vary; however, genetics and environmental and psychological factors have been implicated as correlates. Consequently, both disorders can ultimately interfere with individuals' activities of daily living and decrease their quality of life. African American women are known to have a higher prevalence of obesity and more severe depressive symptoms in comparison to Caucasian women. Likewise, African American children are more obese and experience many factors that influence the onset of depressive symptoms. With increases in the prevalence of childhood obesity and diagnoses of mood disorders in youth, analyzing the family's influence on these outcomes has become increasingly important.
\end{abstract}

The purpose of this correlational study was to examine the associations among child depressive symptoms, body mass index (BMI) Z-scores, and physical activity selfefficacy and maternal depressive symptoms and BMI in African American mother-child dyads. A community sample of 65 African American mother-child dyads was recruited. Data were collected on height and weight to estimate BMI and self-report questionnaires were used to assess depressive symptoms among participating mothers and their children. Additional information on physical activity self-efficacy was collected from each child. Pearson product moment correlation coefficients were estimated to determine associations between variables that were sampled from underlying normal distributions. Spearman correlation coefficients were estimated to assess correlates of maternal BMI because data from this variable did not reflect sampling from a normal distribution.

Results indicated positive correlations between children's depressive symptoms and their BMI Z-scores and their mothers' depressive symptoms. More depressive symptoms in children were related to having a higher BMI Z-score and a mother with more depressive symptoms. Results also indicated important correlations for the children's physical activity self-efficacy with their depressive symptoms, their BMI Zscores, and maternal depressive symptoms. Although several associations were found between the children's physical activity self-efficacy and their depressive symptoms, BMI Z-scores, and maternal depressive symptoms, researchers should cautiously rely on self-reports of physical activity self-efficacy from younger children given that some children had difficulty understanding the self-efficacy measure. Findings suggest that the associations between depressive symptoms, BMI, and physical activity self-efficacy in African American mother-child dyads merit additional examination as such research studies may inform future approaches to prevent and treat obesity and depression in this population. 


\section{TABLE OF CONTENTS}

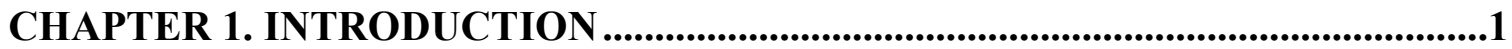

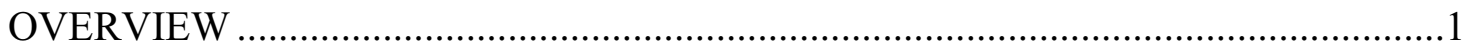

SIGNIFICANCE OF STUDY .........................................................................

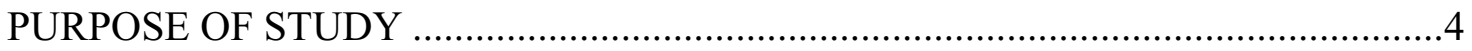

Specific Aim One and Research Hypotheses..........................................................

Specific Aim Two and Research Hypotheses ...................................................

Specific Aim Three and Research Hypotheses ............................................................4

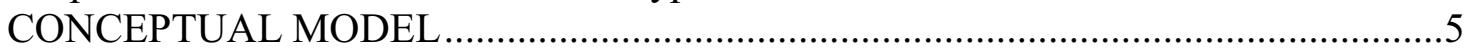

DEFINITIONS OF VARIABLES …................................................................. 10

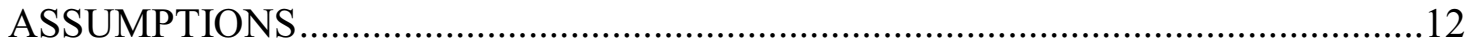

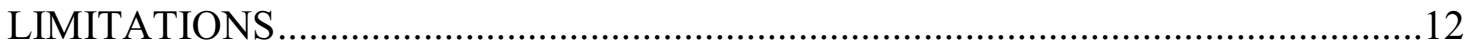

CHAPTER 2. LITERATURE REVIEW ............................................................13

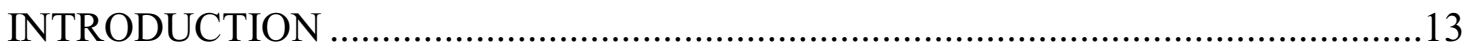

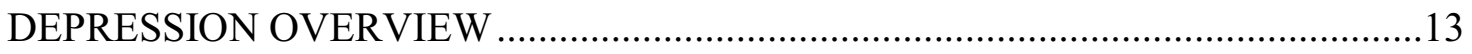

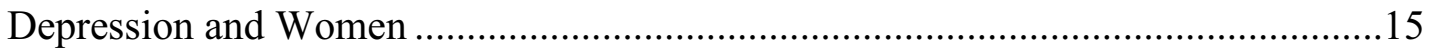

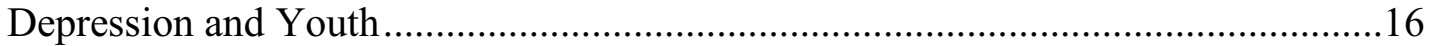

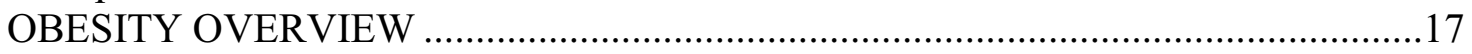

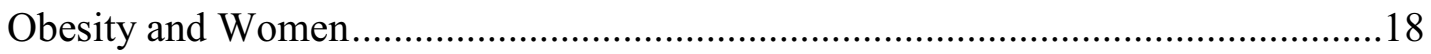

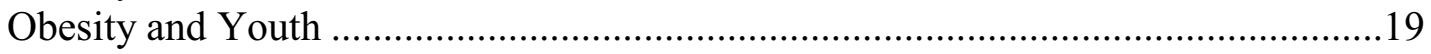

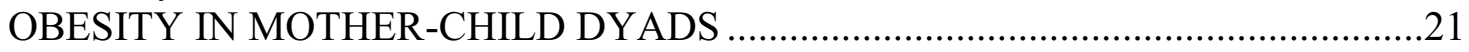

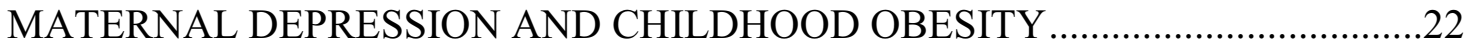

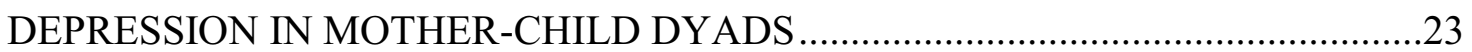

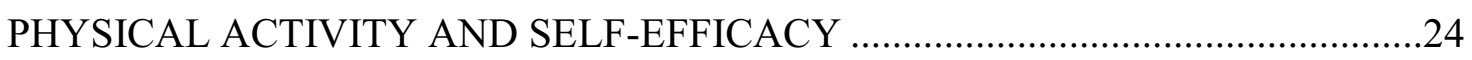

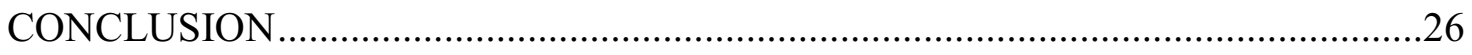

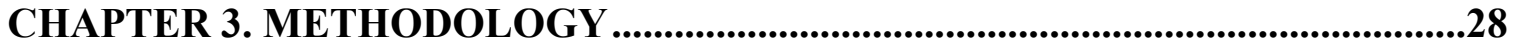

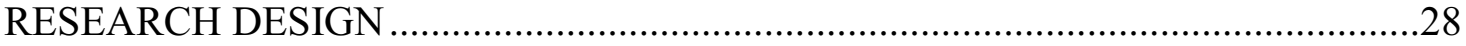

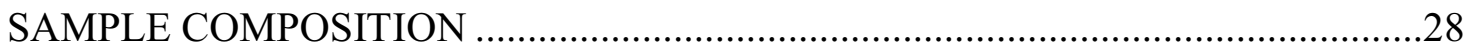

Mother Inclusion Criteria ..................................................................................28

Mother Exclusion Criteria...................................................................................28

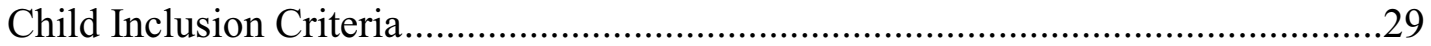

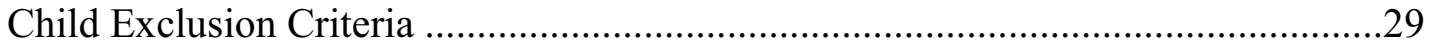

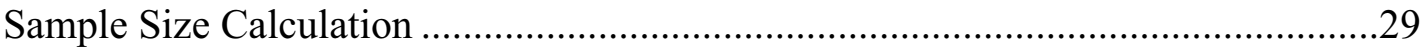

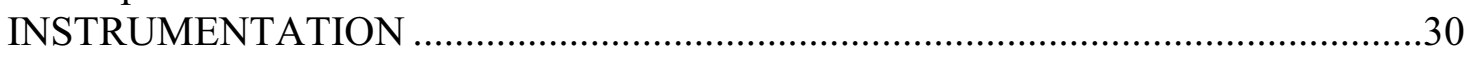

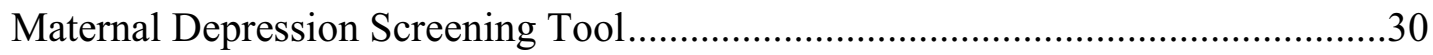

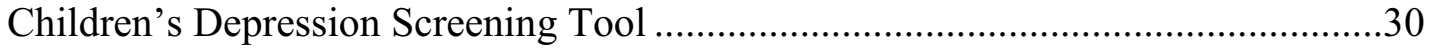

Physical Activity Self-Efficacy Assessment in Children........................................ 31

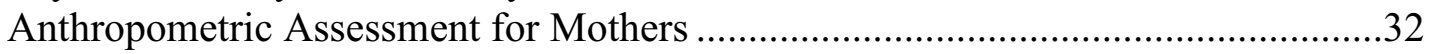

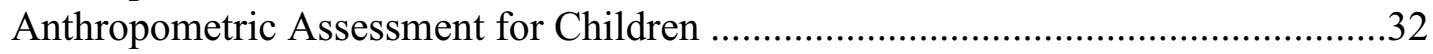

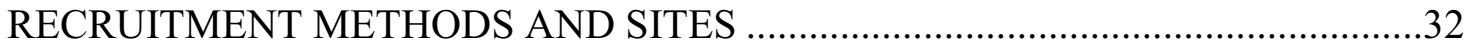

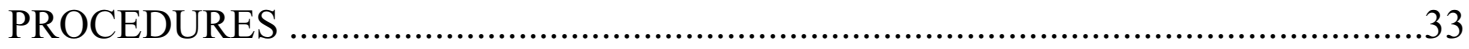

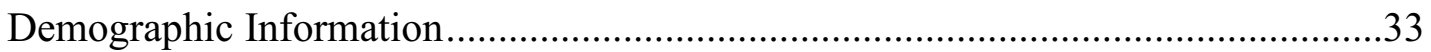




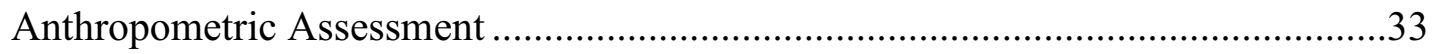

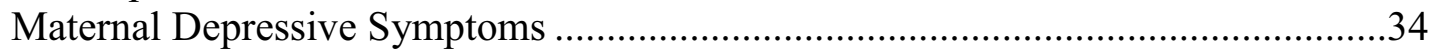

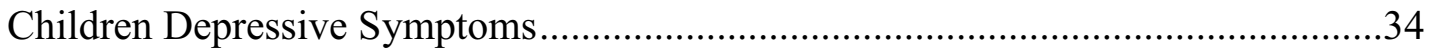

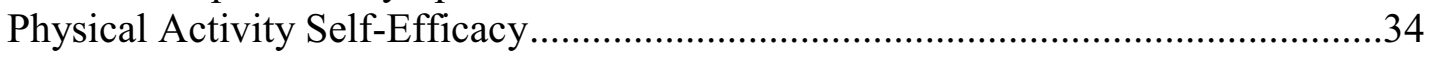

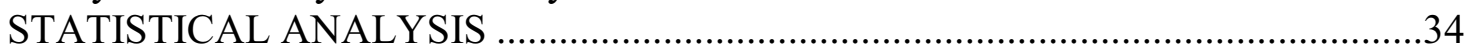

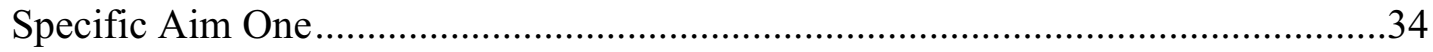

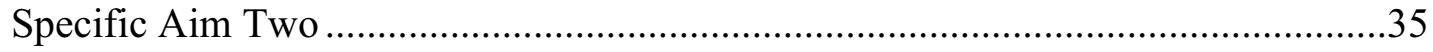

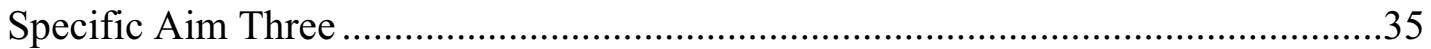

CONSIDERATION OF HUMAN SUBJECTS..........................................................

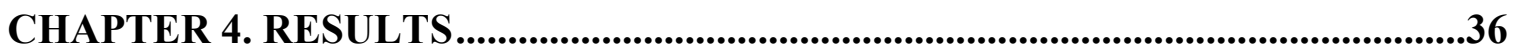

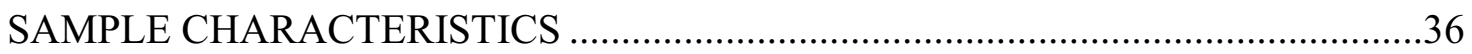

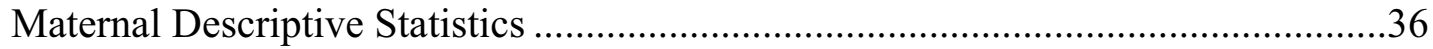

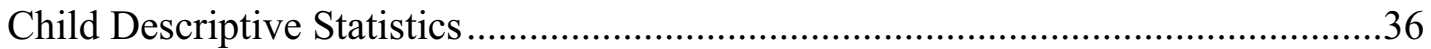

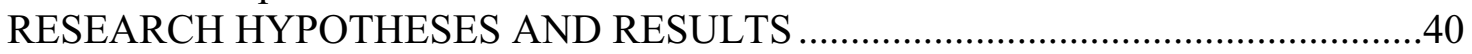

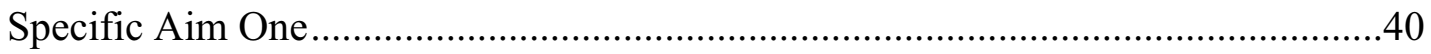

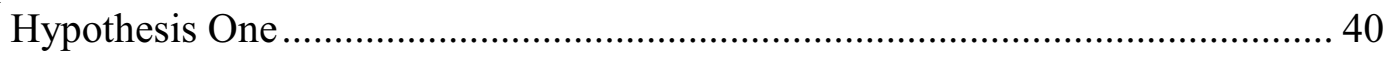

Hypothesis One Results ............................................................................... 40

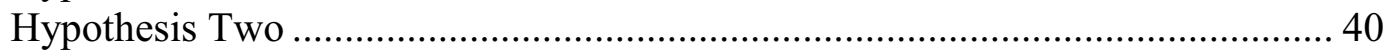

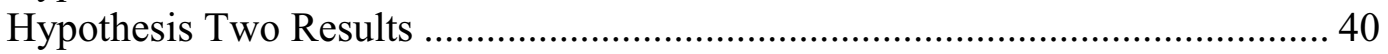

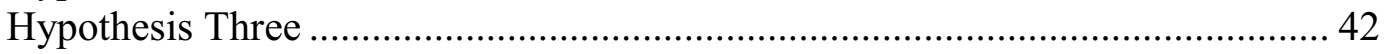

Hypothesis Three Results …………………………................................... 42

Hypothesis Four ……………………….............................................. 42

Hypothesis Four Results ................................................................................ 42

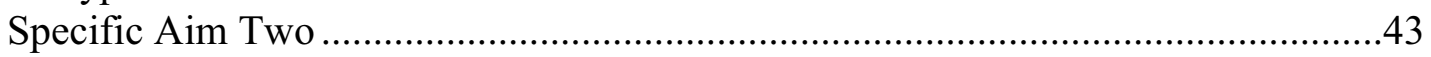

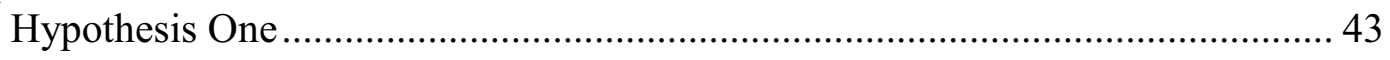

Hypothesis One Results .................................................................................... 43

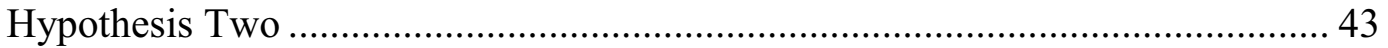

Hypothesis Two Results ................................................................................. 43

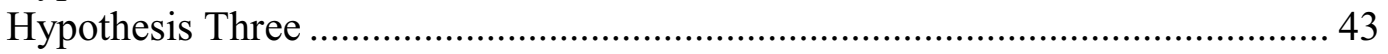

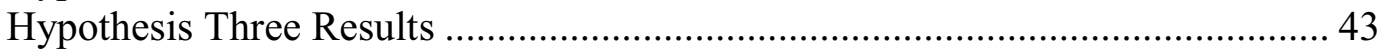

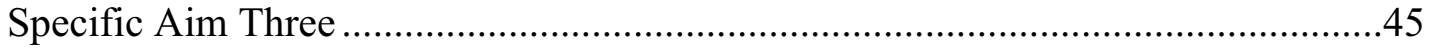

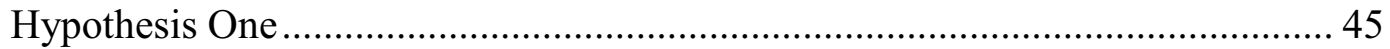

Hypothesis One Results ................................................................................... 45

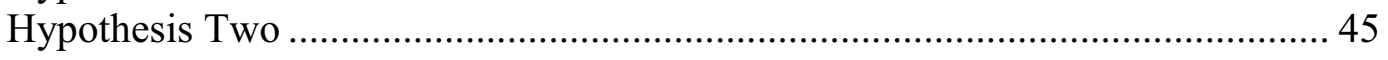

Hypothesis Two Results ................................................................................. 45

CHAPTER 5. DISCUSSION .........................................................................................47

DISCUSSION OF DEMOGRAPHIC FINDINGS …………...................................

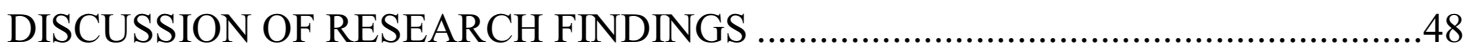

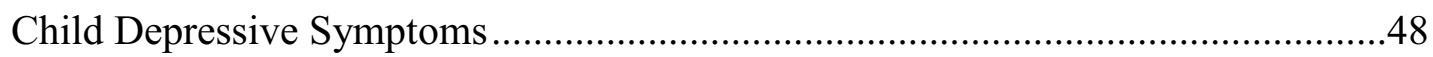

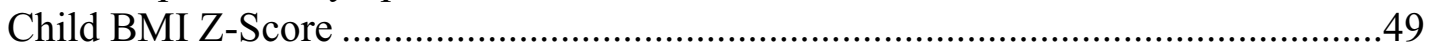

Physical Activity Self-Efficacy.......................................................................... 49

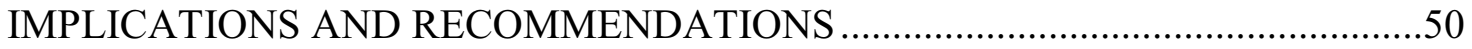

Church Partnerships …………………………………................................5

Primary Care Partnerships ................................................................................... 


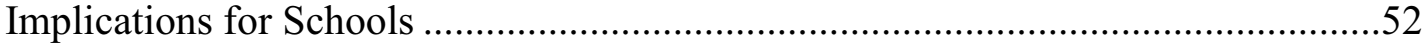

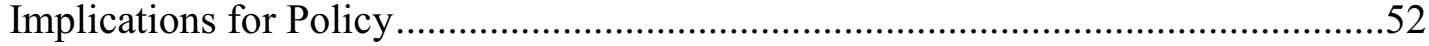

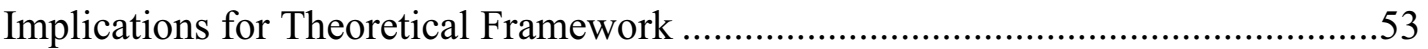

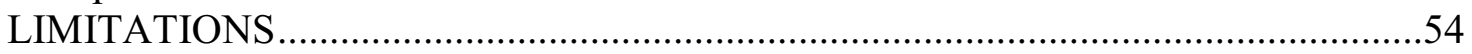

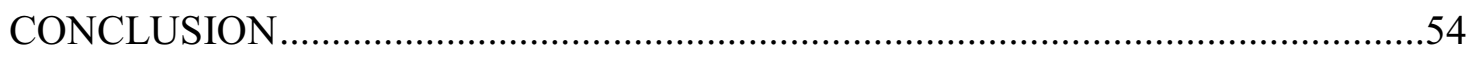

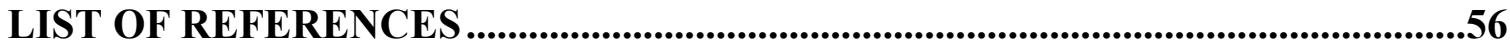

APPENDIX A. PHYSICAL ACTIVITY SELF-EFFICACY SCALE ........................71

APPENDIX B. DEMOGRAPHIC PROFILE QUESTIONNAIRE ..........................73

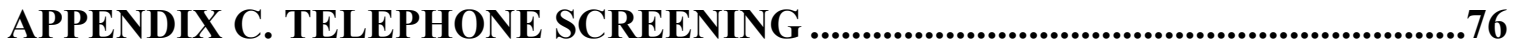

APPENDIX D. MAIN CONSENT AND ASSENT FORMS ........................................77

APPENDIX E. IRB LETTER OF APPROVAL ................................................84

VITA 


\section{LIST OF TABLES}

Table 4-1. Demographic Characteristics of 65 African American Mother-Child Dyads Enrolled in the Study from June-December 2015

Table 4-2. Age, Anthropometric Measures, and BDI®-II Assessments for 65 African American Mothers Enrolled in the Study from June-December 2015

Table 4-3. Anthropometric Measurements, CDI 2, and Physical Activity SelfEfficacy Assessments for 65 African American Children Enrolled in the Study from June-December 2015

Table 4-4. Estimated Correlation Coefficients of Child Depressive Symptoms with Child BMI Z-Score, Maternal BMI, Maternal Depressive Symptoms, and Child Physical Activity Self-Efficacy from 65 Mother-Child Dyads ...41

Table 4-5. Estimated Correlation Coefficients of Child BMI Z-Scores with Maternal BMI, Maternal Depressive Symptoms, and Child Physical Activity Self-Efficacy from 65 Mother-Child Dyads.

Table 4-6. Estimated Correlation Coefficients of Child Physical Activity SelfEfficacy with Maternal BMI, and Maternal Depressive Symptoms from 65 Mother-Child Dyads 


\section{LIST OF FIGURES}

Figure 1-1. Amended Social Cognitive Theory with Study Variables ..........................6

Figure 1-2. Model of Study Variables for Hypothesized Associations in Aim One .........7

Figure 1-3. Model of the Study Variables for Hypothesized Associations in Aim

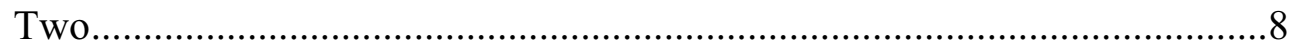

Figure 1-4. Model of the Study Variables for Hypothesized Associations in Aim Three. 


\section{LIST OF ABBREVIATIONS}

AMS

$\mathrm{BDI}^{\circledR}-\mathrm{II}$

BMI

BMI Z-Score

BMS

CDI 2

NHANES

PASES

SAS

SCT
After Maternal Surgery

Beck Depression Inventory ${ }^{\circledR}$-II

Body Mass Index

Body Mass Index percentile Z-score for children

Before Maternal Surgery

Children's Depression Inventory $2^{\mathrm{TM}}$

National Health and Nutrition Examination Survey

Physical Activity Self-Efficacy Scale

Statistical Analysis System Version 9.3

Social Cognitive Theory 


\section{CHAPTER 1. INTRODUCTION}

\section{OVERVIEW}

Childhood and adolescent depression is an area of current research that has steadily increased over the last few decades. The National Alliance on Mental Health (2014) estimates $11 \%$ of children will experience a depressive disorder by the age of 18 . Depressive disorders are multifaceted and are associated with a variety of factors. Manifestations of depressive symptomatology vary between individuals; however, a combination of genetics, environmental, and psychological factors are associated with the development of depression (National Institute of Mental Health, n.d.). Symptoms of depression can ultimately interfere with a child's activities of daily living and decrease their quality of life. Historically, depressive symptoms in children and adolescents were dismissed as the child being moody or disobedient. This perspective contributed to a general disbelief that younger populations do not experience depression (Cash, 2004). However, with the advent of depressive symptom screening tools for youth, more depressed children are being identified and diagnosed.

In adults, estimates indicate that by 2020 depression will be the second leading cause of disability globally. Adult depression is triggered by many factors such as poor socioeconomic conditions and a lack of quality health care treatment (Legrand, 2014). In 2014, national averages indicated 15.7 million adults ( $8.1 \%$ female and $5.1 \% \mathrm{men})$ had at minimum one major depressive episode in the previous year (National Institute of Mental Health, 2014b). When examining gender differences globally, women have higher rates of depressive illnesses than men (Waite \& Killian, 2008). Researchers believe that depression in women not only correlates with decreased physical activity but it also increases the risk for stroke and cardiovascular disease (Harvard Medical School, 2011).

Similar to increases in depression, there has been a significant increase in the rates of overweight and obesity worldwide. The prevalence of overweight and obese children in America has nearly tripled over the last three decades. According to the American Heart Association (2014a) one in three U.S. children and adolescents is characterized as either overweight or obese. Past studies have indicated that increases in childhood obesity rates can be attributed to a variety of causes such as unhealthy eating habits, lack of daily physical activity, and genetic predispositions (Dunton, Kaplan, Wolch, Jerrett, \& Reynolds, 2009; Ebbeling, Pawlak, \& Ludwig, 2002).

Being categorized as overweight or obese as a child and adolescent can negatively affect health status not only during youth, but also into adulthood by affecting long-term health outcomes. Type II diabetes, hypertension, and cardiovascular disease are among many comorbid conditions associated with childhood obesity that can persist into adulthood (Han, Lawlor, \& Kimm, 2010; Lakshman, Elks, \& Ong, 2012). Moreover, researchers found that attention deficit hyperactivity disorder (ADHD), depression, asthma, allergies, and headaches can also accompany childhood obesity (Halfon, Larson, \& Slusser, 2013). 
The World Health Organization (2015b) has affirmed that obesity is a worldwide epidemic for all age groups and genders; however, millions more women are affected than men yearly. Obesity trends within African American women are represented at disproportionately higher rates than any other race nationally (Hicken et al., 2013). When analyzing recent NHANES data, Ogden, Carroll, Kit, and Flegal (2014) found that 82\% of African American women $\geq 20$ years of age were overweight and obese in comparison to $65 \%$ of their Caucasian female counterparts. The highest rates of adult obesity are reported in the Southern and Midwestern United States (Trust for Americas Health and Robert Wood Johnson Foundation, 2015). Research has also implicated positive relationships between the body mass index (BMI) of women and their children (Ørskou, Henriksen, Kesmodel, \& Secher, 2003).

Parental roles are vital in assisting children to establish healthy lifestyle behaviors, especially those of weight maintenance and reduction (Golan \& Crow, 2004b). Mistry, Minkovitz, Strobino, and Borzekowski (2007) established that maternal depressive symptoms have a positive correlation with increased television screen time for children, thus decreasing the child's physical activity levels. Past studies have also examined parental roles in the psychological functioning of the child; however, these findings vary. Elgar, Mills, McGrath, Waschbusch, and Brownridge (2007) established positive relationships between parental depressive symptoms and the child's internalized and externalized problems. However, Pachter, Auinger, Palmer, and Weitzman (2006) found that the effects of maternal depression on behavioral problems among African American children were not specifically mediated through the mother's parenting styles.

With increases in the prevalence of childhood obesity and diagnoses of mood disorders in youth, analyzing the family's influence on these health issues is relevant. Research has shown links between negative maternal outcomes and child outcomes in regards to obesity and depressive symptoms (Ruager-Martin, Hyde, \& Modi, 2010). Past research has also indicated that maternal depression has associations with increased behavioral problems and decreased vocabulary scores in children 5 years of age (Brennan et al., 2000). Furthermore, research focusing on the relationships of BMI and depressive symptoms of African American mother-child dyads could inform interventions delivered in clinical and community settings.

\section{SIGNIFICANCE OF STUDY}

Maternal depression, life stressors, and obesity have been examined in African American women and potential links to unfavorable weight gain and psychological declines within their children are potential outcomes. The current study focuses on African American mother-child dyads and the relationships among child depressive symptoms, BMI, physical activity self-efficacy and maternal depressive symptoms and BMI. Additionally, this study provides additional information about African American childhood depression related to the categories of emotional problems, negative $\mathrm{mood} /$ physical symptoms, negative self-esteem, functional problems, ineffectiveness, and interpersonal problems. This study is also valuable because it adds information about 
depressive symptoms and obesity in children 7-10 years of age. Currently, there is limited research on depressive symptoms in African American children in the early elementary school level. More frequent attention in research of depressive symptoms in African Americans is given to adolescents and adults. Additionally, early interventions that reduce maternal depression have the implication to reduce the rate of mood disorders and internal and externalized problems in children before adolescence (S. Goodman et al., 2011).

Recent data indicate that approximately $50 \%$ of all African American children reside in a single parent household with their mother being the primary caregiver (U.S. Census Bureau, 2011). This statistic is striking in comparison to the current national average of $24 \%$ of children living primarily with their mother (Mather, 2010). Likewise, African American children in comparison to their white counterparts are three times more likely to live in poverty and have the highest poverty rate of any ethnic group (National Center for Education Statistics, 2015a). In Memphis, Tennessee 45\% of children and $33.5 \%$ of African Americans are living in poverty, which is well beyond the national average of $27.6 \%$ (Delavega, 2014). Recent studies have also shown that among women, lower socioeconomic status is linked to higher BMI and decreases in physical activity (Beydoun \& Wang, 2010). Additionally, some researchers believe that when ethnic groups experience poverty they are more likely to experience depression during their lifetime (Gavin et al., 2010).

Major depressive disorders are among the most common and debilitating mental health conditions globally (World Health Organization, 2012, 2015b). According to the Centers for Disease Control and Prevention (2010a) and the National Institute of Mental Health (2014a), the percentage of adults with depression in Tennessee (11\%) is higher than the national average of 6.7 percent. Some researchers believe the prevalence of depression among African American women can be attributed to external stressors and negative life events associated with their communities, violence, and a lack of a social support system (Mitchell \& Ronzio, 2011).

Within the last few decades, the increasing prevalence of obesity has become a major health concerns especially within southern regions of the United States. Recent data from the Memphis Youth Risk Behavior Survey states that approximately 19\% of all high school students are obese and another $25 \%$ described themselves as being overweight (Centers for Disease Control and Prevention, 2014d). Within the same survey $26 \%$ of students reported that they do not attend a physical education course at least once a week (Centers for Disease Control and Prevention, 2014c). In addition to the vast number of overweight and obese children, data from the Behavior Risk Factor Surveillance System (BRFSS) indicated that 40.6 percent of African American adults residing in Tennessee were self-reported as obese, which is 6.9 percent higher than the overall state percentage (Centers for Disease Control and Prevention, 2015h). Possibly contributing to this high prevalence of adult obesity is the lack of daily physical activity. Current statistics show that only 37.7 percent of Tennessee adults self-reported participating in $\geq 150$ minutes of physical activity weekly (National Center for Chronic Disease Prevention and Health Promotion, 2014). 


\section{PURPOSE OF STUDY}

The purpose of this cross-sectional, descriptive study is to examine the associations between child depressive symptoms, BMI, and physical activity self-efficacy and maternal depressive symptoms and BMI.

\section{Specific Aim One and Research Hypotheses}

The associations among child depressive symptoms and child BMI Z-score, maternal BMI, maternal depressive symptoms, and child physical activity self-efficacy were explored. The hypotheses for this aim include the following:

1. Child depressive symptoms are positively associated with child BMI Z-score.

2. Child depressive symptoms are positively associated with maternal BMI.

3. Child depressive symptoms are positively associated with maternal depressive symptoms.

4. Child depressive symptoms are negatively associated with child physical activity self-efficacy.

\section{Specific Aim Two and Research Hypotheses}

The associations among child BMI Z-score and maternal BMI, maternal depressive symptoms and child physical activity self-efficacy symptoms were explored. The hypotheses for this aim include the following:

1. Child BMI Z-score is positively associated with maternal BMI.

2. Child BMI Z-score is positively associated with maternal depressive symptoms.

3. Child BMI Z-score is negatively associated with child physical activity selfefficacy.

\section{Specific Aim Three and Research Hypotheses}

The associations among child physical activity self-efficacy and maternal BMI, and maternal depressive symptoms were explored.

1. Child physical activity self-efficacy is negatively associated with maternal BMI. 
2. Child physical activity self-efficacy is negatively associated with maternal depressive symptoms.

\section{CONCEPTUAL MODEL}

A modified version of the Social Cognitive Theory (SCT) was the theoretical framework utilized for this study (Figure 1-1). The SCT is a triad of reciprocal interactions between personal factors (cognitive, affective, and biological), environmental factors, and individual behavior or behavioral factors (Bandura, 1989). Bandura believed that human functioning and learning are products of relationships among all three factors. This theory also accounts for human behavior that is built from past experiences, and internal and external social reinforcements. The objective of the SCT is to develop a knowledge base and understanding of how individual behavior is maintained or modified through setting goals, creating expectations, modeling behaviors, responding to reinforcements, and developing self-efficacy (Bandura, 2001).

The concept of self-efficacy is a major construct of the SCT. This concept requires individuals to develop positive coping mechanisms and gain confidence in their actions that will enhance a healthy lifestyle (Department of Health, 2009). Individuals should also acquire a determination to make positive behavioral changes that will aid in positive outcomes to their self-care (Centre for Effective Practice, 2007). The level of self-efficacy possessed can be determined by measuring individuals' level of confidence to take on a new behavior (Lorig \& Holman, 2003). Self-efficacy is valuable to the personal and behavioral aspects of the theory, because it can predict whether improvements in the performance of healthcare maintenance will be successfully achieved (Bandura, 2005).

Guided by an adapted version of the SCT, the intentions of this study were to examine associations among environmental factors (maternal variables), personal factors (child variables), and a behavioral factor (child variable). In (Figure 1-2) (Aim One) positive relationships between the child's depressive symptoms and their BMI Z-score, their mother's BMI, and their mother's depressive symptoms are depicted. It also depicts a negative relationship between the child's depressive symptoms and their physical activity self-efficacy. In (Figure 1-3) (Aim Two) positive relationships between the child's BMI Z-score and their mother's BMI and depressive symptoms are depicted. In addition, it shows the negative relationship between the child's BMI Z-score and their physical activity self-efficacy. Lastly, (Figure 1-4) (Aim Three) depicts negative associations between the child's physical activity self-efficacy and their mother's BMI and depressive symptoms. Within the current study the mother is an important part of the child's environment. Maternal environmental variables were categorized as the maternal depressive symptoms and maternal BMI. Child personal variables were categorized as child BMI Z-score, child depressive symptoms, and child physical activity self-efficacy. The study postulates that as environmental changes occur, changes within the child's personal variables should be expected. 


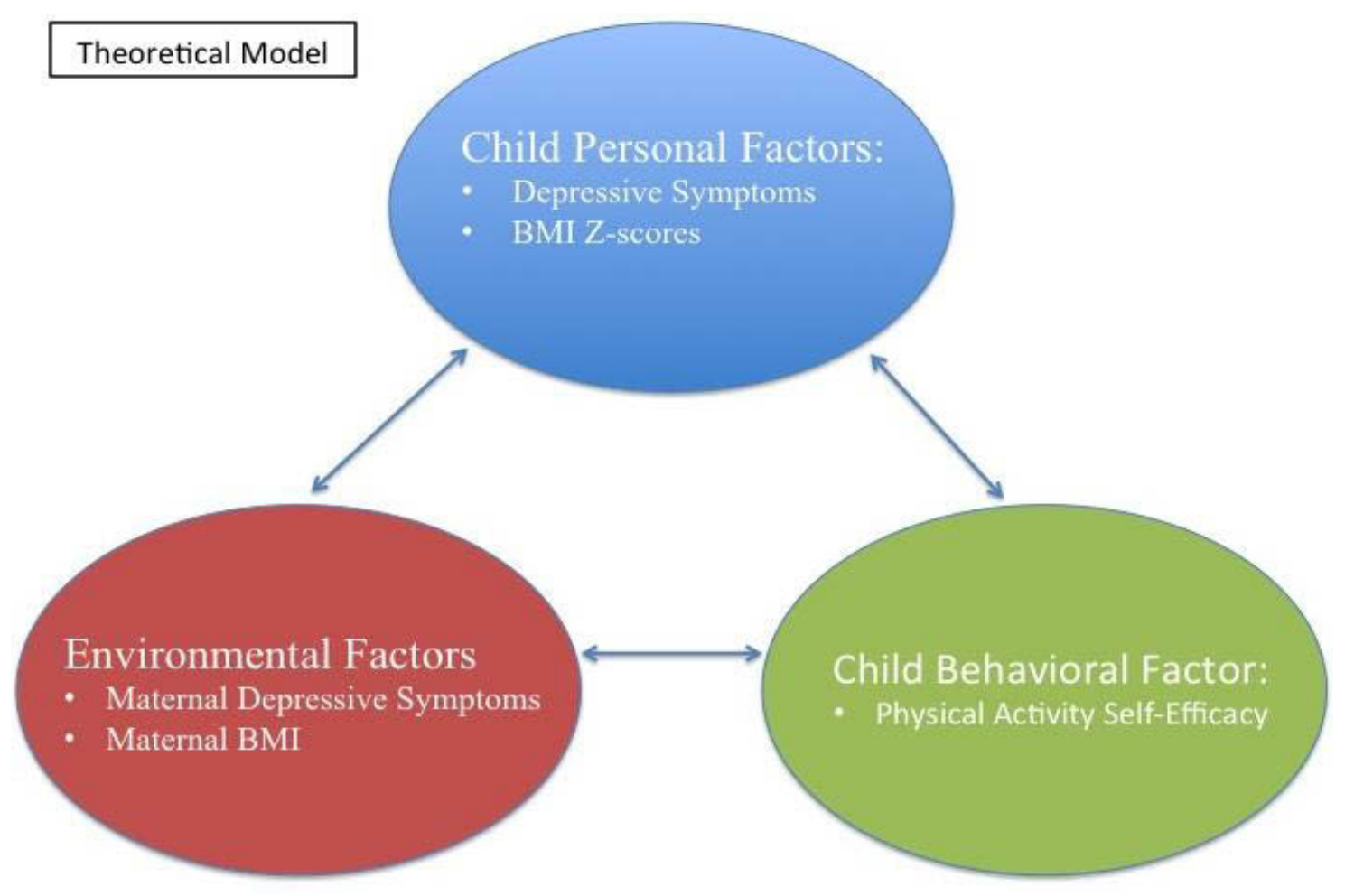

Figure 1-1. Amended Social Cognitive Theory with Study Variables Source of Social Cognitive Theory: Bandura, A. (1989). Human agency in social cognitive theory. American Psychologist, 44(9), 1175. 


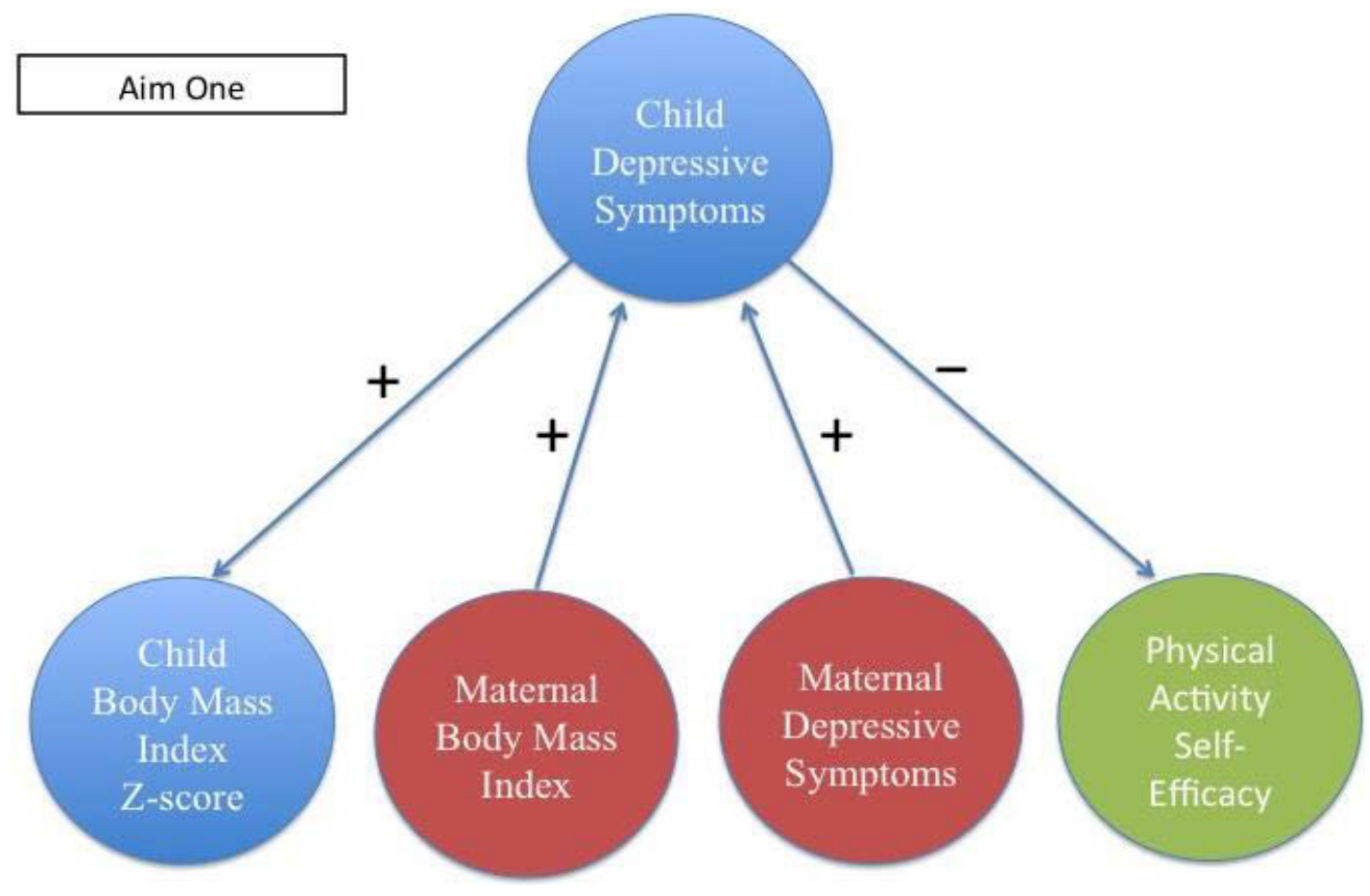

Figure 1-2. Model of Study Variables for Hypothesized Associations in Aim One 


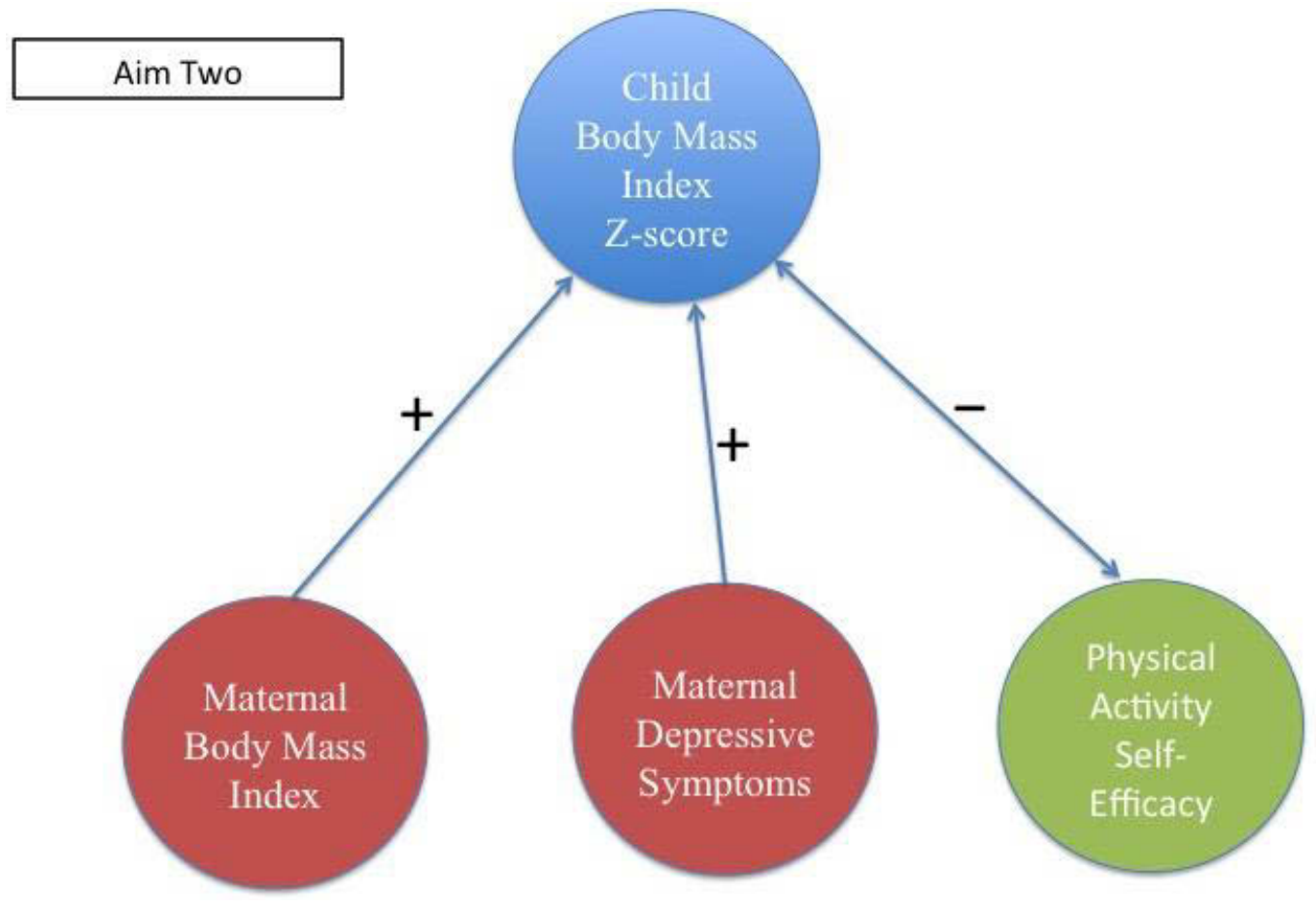

Figure 1-3. Model of the Study Variables for Hypothesized Associations in Aim Two 


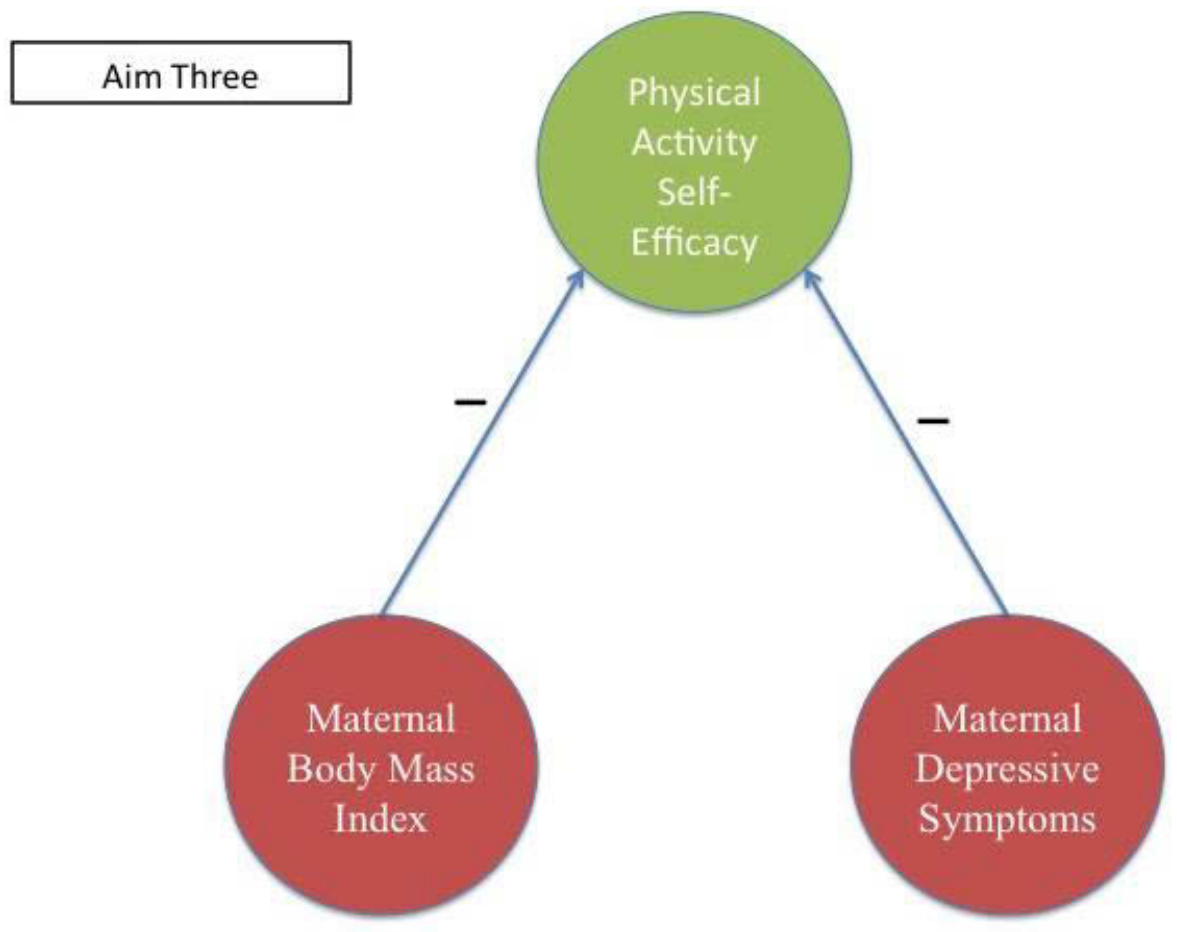

Figure 1-4. Model of the Study Variables for Hypothesized Associations in Aim Three 


\section{DEFINITIONS OF VARIABLES}

Operational and theoretical definitions for the study's variables are presented. Within the literature there are many definitions of the study variables. To enhance clarity, the following definitions for each variable were utilized in this study.

- African American: Individuals that self-identify as Black or "African American" have family lineages that originate from any of the Black racial groups of Africa; therefore, the terms are interchangeable. This definition is also extended to populations that are Afro-Caribbean, such as those from Haiti and Jamaica, or the West Indies (Centers for Disease Control and Prevention, 2015d).

- Mother: Mother participants in this study were the biological parent who gave birth to each respective child participant.

- Child: Child participants in this study were children between the ages of 7-10 years on the day of their participation.

- Gender: Participants self-reported as being either male or female.

- Education: Mother participants reported having some high school, a high school diploma or GED, an Associate Degree, a Bachelor's Degree, a Master's Degree, or a terminal degree.

- Depressive Symptoms in Children: The clinical presentation of depression in pediatric populations can be similar to that of adults. Children can experience changes in mood, appetite, and sleep patterns. Depression in children can be displayed as crying frequently, loss of energy, suicidal ideations, and changes in behavior and grades at school (Anxiety and Depression Association of America, 2015). Unfortunately, many children's depressive symptoms are dismissed and undiagnosed, because the children are assumed to be shy, disobedient, indolent or moody (Cash, 2004). Depressive symptoms in children were measured using the Children's Depression Inventory $2^{\mathrm{TM}}$ (CDI 2). The CDI 2 is a 28-item, multiple choice, self-report screening tool used in this study to assess symptoms of depression in children and adolescents ages 7-17 years (Kovacs \& Multi-Health Systems, 2011).

- Depressive Symptoms in Adults: Depressive symptoms can arise at any time during an individual's lifetime. Though similarities in symptoms among depressed individuals are common, symptoms nevertheless vary from person to person. The severity and duration of symptoms displayed are also dependent on the individual's illness. Typical self-reported depressive symptoms include changes in appetite and sleep patterns, loss of interest in once enjoyable activities, and decreases in energy levels. Depressed individuals also report feeling sad and guilty, being irritable, and experiencing loss of energy and declines in concentration level (U.S. Department of Health and Human Services \& National 
Institutes of Mental Health, 2015). Depressive symptoms in mothers were measured using the Beck Depression Inventory ${ }^{\circledR}-$ II $\left(\mathrm{BDI}^{\circledR}-\mathrm{II}\right)$. The BDI ${ }^{\circledR}-\mathrm{II}$ is a 21-item, self-report inventory used in this study to measure depressive symptoms in mothers (Beck, Steer, \& Brown, 1996).

- Body Mass Index (BMI): BMI is a measurement suggestive of the amount of body fat for an adult male or female in relation to their weight and height (National Institutes of Health, n.d.). Although BMI does not directly quantify the exact amount of individual body fat, nonetheless, it is a sufficient indicator (Centers for Disease Control and Prevention, 2015a). For this study's purpose, maternal weight was measured in pounds and height was measured in inches. BMI was subsequently calculated as weight converted to kilograms, divided by the square of the height converted to meters $\left(\mathrm{kg} / \mathrm{m}^{2}\right)$. Three categories of BMI were utilized; normal weight $\left(18.5-24.9 \mathrm{~kg} / \mathrm{m}^{2}\right)$, overweight $\left(25-29.9 \mathrm{~kg} / \mathrm{m}^{2}\right)$, and obese ( $30 \mathrm{~kg} / \mathrm{m}^{2}$ and above) (Centers for Disease Control and Prevention, 2015a). The average BMI and standard deviation were recorded for the sample.

- Body Mass Index Percentile Z-Score (BMI Z-Score): In pediatric populations a numeric measurement of BMI is calculated comparable to adults; however, it is then plotted on a standardized BMI-for-age and gender percentile chart. The chart allows for an inexpensive and less invasive mechanism for tracking increases or decreases in youth adiposity over time compared to national normative standards (Centers for Disease Control and Prevention, 2015a). Normal weight ranges from greater than or equal to the $5^{\text {th }}$ percentile to less than the $85^{\text {th }}$ percentile. Overweight ranges from greater than or equal to the $85^{\text {th }}$ percentile to less than the $95^{\text {th }}$ percentile, and obesity is greater than or equal to the $95^{\text {th }}$ percentile (Centers for Disease Control and Prevention, 2015b). To better quantify BMI percentiles that were above the top percentile on the pediatric growth chart, Z-scores, standard deviations above and below the mean at the $50^{\text {th }}$ percentile were calculated using The Children's Hospital of Philadelphia (2016) online Pediatric Z-score Calculator.

- Physical Activity Self-Efficacy: As defined by Bandura (1982) self-efficacy “is concerned with judgments of how well one can execute courses of actions required to deal with prospective situations" (p. 122). Self-efficacy is also the individual's belief in themselves and their capability to execute specific actions, such as symptom reduction through behavioral changes (Coleman \& Newton, 2005). Bandura (2005) reveals that self-efficacy is important to the cognitive process, because it allows for goal setting and it provides the individual with the motivation to accomplish their goals. Researchers have found positive relationships between self-efficacy and an individual's physical activity level (Gao, 2012; Matthews et al., 2015). Physical activity self-efficacy was measured using the Physical Activity Self-Efficacy Scale (PASES)(Appendix A). The PASES is a 17-item questionnaire used in this study to assesses support seeking behaviors, barriers, and positive alternatives in relation to physical activity in children (Saunders et al., 1997). 


\begin{abstract}
ASSUMPTIONS
The following assumptions were created for the purpose of this study:

1. Mothers were honest when self-reporting their status as the biological mother of the participating child.
\end{abstract}

2. Participants answered each question about depressive symptoms and physical activity self-efficacy honestly.

3. Participants honestly completed the demographic questions.

4. The instruments selected for use in this study were appropriate for answering the research questions and were valid and reliable.

5. Instrumentation data accurately measure the perceptions of each participant.

6. Height and weight of the participants were collected in an accurate manner.

\title{
LIMITATIONS
}

1. The study included a relatively small sample of mother-child dyads $(n=65)$. A small sample may contribute to non-significant findings, particularly if the sample is not representative of the population and variables of interest lack sufficient variability to facilitate understanding of proposed variable relationships.

2. There was minimal variability within the BMI category for mothers. The majority of the mothers within the study were categorized as overweight or obese. This contributed to limitations in analyses using maternal BMI.

3. $\quad$ BDI $^{\circledR}$-II is reliable test; however, words such as pessimism, indecisiveness, and irritability were unfamiliar to some adult respondents.

4. Many children had never been exposed to the phrase "physical activity" and they may have misunderstood the questions about this construct, which possibly led to inaccurate higher physical activity self-efficacy scores.

5. Several child participants reported higher physical activity self-efficacy scores; however, their BMI percentiles were categorized as overweight and obese.

6. The SCT presumption that changes within the person will occur if their environment changes may not always hold true. 


\section{CHAPTER 2. LITERATURE REVIEW}

\section{INTRODUCTION}

Until recently, few studies have investigated the parental roles contributing to the development of children who are overweight, obese, or depressed. Physical activity levels also play a large role in influencing weight management strategies, which have been associated with obesity and depressive symptoms (Burdette, Whitaker, Harvey-Berino, \& Kahn, 2003). With increases in the prevalence of childhood obesity and diagnosed mood disorders in youth and adults, analyzing possible family and environmental contributions has become increasingly widespread in the literature. It is important to understand that there are a variety parental influences that assist their children to establish healthy lifestyle behaviors especially those of weight maintenance and reduction (Golan \& Crow, 2004a). This literature review presents current knowledge and research in the areas of obesity, depressive symptoms, and physical activity as it applies to women and youth. There is limited research examining relationships between maternal and child depressive symptoms, BMI, and the child's physical activity self-efficacy levels as examined in the current study. This chapter includes current findings about each of these variables. In addition, this chapter will shed light on health and environmental disparities in the areas of depression, obesity, and physical activity as they relate to the African American mother-child dyad.

\section{DEPRESSION OVERVIEW}

Depression is one of the most common and debilitating mental disorders, affecting millions of people yearly worldwide (U.S. Department of Health and Human Services \& National Institutes of Mental Health, 2015). According to the National Alliance on Mental Illness (2016b) approximately 16 million Americans experienced a depressive episode last year; however, less than half of those individuals had proper treatment for their conditions. The World Health Organization (2015a) proclaimed that the lack of treatment for depression can be attributed to deficiencies in resources and lack of properly trained health care workers. Additionally, they asserted that there is stigma associated with mental health disorders that discourages individuals with depression from pursing treatment. In the United States the economic burden of major depressive disorder significantly increased by 22\% from 2005 (\$173 billion) to 2010 (\$210.5 billion). In part, this increase can be attributed to a substantial rise in medical services and workplace related expenditures (Greenberg, Fournier, Sisitsky, Pike, \& Kessler, 2015).

Similar to other chronic disorders, there are multiple predictors for the development of a depressive disorder and the etiology can be biological (genetic) or environmental. Major depressive disorders can be up to three times more common in biological first-degree relatives of individuals who have been diagnosed with depression in their lifetime (American Psychiatric Association, 2000). Though many studies have found incidences that depression is heritable within families, the inheritance of early- 
onset depression, severe depression, and recurrent depression is more frequently observed than other depressive illnesses (Belmaker \& Agam, 2008). In a study of monozygotic and dizygotic twins, researchers discovered significant correlations between genetic and environmental factors in the development of depression (McGuffin et al., 2003). Furthermore, disturbances within the brain's neurotransmitters have been linked to the development of depression. One of the key neurotransmitters, serotonin, has many bodily functions, such as altering an individual's sleep patterns and contributing to mood fluctuations; unfortunately imbalances can lead to depressive symptoms and depression (Buckley, Dawson, \& Isbister, 2014).

Similar to genetic factors there are numerous environmental influences associated with an individual's development of depression. Research indicates that individuals residing in lower socioeconomic status neighborhoods are more likely to develop depression over their lifetime in comparison to those who live in higher socioeconomic status neighborhoods (Galea et al., 2007). Being unemployed is also associated with increased odds of developing major depressive disorder among multiple racial groups both United Sates and foreign born (Gavin et al., 2010). The literature also supports the hypothesis of an association of depression with certain illnesses such as diabetes, neurological conditions, heart failure, chronic pain, and sleep disorders (University of Maryland Medical Center, 2016).

Currently, depression is one of the leading causes of mental illness and it severely impairs an individual's psychosocial functioning in the areas of home management, social activities, personal relationships, and job performance if left untreated (Fried \& Nesse, 2014; Steinberg et al., 2014). Depressive symptoms often result in a person experiencing irrational thoughts, loss of sexual desires, weight management dysfunction, and reduction in decision-making capabilities (Fried \& Nesse, 2014). Major depressive disorder is diagnosed based on criteria outlined on the Diagnostic and Statistical Manual of Mental Disorders $5^{\text {th }}$ Edition (DSM-V) (American Psychiatric Association, 2013). In order to diagnose major depressive disorder at least five of the nine symptoms listed must be present almost every day over a two-week period. These symptoms include depressed mood or irritability, loss of interest in pleasure, change in appetite or changes in weight, changes in sleep patterns, changes in personal activity levels, feelings of fatigue or loss of energy, decreased concentration, feeling guilty or worthless, and suicidal ideations (American Psychiatric Association, 2013). Experiencing a depressed mood or a loss of interest or pleasure in daily activities must be two of the symptoms present in that twoweek period.

Multiple treatment modalities are available for individuals with depression. Several therapy options are known to be effective such as individual psychotherapy, group therapy, cognitive therapy, and family therapy (Townsend, 2014). The National Alliance on Mental Illness (2016b) states that drugs within the classes of tricyclic antidepressants, selective serotonin reuptake inhibitors (SSRIs), monoamine oxidase inhibitors, and serotonin norepinephrine reuptake inhibitors (SNRIs) have had positive outcomes in managing depressive symptoms though outcomes are individual specific. 


\section{Depression and Women}

Current statistics examining gender differences in depression indicate that the prevalence of depression in women is higher than the prevalence in men nationally and globally (National Institute of Mental Health, 2014a; Waite \& Killian, 2008). Research has indicated that depression in women is triggered by many factors such as poor socioeconomic conditions, and a history of past sexual abuse (Chen et al., 2010; Legrand, 2014). Major depression in women has a higher incidence in the first month after a stressful life event, such as an assault, marital and relationship problems, or the loss of an occupation (Kendler et al., 2010). There is also evidence that supports multiple internal risk factors for women becoming depressed, such as pregnancy, childbirth, and hormonal changes, especially those that occur in menopause (University of Maryland Medical Center, 2016). According to Steinberg et al. (2014), one in seven (14.9\%) African American women will battle a major depressive episode in their lifetime; however, African American adults receive less medical treatment (40\%) than their Caucasian counterparts $(54.0 \%)$ indicative of a health disparity by race. Research also suggests that although the prevalence of major depressive disorder in African American women is lower, the severity of major depressive disorder is increased compared to Caucasian women (Boyd \& Waanders, 2013; Steinberg et al., 2014).

Contradictory findings on the prevalence of depression in African American women compared to Caucasian women have been reported. Mitchell and Ronzio (2011) found that the prevalence of depression is higher in African American mothers in comparison to Caucasian mothers, where some states report a higher prevalence in the double digits. The literature presents an array of potential factors that contribute to maternal depression amongst African American women. Researchers believe that depression in African American women is attributed to external stressors and negative life events associated with their communities, violence, and the lack of a social support system (Mitchell \& Ronzio, 2011). In a study of 730 African American women, Mitchell and Ronzio (2011) examined the association between the onset of depression and neighborhood characteristics. Results indicated that in neighborhoods with increased poverty and crime rates, depression in the women was an increased response as they experienced undesirable events in life (Cutrona et al., 2005). Similarly, in a study of 700 African American women residing in a neighborhood with little diversity and economic resources, researchers found that income was negatively associated with financial stress (Schulz et al., 2006). They also revealed direct pathways between the women's financial stress and increased depressive symptoms. The association between stress and increased depressive symptoms in African American women is further studied in the literature. Luke et al. (2009) found that a major contributor to African American women's postpartum depression was the prevalence of stress. Incidences of antenatal depression in African American women increased as maternal age increased past 30 years.

Additionally, they found that emotional factors, such as loneliness and abandonment, and external factors, such as lack of social support and support from a partner contribute to increased levels of stress for mothers (Luke et al., 2009). 
Although maternal depression has increased in prevalence, especially within African American mothers, there is still very minimal literature on the subject.

Unfortunately, some researchers find it difficult to gauge depressive symptomology from African American women, because these women tend to underreport and not recognize their true feelings of depression due to a "strong black woman" perception to which they are attached (Davis, Young, Davis, \& Moll, 2011; M. Davis, Young, Davis, \& Moll, 2007; Nicolaidis et al., 2010). Additionally, research has shown that African Americans underreport symptoms of depression and report more somatic rather than affective symptoms such as loss of appetite and sleep (Iwata, Turner, \& Lloyd, 2002; Zhang \& Gary, 2013). Also, words used to characterize depressive symptoms by African Americans can vary and differ from those used on screening tools (Zhang \& Gary, 2013). More research should be conducted to determine adequacy of depressive symptom screening tools in African American women.

\section{Depression and Youth}

Childhood and adolescent depression has emerged as a research priority because of the increases its prevalence and the consideration of mental health as a vital component of the overall health state of a child. According to the National Institute of Mental Health (2015), 11\% of adolescents between the ages of 12 and 17 experienced a depressive episode in the year 2014. Adolescent girls are twice as likely to experience depression when compared to their male counterparts and this ratio was approximately equivalent as seen in adulthood (Merikangas et al., 2010; Nolen-Hoeksema, 2001). In contrast, authors Kistner, David-Ferdon, Lopez, and Dunkel (2007) found that depressive symptoms, screened by the Children's Depression Inventory, were greater in African American males in comparison to African American girls and Caucasian girls and boys in the $3^{\text {rd }}-5^{\text {th }}$ grade. These authors also found that depressive symptoms in African American boys increased over a six-month follow-up period after their baseline screening (Kistner et al., 2007).

Three decades ago the clinical manifestation of childhood and adolescent depression was inconceivable to clinicians. Children that displayed symptoms of depression were thought to just be experiencing mood swings or disobedience, thus causing clinicians to overlook the underlying problem of depression (Cash, 2004). Although, the prevalence of depressive symptomatology in United States adolescents has appeared to increase, many teenagers do not meet the criteria for a diagnosis of depression. Unfortunately, even with the advent of new screening tools of depressive symptoms in youth, many children and adolescents have undiagnosed depressive disorders because they are assumed to be shy, disobedient, indolent, or moody (Cash, 2004). Consequently, these children go unscreened for depressive symptoms.

Depressive disorders can ultimately interfere with children's activities of daily living and decrease their quality of life extensively. Morbidity, increased substance abuse, dysfunctional relationships, suicidal ideations, and a decrease in scholastic achievement are only a few negative consequences of depressive symptomology in 
children (Kubik, Lytle, Birnbaum, Murray, \& Perry, 2003). In a study of 444 adolescents between the ages of 13 and17, researchers screened them for depressive symptoms at baseline and again six months later. Researchers found that $37.5 \%$ of the participants with moderately severe depressive symptoms and $71.4 \%$ of youth with severe depressive symptoms at baseline exhibited depressive symptoms at their six months follow-up (Richardson et al., 2012). Thus, depressive symptoms tend to persist over time in adolescents. Therefore, screening, preventative measures, interventions and treatments of depression in youth are crucial in preventing future reoccurrences.

Depression and depressive symptoms in African American children, between the ages of 7-10, are unfortunately understudied in the literature. Currently, the literature presents an array of information about depression in African American preteen and teenagers. In a community sample of 897 African American children, ages 10-12, researchers found that participants in the sample with depressive symptoms had caregivers that presented with a type of discipline that was more harsh and inconsistent in comparison to participants who did not have depressive symptoms (Kim et al., 2003). Similar to adults, environmental factors and stressful life events and their associations with increased depressive symptoms in African American youth has been studied. Authors, Davis and Stevenson (2006), examined if socialization discrimination and neighborhood safety correlated with depressive symptoms in 160 African American adolescents. Results indicated an increased sad mood and irritability in participants who perceived their neighborhood to have negative life events (Davis \& Stevenson, 2006). Also, living in a neighborhood that is predominantly Caucasian, was found to significantly increase depressive symptoms in African American adolescents (Wight, Aneshensel, Botticello, \& Sepúlveda, 2005). Natsuaki et al. (2007) examined the relationships between depressive symptoms and experienced stressful events in 777 African American adolescents. Study results identified a significant relationship between stressful life events that occurred at age 11 and substantial increase in depressive symptoms at the age of 13 in these children (Natsuaki et al., 2007).

\section{OBESITY OVERVIEW}

Obesity is a chronic disease that is characterized by an increase in fat within cellular tissues in excessive amounts (Tzanetakou, Katsilambros, Benetos, Mikhailidis, \& Perrea, 2012). The etiology of obesity is multifaceted and varies with each individual case. Researchers have established multiple risk factors for the development of obesity, such as genetics, improper eating habits, and lack of regular physical activity (Garaulet, Ordovas, \& Madrid, 2010). Moreover, researchers have also identified possible negative associations between obesity and lower socioeconomic status. Drewnowski (2009) found that individuals with lower education and income levels may gravitate towards purchasing food products higher in sugars and fats due to the affordability; thus increasing their likelihood of becoming obese. Within the last two decades the prevalence of obesity worldwide has doubled (World Health Organization, 2016b). The World Health Organization (2015b) estimated over 600 million adults over the age of 18 years were categorized as obese in 2014. Likewise, the obesity epidemic in the United States 
has continuously increased over the last 20 years despite recent preventative efforts and interventions. Current obesity statistics within the United States indicate that approximately $35 \%$ of adults and $17 \%$ of youth between the ages of 2-19 years are obese (Centers for Disease Control and Prevention, 2015c, 2015e). When exploring regional differences in current rates of obesity, southern states were found to have the highest overweight and obesity percentages among adults out of all other regions in the United States (Trust for Americas Health and Robert Wood Johnson Foundation, 2015).

With the growing number of obese individuals, development of interventions and treatments are highly necessary because the disease has an economic impact, and a burden on society that continues to increase yearly. In 2015, the estimated cost of obesity within the United States was between 147- 210 billion dollars per year (Trust for Americas Health and Robert Wood Johnson Foundation, 2015). Although obesity is considered a preventable disease, current recommendations for the treatment of obesity suggest lifestyle and behavioral modifications. These include decreasing caloric intake, increasing the consumption of healthier foods, setting realistic weight loss goals, such as losing 1-2 pounds per week, increasing daily physical activity, and possibly initiating a medication regime (National Institues of Health, 2012). Unfortunately, it has been acknowledged within the literature that African Americans perform less physical activity each week in comparison to their Caucasian counterparts. According to the Centers for Disease Control and Prevention (2014b) only 17\% of African Americans compared to 23\% Caucasians met the 2008 Physical Activity Guidelines recommended for muscle strengthening and aerobic activity. Men were also likely to be more physically active than women. If left untreated, obesity can lead to many comorbidities, such as type II diabetes, hypertension, sleep apnea, gall stones, hyperlipidemia, gall bladder disease, and heart disease (Centers for Disease Control and Prevention, 2010b, 2015c).

\section{Obesity and Women}

Obesity is a debilitating disease that can lead to the deterioration of a woman's health in a variety of ways. Globally, obesity trends among women are higher than those of males (World Health Organization, 2015b). After adjusting for age, approximately $35 \%$ of American women 20 years of age and older are categorized as overweight or obese (Ogden et al., 2014). Researchers acknowledge that obesity in women increases their risk for developing hypertension, type II diabetes, metabolic syndrome, and endometrial cancers (Kopelman, 2007; Yach, Stuckler, \& Brownell, 2006). Additionally, long-term consequences of obesity include increased cardiovascular problems and more frequent cardiovascular related hospitalizations in obese women when compared to women of normal body weight (Murphy et al., 2006).

Obesity trends among ethnic minority groups, especially those of African American women, have been reported and substantial disparities are apparent. African American and Hispanic American women have considerably higher rates of overweight and obesity in comparison to other ethnic groups nationally (Hicken et al., 2013). Ogden et al. (2014) have found that $82 \%$ of African American women and $77 \%$ of Hispanic 
American women 20 years of age and older were either overweight or obese in contrast to only $65 \%$ of their Caucasian female counterparts. It is possible that obesity triggers subsequent depression due to one's low self-esteem, which is also more common in African American women than Caucasian women (Legrand, 2014).

The extreme differences in the rates of obesity among ethnic minorities have been studied with linkages to socioeconomic and environmental factors. In a review of 333 articles relating to obesity and socioeconomic status, researchers found inverse relationships between socioeconomic status and obesity in highly developed countries (McLaren, 2007). The Black Women's Health Study surveyed 59,000 African American women between the ages of 21-69 years biennially from 1995-2005. Researchers created a neighborhood socioeconomic status score from examining various factors such as median household income and the percent of college graduates 25 years and older. Lower scores were indicative of lower neighborhood socioeconomic status. Respondent height and weight information was also collected with each survey. Results indicated that African American women who resided in neighborhoods with lower socioeconomic scores were more likely to become obese in comparison to African American women who lived in more prosperous neighborhoods (Coogan et al., 2010). A similar study examined the literature on how "obesogenic" environments relate to the development of obesity and health behaviors within African American, Hispanic American, and lower socioeconomic groups. After reviewing 45 published studies, authors determined that access to superstores, workout facilities, and environmental safety all influence body mass index, thus limited access to these entities increase the risk for obesity within the specific sample (Lovasi, Hutson, Guerra, \& Neckerman, 2009).

The consumption of specific foods and deficient daily physical activity has been studied and identified as contributors to weight gain among African American women. In a qualitative study to identify promoters and barriers in the consumption of fruit, vegetables, and fast food, researchers found that low-income African American women's cravings and cheating on diets promoted fast food eating, while inconvenience and unavailability were barriers to eating fruits and vegetables (Lucan, Barg, \& Long, 2010). Nevertheless, researchers believe more investigations within African American communities should be conducted to determine buying practices that are culturally motivated because of the importance of understanding how their preferences contribute to African American women's daily dietary intake (Odoms-Young, Zenk, \& Mason, 2009). Research also suggests that African American women report low levels of physical activity due to lack of time, unsafe environments to walk or exercise, caregiver barriers, and lack of motivation (Miller, Marolen, \& Beech, 2010; Pekmezi et al., 2013).

\section{Obesity and Youth}

Within the last three decades there has been a continual rise in the prevalence of childhood obesity worldwide (Han et al., 2010). On a national level, the American Heart Association (2014b) reported that one in three children and adolescents in the United States has a BMI that is characterized as either overweight or obese. Data from the 2009- 
2010 National Health and Nutrition Examination Survey (NHANES) confirm a significant growth in the prevalence of obese males 2-19 years of age but not of females (Ogden, Carroll, Kit, \& Flegal, 2012). However, Li, Ford, Mokdad, and Cook (2006) contended that assessing abdominal obesity is a better indicator for potential risk of type II diabetes and cardiovascular disease than total body obesity. In their study comparing waist circumferences of children and adolescents of varying NHANES surveys they found that from NHANES III (1988-1994) and NHANES (1999-2004) boys (aged 6-11 years) had significant increases in unadjusted mean waist circumferences from $61.9 \mathrm{~cm}$ to $64.5 \mathrm{~cm}$. Within the same time frame, they found that girls (aged 6-11 years) also had significant increases in their unadjusted mean waist circumferences from $61.7 \mathrm{~cm}$ to 64.7 $\mathrm{cm}$. Similar to adults, the prevalence of obesity in ethnic minority children was substantially higher in comparison to other races. Recent data from the Centers for Disease Control and Prevention confirmed that 22\% of Hispanic, $20 \%$ of African American, and $14 \%$ of Caucasian youths are identified as obese (Centers for Disease Control and Prevention, 2014a).

Complications associated with obesity during childhood can parallel adult obesity complications, such as increases in insulin resistance, dyslipidemia, obstructive sleep apnea, and nonalcoholic fatty liver disease (Daniels, 2009). Obese children and adolescents also have multiple risk factors that increase their probability of developing cardiovascular complications if not intervened (Wethington, Pan, \& Sherry, 2013). In addition, after analyzing data from a national diabetes study (SEARCH for Diabetes in Youth) researchers observed that obesity was prevalent in $79 \%$ of youth who were diagnosed with type II diabetes (Liu et al., 2010). Without proper self-management strategies to aid in weight reduction and beneficial interventions to decrease the incidences of overweight-obese children and adolescents, obesity and obesity related comorbidities are more likely to occur in adulthood (Centers for Disease Control and Prevention, 2014b; Zhao \& Grant, 2011).

Possible causes of the upsurge in childhood obesity rates have been studied and identified within the literature. Limited access to healthier foods that are affordable and an increased intake of sugary beverages are two well-known and explored causes of childhood obesity (Alliance for a Healthier Generation, 2016). In a study of 177 innercity youth, 6-8 years old, investigators determined that children had higher BMI percentiles, when they lived on a block with one or more convenience stores in contrast to children who did not have convenience stores located on their block (Galvez et al., 2009). In a systematic review of literature, Malik, Pan, Willett, and $\mathrm{Hu}$ (2013) found that over the last 20 years the consumption of fruit drinks and fruitades has markedly increased among toddlers and youth. In an 18 month study of 477 children aged 4-11 years, researchers found that participants who were provided a daily sugary drink had higher BMI Z-scores and body adiposity in comparison to participants who received a placebo drink with no added sugar (de Ruyter, Olthof, Seidell, \& Katan, 2012).

Research also suggests childhood obesity is a consequence of increased portion sizes and decreased daily physical activity (Alliance for a Healthier Generation, 2016; Jiménez-Pavón, Kelly, \& Reilly, 2010). When investigating central obesity in adolescents 
and their diet, researchers found that lower consumption of fruits, vegetables, dairy products, and grains were associated with increased central obesity (Bradlee, Singer, Qureshi, \& Moore, 2010). Research also indicates that increasing weekly physical activity in moderate to high amounts can decrease body fat percentages and increase cardiovascular fitness in girls (Barbeau et al., 2007). In contrast, when comparing diet only interventions to diet in conjunction with aerobic exercise effects on BMI of obese children, Ho et al. (2013) found no significant difference between the two groups, thus indicating the need for further research into whether BMI is the best tool to measure changes in adiposity within children.

\section{OBESITY IN MOTHER-CHILD DYADS}

Obesity associations between mother-child dyads have been examined within the literature and numerous factors are possibly linked to their joint weight gains. Genetic, behavioral, and environmental interactions that influence obesity have been reported; however, it is not substantially validated as to whether one factor is more significant in contributing to weight gain or reduction in mothers and their children (Zhao \& Grant, 2011). The idea of a genetic component predisposing adults and children to obesity has been established through previous genomic research and abnormalities in the secretion of leptin, a protein produced by adipose tissue, which assists in the regulation hunger sensations (Ahima, 2008; Han et al., 2010). As previously specified, overweight and obesity are more frequently observed in African American and Hispanic mothers and children in comparison to Caucasians and Asians (Caprio et al., 2008; Ogden et al., 2014; Zhao \& Grant, 2011).

Research also indicates that children have a higher risk of becoming obese when both their mothers and fathers are obese; however, the gestational weight of a baby is greatly influenced by maternal factors (Jaquet et al., 2005). Hinkle, Sharma, and Dietz (2010) examined pre-gestational weight and weight gain during pregnancy and found that mothers, who are more obese and gain more gestational weight, are at a higher risk for delivering large-for-gestational-age babies. Another study sought to determine if alterations in maternal phenotype would affect their offspring's genotype. In a study of 20 obese mothers researchers compared methylation levels of genes and their affect on cardiometabolic pathways between siblings who were born before their mother underwent gastrointestinal bypass surgery (BMS) to siblings born after maternal gastrointestinal bypass surgery (AMS). Results signaled that AMS siblings had lower BMI's and they displayed greater insulin sensitivity and better cardiometabolic risk profiles than their siblings born before BMS (Guénard et al., 2013).

In a similar cross-sectional study, Smith et al. (2009) compared the BMI of individuals who were born before maternal biliopancreatic diversion bariatric surgery (BMS), to their siblings, who were born after their mother's biliopancreatic diversion bariatric surgery (AMS). Study results depicted lower birth weights and lower placements of BMI percentiles for children born to the AMS group. BMS mothers had substantially higher BMI's during pregnancy and experienced more pregnancy-related complications 
than AMS mothers. These studies imply that improvements within the maternal intrauterine environment promote better weight related outcomes in their offspring even into adolescent years (Smith et al., 2009).

Research also suggests that obesity and behaviors of mothers after parturition place their children at higher risk for the development of childhood obesity (RuagerMartin et al., 2010). Recent study outcomes have depicted lower breastfeeding rates among obese women. As a consequence obese mothers who avoid breastfeeding initiate formula-feeding and introduce solid foods to their offspring much earlier, thus increasing the risk for weight gain in their children within the first year of life (Poston, Harthoorn, \& Van der Beek, 2011). Maternal diet and eating practices have been investigated and results indicate that mothers can influence the availability of specific foods and food selection preferences of their children, which can affect their children's future food selections and weight status (Thompson, 2013). Obese mothers and their children are also less likely to participate in necessary physical activity to assist in weight gain prevention, thus creating lasting behaviors for the children into adolescence if no interventions are introduced (Klohe-Lehman et al., 2007)

\section{MATERNAL DEPRESSION AND CHILDHOOD OBESITY}

Maternal psychological state has been studied and the association with their children's weight has been explored in recent studies. Researchers believe that depressive symptoms among mothers do increase the risk for weight gain in their child through a variety of mechanisms (Lampard, Franckle, \& Davison, 2014). Past studies have examined the relationships between maternal postpartum depression and weight development of their child. Ertel, Koenen, Rich-Edwards, and Gillman (2010) evaluated overall adiposity of 3 -year-old toddlers born to mothers experiencing antenatal and postpartum depression. Results indicated that higher overall adiposity was more frequently exhibited in toddlers of mothers with postpartum depression than in toddlers of mothers with antenatal depression. Possible explanations for these findings include decreased breastfeeding in mothers with postpartum depression, and unhealthy eating and physical activity habits for both mother and child (Ertel et al., 2010).

The presence of maternal depression symptoms may increase the likelihood of negatively impacting parenting behavior and the mothers' daily interactions with their children, thus increasing the risk for childhood obesity. In a study evaluating the parenting style of depressed mothers from various socio-economic statuses, investigators determined that a permissive parenting style was most likely associated with childhood obesity (Topham et al., 2010). Researchers believed that maternal depression that occurs in later child developmental stages can be associated with increased child body fat as a result of food choices within the home and the child's adiposity (Lampard et al., 2014). Past studies have indicate a strong negative association between maternal depression and parental involvement; less involved mothers and depressed mothers also had children who watched more television (Mistry et al., 2007). In a similar study examining the associations between depression in low-income mothers and the amount of television 
watched by their preschool child, where $31 \%$ of the mothers were depressed and $30 \%$ were obese, researchers found that the amount of time a child watched television increased as maternal depressive symptoms in conjunction with obesity increased in comparison to children with mothers who were not depressed or obese (Burdette et al., 2003). As a negative consequence of increased television screen time, a child's physical activity levels decreased as did the child's consumption of fruits and vegetables (Hamer, Stamatakis, \& Mishra, 2009). Reductions in children's physical activity can possibly lead to future increases in BMI and potential health complications.

The association of the child's BMI, gender, and the initial onset of maternal depression during childhood have been examined. Duarte, Shen, Wu, and Must (2012) measured BMI changes in boys and girls from kindergarten to fifth grade. Results indicated that the presentation of maternal depression affected children's BMI but effects varied by their age and gender. Third grade girls, who had mothers that exhibited severe depressive symptoms, had higher BMI's by fifth grade in comparison to boys. However, kindergarten boys with severely depressed mothers had higher BMI's in the fifth grade. In a similar study Wang et al. (2013) found that, when compared to children from mothers who were not depressed at any of these specific periods, children were almost twice as likely to be overweight when their mothers were depressed at three specific time points in the child's life: at twelve months, twenty-four months, and thirty-six months of age.

Lastly, though depression and obesity are two distinct conditions with separate trajectories for etiology, similarities between developmental pathways have been investigated in children and adults. Reeves, Postolache, and Snitker (2008) found that inflammatory levels are increased in obese children, specifically the pro-inflammatory cytokine IL-6. Likewise, multiple adult studies on increased inflammatory processes in individuals with mood disorders have shown associations between increased proinflammatory cytokine IL-6 levels and increased incidences of depression (Brietzke et al., 2009; Dowlati et al., 2010). The neurotransmitter serotonin, which can affect mood and appetite, has also been linked with irregularities and decreased levels in individuals with obesity and those with depression (Buckley et al., 2014; Zhao, Goldberg, \& Vaccarino, 2013). Although research has identified the possibilities for these associations, the majority of published work consists of information gathered from adult or Caucasian populations. Consequently, there is a gap in this literature for African American mothers and their children. More research is needed in minority populations to validate these potential associations.

\section{DEPRESSION IN MOTHER-CHILD DYADS}

Recent studies have examined the relationship of depressive symptoms in motherchild dyads and how maternal roles are key in the psychological functioning of the child. Maternal depression can decrease mother-child engagements and promote negative relationships and interactions with implications for the child at every developmental stage. Research in the past has indicated that depressed mothers suffering from chronic 
psychiatric illness tend to give birth to infants who had cognitive and affective disturbances (Abrams, Field, Scafidi, \& Prodromidis, 1995). These children exhibited less motor skills, less facial expressions such as smiling, and used less verbal skills, when compared to children born to mothers who were not depressed. In addition, infants born to depressed mothers demonstrated symptoms of irritability and the inability to track sounds, when compared to infants born to mothers who were not depressed (Abrams et al., 1995).

More recent studies of depressed mothers and their infants indicate that trends are similar. In a systematic review of maternal depression and subsequent infant outcomes, researchers found that infants born to prenatally depressed mothers exhibited symptoms of being less attentive and alert, and more aroused than infants born to non-depressed mothers (Field, Diego, \& Hernandez-Reif, 2009). Likewise, infants of depressed mothers had longer response times to a happy or sad face stimulus (Hernandez-Reif, Field, Diego, Vera, \& Pickens, 2006). In another similar study that investigated the social behaviors of infants born to depressed mothers, researchers established that the infants presented with lower social engagements, their regulatory behaviors were less developed, and they were emotionally less positive (Feldman et al., 2009).

Children of depressed mothers are also at risk for experiencing difficulties with social and emotional life, as well as experiencing conduct problems (Gross, Velazco, Briggs, \& Racine, 2013). Elgar et al. (2007) established positive relationships between parental (mother and father) depressive symptoms and the child's perceived internalized and externalized problems. Moreover, negative parenting, such as rejection and withdrawal, were found to be correlated with increased childhood depression while less childhood depression was correlated with positive parenting involving warmth (McLeod, Weisz, \& Wood, 2007). Continued research and literature surrounding the depression of African American mothers and children will allow for a more concise understanding of how children with depressed mothers are found to have different trajectories in life as opposed to children whose mothers are not depressed (Boyd \& Waanders, 2013).

\section{PHYSICAL ACTIVITY AND SELF-EFFICACY}

Throughout the literature the term physical activity has a broad meaning that has made it extremely difficult to define and quantify. The general consensus is that physical activity is any form of muscular movement or motions an individual performs, which requires more energy utilization than at resting state (National Institutes of Health, 2015). Being physically active includes, but is not limited to, walking, dancing, swimming, yoga, and performing manual labor outside (Centers for Disease Control and Prevention, 2015f; United States Department of Agriculture, 2015). Contrary to the belief that young children are very physically active, researchers insist that children are leading more sedentary lifestyles with a reduction in physical activity and increases in hours spent with technology, such as video games and television (President's Council on Fittness Sports \& Nutrition, 2015; Williams et al., 2008). The current childhood obesity epidemic has prompted an immediate need to increase physical activity in children to combat this 
problem worldwide. The Office of Disease Prevention and Health Promotion (2016) has established healthy physical activity guidelines for United States adults and youth. According to standards, children and adolescents should perform a minimum of 60 minutes of aerobic physical activity each day. Weekly, they should perform three days of vigorous aerobic activities, three days of muscle strengthening, and three days of bone strengthening activities (Centers for Disease Control and Prevention, 2015g). If these guidelines are followed, children should have lower levels of body fat, stronger muscles, and increased cardiorespiratory fitness (Office of Disease Prevention and Health Promotion, 2016). Ethnic differences in the amount of physical activity have been well documented in the literature. According to the U.S. Department of Health and Human Services Office of Minority Health (2013), 55\% of African American adults 18 years and older did not meet the necessary physical activity guidelines in 2011 . Recent studies have also shown that young boys are more physically active than girls; however, African American boys and girls have similar prevalence of obesity $(21 \%$ for boys and $20 \%$ for girls) (Hinkley, Crawford, Salmon, Okely, \& Hesketh, 2008; Trust for America's Health \& Robert Wood Johnson Foundation, 2014).

Within the literature, self-efficacy has been acknowledged to facilitate the act of physical activity for the purpose of weight reduction. Bandura (1989) states that selfefficacy is important to the cognitive process, because it allows for goal setting and the motivation to accomplish those goals. Goal setting is essential to behavioral changes, because it sets limits on unhealthy routines, and it creates a sense of accomplishment for the person when goals are attained (Lorig \& Holman, 2003). Self-efficacy promotes selfmotivation and enhances personal accomplishments, especially after mastering difficult tasks (Bandura, 1994). In addition, self-efficacy also permits an individual to positively believe in themselves and their capability to execute specific actions, such as weight reduction through behavioral changes (Coleman \& Newton, 2005). Physical activity selfefficacy affords an individual the opportunity to evaluate the results of their actions; therefore, more physical activity will be performed if the expectations of losing weight are met (Dishman et al., 2005).

Negative consequences of self-efficacy emerge when goals are not met due to past failures or noticeable failures of others. Additionally, an inability to control valuable aspects of one's life is instrumental in the formation of depression, especially in children (Bandura, Pastorelli, Barbaranelli, \& Caprara, 1999). Improving one's self-efficacy through physical activities can assist an individual to achieve better self-perception and alleviate depressive symptoms. Exercise can improve one's emotional, physical, and mental status, often leading to a reduction in mild-to-moderate depression. According to Legrand (2014), a significant reduction in depressive symptoms and an increase in physical self-esteem and perceived physical condition was found in low-income women who, participated in a seven-week exercise training program. Examining the connections between self-efficacy and childhood outcomes, such as BMI, depressive symptoms, and physical activity are important especially when considering parental factors. According to researchers, the human agent asserts control over personal behaviors; however, modeling of behaviors can reinforce positive or negative outcomes (Bandura, Ross, \& Ross, 1963). Parents can model either healthy or unhealthy behaviors for their children. Past studies 
have indicated that physically active mothers have children that are twice as likely to be physically active compared to children of inactive mothers (Moore et al., 1991).

To date, few studies have explored physical activity and its associations with selfefficacy in African American children. In a study of 202 rural African American $6^{\text {th }}$ graders, researchers investigated predictors of moderate and vigorous physical activity (MVPA) and vigorous physical activity (VPA) (Trost et al., 1997). Researchers found that overcoming barriers to physical activity self-efficacy was positively correlated with VPA and MVPA in both girls and boys. Support seeking behaviors of self-efficacy was also positively correlated with MVPA in boys (Trost et al., 1997). In a study examining predictors of physical activity in 194 children (21 African American) 10-14 years of age, investigators found that self-efficacy was a positive predictor of physical activity and the mastery approach to achieving a goal (Gao, Lochbaum, \& Podlog, 2011). Physical activity self-efficacy is also moderately correlated with "prosocial behaviors" in children, such as cooperating, following directions, and giving verbal praises to members while playing on a sports team (XiaoXia, Ping, McBride, JiLing, \& Thornton, 2016).

\section{CONCLUSION}

The prevalence of depression and obesity are steadily increasing globally despite the abundance of preventative information and interventions available within the literature. The (World Health Organization, 2016a), states the number of overweight and obese infants ( 0 to 5 years of age) in the year 1990 was approximately 32 million globally; however, by the year 2013 the number had increased to 43 million. This increase is primarily recorded in developed countries. Though the prevalence of obesity among United States children (17\%) has remained stable, obesity among children 2-19 years of age is still too high (World Health Organization, 2016a). Additionally, African Americans comprise of only $13 \%$ of the total population of the United States, but African American women and children are plagued with overweight and obese BMI's at disproportionally higher rates than their Caucasian counterparts (Alliance for a Healthier Generation, 2016; Centers for Disease Control and Prevention, 2015h; United States Census Bureau, 2015). A growing body of research has acknowledged factors possibly contributing to this epidemic. The association between genetics and obesity has been examined and validated within literature; however, environmental associations with obesity are also well documented. Research has indicated that African Americans living within lower socioeconomic status environments have fewer supermarkets to purchase fresh produce but more convenience stores and fast food outlets, which contribute to an "obesogenic" environment. Characterizing this sedentary lifestyle is the lack of daily physical activity. Nationally, lower percentages of African Americans meet the suggested guidelines for daily physical activity in comparison to other races. In part, unsafe neighborhood conditions and lack of access and affordability of a workout facility have been instrumental in limiting physical activity for African Americans. Unfortunately, maternal obesity can also influence the weight and health outcomes of children through modeling unhealthy eating and physical activity behaviors. Potential risks for increases in 
weight gain in children after being exposed to an "obesogenic" environment while in utero are also well documented.

Unlike obesity, disparities the prevalence of depression among African Americans, especially women, compared with other races persist within the literature. Researchers believe this inequality is attributable to health care disparities and underreporting of symptoms in this population. Nevertheless, it has been recognized that the severity of depressive symptoms and major depression in African American mothers is worse than Caucasian mothers. Similar to the development of obesity, the associations between genetics, environment, and depression are well known. Lower socioeconomic status and environmental and emotional stressors have all been linked to depression in African American women. In response to maternal depressive symptoms, children's psychological and physiological health and well-being are affected. Research has indicated that maternal depression decreases mothers' engagement in their child's activities, thus creating negative relationships. Maternal depression also influences negative behaviors in infants, such as a reduction in attentiveness, which can be precursors for conduct and emotional problems into childhood. Moreover, studies have shown a possible association between maternal depression and childhood obesity. Studies suggest that children of depressed mothers have an increased possibility of becoming obese due to permissive parenting styles that affect the child's eating habits and time allowed to watch television each day.

Currently, there is limited research in African American women and their young children exploring the associations among depressive symptoms, obesity, and physical activity self-efficacy. Therefore, this study will provide insights into associations among these factors in younger African American children. Hopefully, this study can inspire future research, considerations for practice, and policy initiatives that improve the health and social outcomes of affected mother-child dyads. 


\section{CHAPTER 3. METHODOLOGY}

This chapter presents a comprehensive review of the research design, sample, setting, and the various tools utilized for data collection and statistical analysis. Also included in this chapter is a description of approaches used to assure the protection of human subjects involved within the study.

\section{RESEARCH DESIGN}

This study was designed as a cross-sectional, descriptive, correlational study of depressive symptoms, body mass index (BMI), and physical activity self-efficacy relationships between African American mothers and children. Research questions were formulated to determine whether or not relationships existed between child depressive symptoms, BMI percentile, physical activity self-efficacy and maternal depressive symptoms and BMI. Data obtained from BMI measurements and self-reported questionnaires on depressive symptoms and physical activity self-efficacy were collected from participants once and analyzed utilizing correlational methods.

\section{SAMPLE COMPOSITION}

A convenience sample of 65 mother-child dyads was recruited to answer individual self-inventories and have BMI measurements obtained. Each family was limited to only one mother-child dyad. A prescreening process for mothers and their children assisted in identifying potential participants. Mothers also completed the Demographic Profile Questionnaire on themselves and their child before completing other study instruments (Appendix B).

\section{Mother Inclusion Criteria}

Mothers chosen for participation were all ages and reported being the biological mother of the participating child. Mothers also self-identified as being either African American/black or black/biracial. To properly respond to questionnaires women who could read and understand English were chosen. Normal weight, overweight, and obese women were selected as long as they met the requirements to physically stand up straight without any assistance.

\section{Mother Exclusion Criteria}

Mothers who were selected for participation were not currently taking weight loss medications. If they acknowledged they were currently taking a prescribed antidepressant medication they also were excluded from participation. Additional factors that excluded 
women from being selected for study participation included having a history of gastric bypass or weight loss surgery, and stating a current enrollment in a weight loss program. Lastly, women who were pregnant, could not stand up straight, and could not speak or read in English were excluded from participation.

\section{Child Inclusion Criteria}

Children, accepted for participation, were identified by their mothers as either African American/black or black/biracial. Their ages ranged from 7-10 years and male and female participants were accepted. Their body mass index percentiles represented normal weight, overweight, and obese. Children were required to speak English and have the ability to stand up straight without assistance.

\section{Child Exclusion Criteria}

Children who did not meet the age or ethnicity requirements were excluded from participating within the study. If the child was currently taking an antidepressant, their results for the Childhood Depression Inventory 2 could potentially be misleading; therefore, they were excluded from participation. Children who had underweight BMI percentiles were also excluded. Children who could not stand up straight for height measurements or who had a device (e.g., leg or arm cast) that would result in inaccurate weight measurement were not chosen for participation. Lastly, only one child per mother was allowed to enroll in the study.

\section{Sample Size Calculation}

All of the study's aims were analyzed using an estimated correlation coefficient, therefore calculating an appropriate effect size to determine the magnitude of variable associations, sample size, and level of alpha were especially critical (Cohen, 1988). Within the literature there are numerous methods to calculate each of these factors. Using SAS, a power analysis was completed and determined that $\mathrm{N}=62$ was a suitable sample size with a power of 0.5 , estimated correlation coefficient of .25 , and a $p$ value $\leq .05$ for a two tailed test. Corresponding estimated correlation coefficients Cohen's criterion was used to establish a small $(\mathrm{r}=.10)$ and medium $(\mathrm{r}=.30)$ effect size for the study (Cohen, 1992). To assist with future modeling, associations with a $p$ value $\leq .2$ were included in the acceptance range. These associations may be greater in larger samples. 


\section{INSTRUMENTATION}

\section{Maternal Depression Screening Tool}

The Beck Depression Inventory ${ }^{\circledR}-11\left(\mathrm{BDI}^{\circledR}-\mathrm{II}\right)$ is one of the most widely utilized instruments for measuring the severity of adult and adolescent depressive symptoms. It is most appropriate for the use in individuals 13 years and older. The 21 -item self-report inventory was considerably modified from the original Beck Depression Inventory (BDI) by eliminating four items (Weight Loss, Body Image Change, Somatic Preoccupation, and Work Difficulty) and substituting them with four new items (Agitation, Worthlessness, Concentration Difficulty, and Loss of Energy) (Beck et al., 1996). The $\mathrm{BDI}^{\circledR}$-II was constructed to assess depressive symptomology consistent with depressive disorders' diagnostic standards as outlined in the American Psychiatric Association's Diagnostic and Statistical Manual of Mental Disorders-Fourth Edition (DSM-IV). With the addition of new questions to align with the DSM-IV diagnosis of depression, the $\mathrm{BDI}^{\circledR}$-II measures somatic, cognitive, affective, and vegetative aspects of depression (Smarr \& Keefer, 2011). Response items are representative of the respondent's feelings over the past two weeks and each question is rated from 0 to 3 points, where a score of 0 is indicative of no depressive symptoms and a score of 3 is the highest for depressive symptomology. Total scores have four categorical ranges for depressive symptoms, minimal (0-13), mild (14-19), moderate (20-28), and severe (29-63).

The authors established psychometric properties by testing the BDI ${ }^{\circledR}$-II in a group of 120 college students and in 500 individuals from four various psychiatric outpatient clinics. Unfortunately, only 21 (4\%) of the 500 participants were African American. A Cronbach's alpha of .92 was established for the outpatients and .93 for the college students. Additionally, a test-retest stability of .93 was obtained after retesting 1-week after the initial therapy session of 26 outpatients. Although the BDI ${ }^{\circledR}$-II was constructed to determine the various levels of depression in psychiatric adult and adolescent patients, additional studies have found it to be equally useful in identifying depressive symptoms in community populations (Kneipp, Kairalla, Stacciarini, \& Pereira, 2009; Whisman, Judd, Whiteford, \& Gelhorn, 2013).

\section{Children's Depression Screening Tool}

The Children's Depression Inventory $2^{\mathrm{TM}}$ (CDI 2) is a multiple choice, multi-rater screening tool used to assess for symptoms of depression in children and adolescents ages 7-17 years (Kovacs \& Multi-Health Systems, 2011). There are four distinct forms: the CDI 2 Self-Report (CDI 2:SR), CDI 2 Self-Report Short Form (CDI 2:SR [S]), a parent respondent form (CDI 2:P), and a teacher respondent form (CDI 2:T). This study utilized the full length, 28 questions CDI 2:SR form. From a list of three sentences, the child respondent chooses the answer that best addresses their feelings and emotional and physical state within the last two weeks. Scores for each question are rated from 0 to 2 , where a score of 0 signifies normalcy and no depressive symptoms. A score of 1 indicates 
a depressive symptom that is not disabling and a score of 3 is the highest indicating a clinically depressive symptom. However, half of the questions are scored in reverse order (Kovacs \& Multi-Health Systems, 2011).

In regards to the DSM-IV criteria for depression, the CDI 2 measures an overall total score for depressive symptoms, two scales that assess emotional problems and functional problems, and four subscales that measure negative mood/physical symptoms, negative self-esteem, ineffectiveness and interpersonal problems. Each item on the CDI 2 is categorized in one of the four subscales and the sum of all items in that category will provide an overall score for the particular subscale. Together, the addition of two subscales, negative mood/physical symptoms and negative self-esteem, comprise the raw score for emotional problems. Likewise, the raw score for functional problems is the sum of the two subscales, ineffectiveness and interpersonal problems. The overall total score is calculated by summing the scores of the emotional and functional problems. In this study scores will be reported for all four subscales, the two scales, and the overall total score.

Considering age and gender differences raw scores for the overall total score, the two scales, and four subscales are converted to $T$-scores for standardization. Average to high average scores range from $\leq 40-64$. Elevated scores range from 65-69 and very elevated scores are $\geq 70$. Although use of the CDI 2 is relatively new, researchers have established reputable psychometric properties (Kovacs \& Multi-Health Systems, 2011). In a sample of 1,100 American children ages 7-19 an alpha of .91 was obtained for the overall total score, indicative of high internal consistency. The total score also reflected high coefficient alphas (.88-.92) when examining gender and age groups independently. The original Children's Depression Inventory $\left(\mathrm{CDI}^{\mathrm{TM}}\right)$ reports an alpha $\geq 80$ for the total score when combining results from previous research utilizing the instrument (Kovacs \& Multi-Health Systems, 2011).

\section{Physical Activity Self-Efficacy Assessment in Children}

The Physical Activity Self-Efficacy Scale (PASES) is a 17-item self-report questionnaire that assesses support seeking behaviors, barriers, and positive alternatives in relation to physical activity in children (Appendix A). The self-administered inventory takes approximately 5-10 minutes to complete and it can be read to the child if assistance is needed. The responses are assessed using a dichotomous scale allowing the child to select yes or no to each question and one point is awarded for each yes answer. Scores in each category are summed and the highest attainable score for each section includes an overall total score of 17, 7 for support seeking, 4 for barriers, and 6 positive alternatives. There are no particular cutoff scores to indicate low, moderate, or high self-efficacy; however, higher scores are indicative of positive outcomes for each section (Saunders et al., 1997). For the purpose of this study scores will be reported for all three categories of the PASES. 
To determine the instrument's psychometric properties, researchers administered the scale to 558 fifth graders in South Carolina; however, only $80 \%$ the sample's responses were used to calculate the test's psychometrics. Test-retest data were collected one year from 57 children from the original sample. Results from the total and retest sample include: support seeking $(\mathrm{n}=319$, Cronbach's alpha $=0.71$, test-retest reliability $=$ $0.76)$; barriers $(\mathrm{n}=323$, Cronbach's alpha $=0.71$, test- retest reliability $=0.82)$; and positive alternatives $(n=321$, Cronbach's alpha $=0.54$, test-retest reliability $=0.61)$ (Saunders et al., 1997).

\section{Anthropometric Assessment for Mothers}

Height and weight measurements for each participant were collected and assessed by the investigator. Women were categorized as normal weight, overweight, or obese after their BMI was calculated. Used worldwide as a screening mechanism to determine body fatness, BMI depicts the relationship between a person's weight and height and has been associated with certain metabolic and disease processes (Centers for Disease Control and Prevention, 2015a). Researchers also report higher BMI findings in women and ethnic minority groups (Flegal, Carroll, Kit, \& Ogden, 2012). In this study maternal BMI was calculated by dividing mothers' weight in kilograms by their height in meters squared $\left(\mathrm{kg} / \mathrm{m}^{2}\right)$. The National Institutes of Health and Department of Health and Human Services (n.d.) BMI calculator was used to determine maternal BMI. Normal weight BMI ranged from $18.5-24.9 \mathrm{~kg} / \mathrm{m}^{2}$, overweight BMI ranged from $25-29.9 \mathrm{~kg} / \mathrm{m}^{2}$, and obese $\mathrm{BMI} \geq 30.0 \mathrm{~kg} / \mathrm{m}^{2}$.

\section{Anthropometric Assessment for Children}

Height and weight information for each child was collected and assessed by the investigator. The calculation of BMI in children and adolescents between the ages of 2-20 years is comparable to that of adults; however, age and gender are accounted for. A BMIfor-age percentile chart is used to determine BMI percentiles that can be correlated with national data from the National Health and Nutrition Examination Survey (NHANES). Normal weight youth BMI ranges from the $5^{\text {th }}$ percentile to less than the $85^{\text {th }}$ percentile. Overweight youth present with a BMI $\geq 85^{\text {th }}$ percentile but less than the $95^{\text {th }}$ and obese youth have a BMI $\geq 95^{\text {th }}$ percentile (Centers for Disease Control and Prevention, 2015b). Percentiles were calculated and converted to Z-scores using The Children's Hospital of Philadelphia (2016) online Pediatric Z-score Calculator which follows current CDC recommendations for BMI Z-score calculations.

\section{RECRUITMENT METHODS AND SITES}

Mother-child dyads were recruited through flyers posted at local churches, elementary schools, the University of Tennessee Health Science Center, and community centers within the greater Memphis, TN area. Weekly visits to churches and community 
centers also increased face-to-face interactions with parents, which allowed the opportunity to explain the study to those who displayed interest. An initial telephone screening process also played a role in determining eligibility for participation (Appendix C). Upon meeting all inclusion criteria for participation, individuals were provided with a date, time, and location to meet with the study investigator. On the day of participation in the study, study concepts, purpose, procedures, and incentives upon completing the study were discussed with all participants. Before consenting, mothers and children were encouraged to ask questions to gain better clarity of the study and they were informed that their participation was strictly voluntary. Children were asked if they understood the study's purpose, what data would be collected, and procedures for data collection. Prospective participants were also made aware of their right to withdraw or opt out of the study even after signing consent documents. Before beginning the study, the researcher verified that each dyad had a signed consent form on file and assent form if the child was 8 years and older. Children who were 8 years and over assented to participation by acknowledging in their own words their intent to participate and their understanding of the study and procedure. Consent and assent forms (Appendix D) are archived in a secure and locked file by the researcher.

\section{PROCEDURES}

After meeting all initial criteria for the study and signing consent and assent forms the researcher conducted the study with mother and child participants following the procedures as presented below.

\section{Demographic Information}

Each mother was provided a Demographic Profile Questionnaire (Appendix B) for reporting demographic information about herself and her child. The Demographic Profile Questionnaire also included a medical information section where she answered questions about her child's health.

\section{Anthropometric Assessment}

While the mother completed the demographic paperwork the child was asked to remove his or her shoes and anything within their pockets. The scale was set to $0 \mathrm{lbs}$. before each participant was measured and their weight was collected in pounds. Instructing participants to place their heels to the back of the stadiometer and look straightforward, measurements for height were then collected in inches. Maternal weight and height measurements were collected using the same procedure after the child's measurements had been obtained. 


\section{Maternal Depressive Symptoms}

The BDI ${ }^{\circledR}$-II was provided to the mother in an area from her child. Directions were read and the mother responded to the questionnaire in privacy. Ten mothers requested that the researcher read each question aloud and mothers chose their response on a separate test. The approximate time for administration was 5 minutes.

\section{Children Depressive Symptoms}

Away from the parent, the researcher administered the CDI 2 to the child. Before beginning, the researcher read the instructions and informed the child to be as honest as possible. Each question was read aloud by the researcher as the child followed along on a copy of the form. The child was asked to mark on the form the answer that was most applicable to the child's feelings over the past two weeks. Time for administering the CDI 2 was approximately 20 minutes.

\section{Physical Activity Self-Efficacy}

After completing the CDI 2, the researcher administered the PASES to the child. Similar to the CDI 2 the researcher read the directions and each question aloud as the child participant followed along on a form and chose the appropriate answer on the form. Administration of the PASES was approximately 10 minutes.

\section{STATISTICAL ANALYSIS}

Data analysis was completed using Statistical Analysis System (SAS) version 9.3. Descriptive statistics were calculated for the child sample using data from the Demographic Profile Questionnaire, CDI 2, PASES, and child anthropometric assessment. Descriptive statistics were calculated for the mother sample using data from the Demographic Profile Questionnaire, BDI ${ }^{\circledR}$-II, and mother anthropometric assessment. Means, standard deviations, and ranges were calculated for maternal age, weight, height, BMI, and depressive symptoms scores $\left(\mathrm{BDI}^{\circledR}-\mathrm{II}\right)$. Likewise, means, standard deviations, and ranges were calculated for child age, weight, height, BMI Z-score, depressive symptoms scores (CDI 2), and physical activity self-efficacy scores (PASES).

\section{Specific Aim One}

Pearson product moment correlation coefficient estimates was used to examine the associations between child depressive symptoms and child BMI Z-score, maternal depressive symptoms, and child physical activity self-efficacy. A Spearman correlation coefficient estimate was used to explore the association between child depressive 
symptoms and maternal BMI because maternal BMI was not sampled from an underlying normal distribution. A p-value $\leq .20$ was considered statistically significant.

\section{Specific Aim Two}

The associations between child BMI Z-scores and maternal depressive symptoms and child physical activity were estimated using Pearson product moment correlation coefficients. The association between child BMI Z-scores and maternal BMI were estimated using a Spearman correlation coefficient because maternal BMI was not sampled from an underlying normal distribution. Correlations with a $p$-value $\leq .20$ were considered statistically significant.

\section{Specific Aim Three}

A Spearman correlation coefficient was estimated to quantify the association between child physical activity self-efficacy and maternal BMI. The association between child physical activity self-efficacy and maternal depressive symptoms was estimated by a Pearson correlation coefficient because both variables were sampled from an underlying normally distribution. A p-value $\leq .20$ was considered statistically significant

\section{CONSIDERATION OF HUMAN SUBJECTS}

The Institutional Review Board of the University of Tennessee Health Science Center (UTHSC) approved this study (Appendix E). Also, the Shelby County School System Office of Planning and Accountability approved the study for five schools within their district. There was minimal potential risk for all study participants.

Procedures performed were noninvasive physiological measures (height and weight assessment) and administration of self-reported questionnaires (BDI ${ }^{\circledR}$-II, CDI 2 , and PASES). Completion of the BDI ${ }^{\circledR}$-II and CDI 2 could elicit uncomfortable and troublesome feelings and emotions. Consideration was given to children because they could become stressed, tired, or bored from completing two questionnaires consecutively. Breaks were offered periodically to participants. Participants who were identified as obese and those who displayed moderately to severe depressive symptoms were notified and recommended to follow-up with their primary care physician. If the participant did not have a primary care provider, then a referral to the appropriate health care facility was provided.

To prevent loss of confidentiality, names were coded, paper exams were kept locked in a filing cabinet in the $\mathrm{PhD}$ student offices at UTHSC, and computer software with participant information was password protected. Participants' names and other identifying information will not be included in any publications or presentations. 


\section{CHAPTER 4. RESULTS}

Three specific aims were examined in this study. The investigator first sought to determine whether associations of child depressive symptoms with child BMI Z-scores, maternal BMI, maternal depressive symptoms and child physical activity self-efficacy existed. Second, the study explored the associations of child BMI Z-scores with maternal BMI, maternal depressive symptoms, and child physical activity self-efficacy. Lastly, this study examined associations between child physical activity self-efficacy with maternal BMI and maternal depressive symptoms. All associations were performed utilizing African American mother-child dyads. Research has implicated that maternal weight and depressive symptomology have influenced weight and behavioral outcomes in their children (Gross et al., 2013; Pachter et al., 2006). However, the direct pathway in whether obesity is a predictor of depression or vice versa has not been established.

\section{SAMPLE CHARACTERISTICS}

\section{Maternal Descriptive Statistics}

Demographic characteristics of the sample of mothers (ethnicity, education, and marital status) were reported as frequencies and percentages (Table 4-1). The overall number of participants consisted of 65 mother-child dyads $(\mathrm{N}=130)$. The ethnicity of maternal participants included $63(96.92 \%)$ self-identifying as black and $2(3.08 \%)$ selfidentifying as black/biracial. Education was self-reported in five categories. The majority of the women was single $(73.85 \%)$ and had attained a high school or college education (76.92). An illustration summary of statistics for maternal age, anthropometric measurements, and BDI ${ }^{\circledR}$-II overall scores can be found in (Table 4-2).

\section{Child Descriptive Statistics}

Demographic characteristic of the sample of children (ethnicity, gender, medical, and grade level) were expressed as frequencies and percentages, summarized in Table 4-1. The mothers identified sixty-four $(98.46 \%)$ of the children as being ethnically black and $1(1.54 \%)$ was identified as black/biracial. Thirty-four $(52.31 \%)$ were female and 31 $(47.69 \%)$ were male. The most commonly reported medical condition for the sample was asthma (20\%). Children's grade level consisted of first $(3.08 \%)$, second (24.62\%), third (29.23\%), fourth (18.46), fifth (20\%), and sixth (4.62\%). Depictions of anthropometric measurements, CDI 2 scores, and physical activity self-efficacy scores for the children can be found within (Table 4-3). 
Table 4-1. Demographic Characteristics of 65 African American Mother-Child Dyads Enrolled in the Study from June-December 2015

\begin{tabular}{|c|c|c|c|c|}
\hline \multirow[b]{2}{*}{ Characteristics } & \multicolumn{2}{|c|}{ Mothers } & \multicolumn{2}{|c|}{ Children } \\
\hline & $\mathbf{n}$ & $\%$ & $\mathbf{n}$ & $\%$ \\
\hline \multicolumn{5}{|l|}{ Ethnicity } \\
\hline Black & 63 & 96.92 & 64 & 98.46 \\
\hline Black/Biracial & 2 & 3.08 & 1 & 1.54 \\
\hline \multicolumn{5}{|l|}{ Gender } \\
\hline Female & -- & -- & 34 & 52.31 \\
\hline Male & -- & -- & 31 & 47.69 \\
\hline \multicolumn{5}{|l|}{ Medical } \\
\hline No Medical & -- & -- & 46 & 70.77 \\
\hline Asthma & -- & -- & 13 & 20.00 \\
\hline ADHD & -- & -- & 3 & 4.62 \\
\hline Hypertension & -- & -- & 1 & 1.54 \\
\hline Type II Diabetes & -- & -- & 1 & 1.54 \\
\hline Other & -- & -- & 1 & 1.54 \\
\hline \multicolumn{5}{|l|}{ Child's Grade Level } \\
\hline First & -- & -- & 2 & 3.08 \\
\hline Second & -- & -- & 16 & 24.62 \\
\hline Third & -- & -- & 19 & 29.23 \\
\hline Fourth & -- & -- & 12 & 18.46 \\
\hline Fifth & -- & -- & 13 & 20.00 \\
\hline Sixth & -- & -- & 3 & 4.62 \\
\hline \multicolumn{5}{|l|}{ Mother's Education } \\
\hline Some High School & 15 & 23.08 & -- & -- \\
\hline High School & 28 & 43.08 & -- & -- \\
\hline Diploma /GED & & & & \\
\hline Associate's Degree & 9 & 13.85 & -- & -- \\
\hline Bachelor's Degree & 8 & 12.31 & -- & -- \\
\hline Master's Degree & 5 & 7.69 & -- & -- \\
\hline \multicolumn{5}{|l|}{ Marital Status } \\
\hline Single & 48 & 73.85 & -- & -- \\
\hline Married & 13 & 20.00 & -- & -- \\
\hline Divorced & 4 & 6.15 & -- & -- \\
\hline
\end{tabular}


Table 4-2. Age, Anthropometric Measures, and BDI®-II Assessments for 65 African American Mothers Enrolled in the Study from June-December 2015

\begin{tabular}{|c|c|c|c|}
\hline Variable & Mean & SD & Range \\
\hline 1. Age in Years & 34.00 & 7.33 & $24-53$ \\
\hline 2. Weight in Pounds & 195.36 & 46.54 & $104.20-342.60$ \\
\hline 3. Height in Inches & 63.97 & 3.00 & $56-74$ \\
\hline 4. Body Mass Index & 33.17 & 6.98 & $14.40-56.10$ \\
\hline 5. $\mathrm{BDI}^{\circledR}$-II Overall Score & 11.72 & 11.15 & $0-48$ \\
\hline
\end{tabular}


Table 4-3. Anthropometric Measurements, CDI 2, and Physical Activity SelfEfficacy Assessments for 65 African American Children Enrolled in the Study from June-December 2015

\begin{tabular}{|c|c|c|c|}
\hline Variable & Mean & SD & Range \\
\hline \multicolumn{4}{|l|}{ Anthropometric Measurements } \\
\hline 1. Age in Years & 8.45 & 1.19 & $7-10$ \\
\hline 2. Weight in Pounds & 84.88 & 4.26 & $47.6-211$ \\
\hline 3. Height in Inches & 54.00 & 30.94 & $47-63$ \\
\hline 4. Child BMI Z-Score & 0.95 & 1.06 & $-1.66-2.67$ \\
\hline \multicolumn{4}{|c|}{ Children's Depression Inventory $2^{\mathrm{TM}}$} \\
\hline 1. Overall Score & 55.88 & 9.93 & $40-80$ \\
\hline 2. Emotional Problems & 54.69 & 9.35 & $42-78$ \\
\hline $\begin{array}{l}\text { 3. Negative Mood/Physical } \\
\text { Symptoms }\end{array}$ & 55.55 & 12.07 & $42-90$ \\
\hline 4. Negative Self-Esteem & 51.71 & 8.51 & $44-90$ \\
\hline 5. Functional Problems & 56.09 & 11.68 & $40-90$ \\
\hline 6. Ineffectiveness & 53.71 & 10.95 & $40-90$ \\
\hline 7. Interpersonal Problems & 56.28 & 14.33 & $42-90$ \\
\hline \multicolumn{4}{|c|}{ Physical Activity Self-Efficacy Scale } \\
\hline 1. Overall Score & 11.68 & 2.78 & $4-17$ \\
\hline 2. Support Seeking & 5.80 & 1.34 & $2-7$ \\
\hline 3. Barriers & 2.02 & 1.32 & $0-4$ \\
\hline 4. Positive Alternatives & 3.85 & 1.43 & $1-6$ \\
\hline
\end{tabular}




\section{RESEARCH HYPOTHESES AND RESULTS}

\section{Specific Aim One}

Examine the associations between child depressive symptoms and child BMI Zscore, maternal BMI, maternal depressive symptoms, and child physical activity selfefficacy.

\section{Hypothesis One}

Child depressive symptoms are positively associated with child BMI Z-score.

\section{Hypothesis One Results}

Child depressive symptoms were assessed with the CDI 2 self-report form; the normality assumptions were satisfied. A total score for depressive symptoms, two scales (emotional problems and negative mood/physical symptoms), and four subscales (negative self-esteem, functional problems, ineffectiveness, and interpersonal problems) of depressive symptoms were reported as T-scores for generalizability between ages, and male and female participants. Pearson product moment correlation coefficients were estimated to quantify associations with child BMI Z-score. Higher CDI 2 total scores, scales, and subscales are indicative of increased depressive symptoms. Positive correlations existed between child BMI Z-score and CDI 2 total score $(\mathrm{r}=0.187, p=$ $.137)$, functional problems $(\mathrm{r}=0.187, \mathrm{p}=.136)$, and interpersonal problems $(\mathrm{r}=0.234, \mathrm{p}$ $=.064)$. These results indicated that African American children within the study with higher BMI Z-scores also had higher depressive symptoms, functional problems, and interpersonal problems. Estimated Pearson correlation coefficients of child depressive symptoms and BMI Z-score are summarized in (Table 4-4).

\section{Hypothesis Two}

Child depressive symptoms are positively associated with maternal BMI.

\section{Hypothesis Two Results}

Maternal BMI values were not sampled from an underlying normal distribution; thus nonparametric correlational analysis was conducted. Spearman correlation coefficients estimated associations between child depressive symptoms (overall score, emotional problems, negative mood/physical symptoms, negative self-esteem, functional problems, ineffectiveness, and interpersonal problems) and maternal BMI. No statistically significant associations between children's depressive symptoms and their mother's BMI were found. Estimated Spearman correlation coefficients of child depressive symptoms and maternal BMI are summarized in Table 4-4. 
Table 4-4. $\quad$ Estimated Correlation Coefficients of Child Depressive Symptoms with Child BMI Z-Score, Maternal BMI, Maternal Depressive Symptoms, and Child Physical Activity Self-Efficacy from 65 Mother-Child Dyads

\begin{tabular}{|c|c|c|c|c|c|c|c|}
\hline \multirow[b]{2}{*}{$\begin{array}{l}\text { Child Depressive } \\
\text { Symptoms }\end{array}$} & \multicolumn{7}{|c|}{ Measures } \\
\hline & Z-Score & MBMI & MDEP & SETS & SS & $\mathbf{B}$ & PA \\
\hline 1. Total Score & $0.187^{*}$ & -0.017 & $0.191^{*}$ & -0.078 & -0.115 & $0.177^{*}$ & $-0.163^{*}$ \\
\hline 2. Emotional Problems & 0.123 & -0.018 & $0.245^{* * *}$ & 0.014 & -0.026 & $0.226^{*}$ & -0.158 \\
\hline $\begin{array}{l}\text { 3. Negative Mood/Physical } \\
\text { Symptoms }\end{array}$ & 0.119 & -0.011 & $0.319^{* * * *}$ & 0.003 & 0.021 & 0.108 & -0.144 \\
\hline 4. Negative/Self-Esteem & 0.053 & -0.102 & -0.056 & 0.030 & -0.082 & $0.309 * * *$ & -0.089 \\
\hline 5. Functional Problems & $0.187^{*}$ & -0.043 & 0.100 & -0.140 & $-0.171^{*}$ & 0.088 & -0.126 \\
\hline 6. Ineffectiveness & 0.101 & -0.059 & 0.086 & $-0.162 *$ & -0.145 & -0.067 & -0.038 \\
\hline 7. Interpersonal Problems & $0.234 * *$ & 0.036 & 0.145 & -0.122 & $-0.244 * *$ & $0.231 * *$ & $-0.213 * *$ \\
\hline
\end{tabular}

Note: $\mathrm{BMI}=$ body mass index; Z-score = Z-score of child BMI; MBMI = Maternal BMI; MDEP = Maternal Depression Scores; SETS = Self-Efficacy Total Score; SS= Support Seeking; B = Barriers; and PA = Positive Alternatives. Correlations with maternal BMI (MBMI) were estimated with Spearman correlation coefficients. All other associations were estimated with Pearson product-moment correlation coefficients. Correlation coefficient values marked with an asterisk* were statistically significant $\left({ }^{*} p<.20 ; * * p<.10\right.$; $* * * p<.05 ; * * * * p<.01)$. 


\section{Hypothesis Three}

symptoms.

Child depressive symptoms are positively associated with maternal depressive

\section{Hypothesis Three Results}

Maternal depressive symptoms were assessed and self-reported using the BDI ${ }^{\circledR}$-II and a total overall score for depressive symptoms was calculated. Higher total scores were suggestive of increased depressive symptoms. Pearson product moment correlation coefficients were calculated to quantify associations between child and maternal depressive symptoms. Results indicated that in African American mothers, higher maternal depressive symptoms were associated with higher overall child depressive symptoms $(\mathrm{r}=0.191, \mathrm{p}=.127)$, higher child emotional problem scores $(\mathrm{r}=0.245, \mathrm{p}=$ $.049)$, and negative mood/physical symptom scores $(r=.319, p=.010)$. Estimated Pearson product moment correlation coefficients of child and maternal depressive symptoms are summarized in Table 4-4.

\section{Hypothesis Four} efficacy.

Child depressive symptoms are negatively associated with physical activity self-

\section{Hypothesis Four Results}

The children's physical activity self-efficacy was assessed in four categories on the PASES self-report questionnaire: total score, support seeking, barriers, and positive alternatives. Higher scores in each category indicate positive physical activity selfefficacy. Pearson's product moment correlation coefficients were estimated to quantify associations between child depressive symptoms and physical activity self-efficacy.

Child depressive symptoms total score was positively correlated with barriers $(\mathrm{r}=$ $0.117, \mathrm{p}=.158)$ and negatively associated with positive alternatives $(\mathrm{r}=-0.163, \mathrm{p}=$ .193 ). These results indicated that as depressive symptoms increased in children they reported fewer barriers to being physically active, but they felt there were less positive alternatives to being physically active.

Children who reported higher emotional problems reported fewer barriers to being physically active $(\mathrm{r}=0.226, \mathrm{p}=.070)$. Those who reported higher negative self-esteem also reported fewer barriers to being physically active $(r=0.309, p=.012)$.

Children with increased functional problems were less likely to exhibit supportseeking characteristics for physical activity $(\mathrm{r}=-0.171, \mathrm{p}=.174)$. When symptoms of ineffectiveness were higher in children they reported lower overall physical activity selfefficacy scores $(r=-0.162, p=.199)$. 
Lastly, children with higher interpersonal problems were less likely to exhibit support- seeking characteristics for physical activity $(r=-0.244, p=.050)$. They also reported less positive alternatives to being physically active $(r=-0.213, p=.088)$, but they reported fewer barriers to being physically active $(r=0.231, p=.064)$. Estimated Pearson product moment correlation coefficient of child depressive symptoms and physical activity self-efficacy are summarized in Table 4-4.

\section{Specific Aim Two}

Examine the associations between child BMI Z-score and maternal BMI, maternal depressive symptoms and child physical activity self-efficacy symptoms.

\section{Hypothesis One}

Child BMI Z-score is positively associated with maternal BMI.

\section{Hypothesis One Results}

A Spearman product moment correlation coefficient was estimated to quantify the association between child BMI Z-score and maternal BMI, due to violations of the normality assumptions by maternal BMI. No statistically significant association between child BMI Z-score and maternal BMI were found $(\mathrm{r}=0.132, \mathrm{p}=.295)$ (Table 4-5).

\section{Hypothesis Two}

Child BMI Z-score is positively associated with maternal depressive symptoms.

\section{Hypothesis Two Results}

Pearson correlation coefficient was estimated to quantify the associations between child BMI Z-score and maternal depressive symptoms. No statistically significant association was found and the result is found on Table 4-5.

\section{Hypothesis Three}

Child BMI Z-score is inversely associated with child physical activity selfefficacy.

\section{Hypothesis Three Results}

Pearson product moment correlation coefficients were estimated to quantify associations between child BMI Z-score and physical activity self-efficacy. Child BMI Zscore was positively associated with overall physical activity self-efficacy $(r=0.250, p=$ $.045)$, support-seeking $(\mathrm{r}=0.231, \mathrm{p}=.065)$, and barriers $(\mathrm{r}=.249, \mathrm{p}=.045)$. Results are indicated on Table 4-5. 
Table 4-5. $\quad$ Estimated Correlation Coefficients of Child BMI Z-Scores with Maternal BMI, Maternal Depressive Symptoms, and Child Physical Activity SelfEfficacy from 65 Mother-Child Dyads

\begin{tabular}{lcccccc}
\hline & \multicolumn{7}{c}{ Measures } \\
\cline { 2 - 7 } Variable & MBMI & MDEP & SETS & SS & B & PA \\
\hline Child BMI Z-Score & 0.132 & 0.057 & $0.250^{* * *}$ & $0.231^{* *}$ & $0.249^{* * *}$ & 0.036 \\
\hline
\end{tabular}

Note: $\mathrm{BMI}=$ body mass index; $\mathrm{MBMI}=$ Maternal BMI; MDEP = Maternal Depression Scores; SETS = Self-Efficacy Total Score; SS= Support Seeking; B = Barriers; and PA = Positive Alternatives. Correlations with maternal BMI (MBMI) were estimated with Spearman correlation coefficients. All other associations were estimated with Pearson product-moment correlation coefficients. Correlation coefficient values marked with an asterisk* were statistically significant $(* * p<.10 ; * * * p<.05)$. 


\section{Specific Aim Three}

Examine the associations between child physical activity self-efficacy and maternal BMI, and maternal depressive symptoms.

\section{Hypothesis One}

Child physical activity self-efficacy is negatively associated with maternal BMI.

\section{Hypothesis One Results}

Spearman correlation coefficients were estimated to quantify associations between child physical activity self-efficacy and maternal BMI. No statistically significant associations were found (Table 4-6).

\section{Hypothesis Two}

Child physical activity self-efficacy is negatively associated with maternal depressive symptoms.

\section{Hypothesis Two Results}

Pearson product moment correlation coefficients were estimated to quantify associations between child physical activity self-efficacy and maternal depressive symptoms. As maternal depressive symptoms increased, support-seeking behaviors of the child decreased $(r=-0.200, p=.109)$. Estimated Pearson product moment correlation coefficients are displayed in Table 4-6. 
Table 4-6. Estimated Correlation Coefficients of Child Physical Activity SelfEfficacy with Maternal BMI, and Maternal Depressive Symptoms from 65 MotherChild Dyads

\begin{tabular}{lcc}
\hline & \multicolumn{2}{c}{ Measures } \\
\cline { 2 - 3 } Child Physical Activity Self- & Maternal BMI & $\begin{array}{c}\text { Maternal Depressive } \\
\text { Symptoms }\end{array}$ \\
\hline 1. Total Score & 0.038 & -0.129 \\
2. Support Seeking & 0.129 & $-0.200^{*}$ \\
3. Barriers & 0.007 & 0.012 \\
4. Positive Alternatives & -0.016 & -0.114 \\
\hline
\end{tabular}

Note: BMI=body mass index. Correlations with Maternal BMI were estimated with Spearman correlation coefficients. Correlations with Maternal Depressive Symptoms were estimated with Pearson product-moment correlation coefficients. The $p$ value for the association between Support Seeking and Maternal Depressive Symptoms is statistically significant $(p=.109)$. 


\section{CHAPTER 5. DISCUSSION}

The current study was conducted to determine whether associations among depressive symptoms, obesity, and physical activity self-efficacy existed in African American mother-child dyads. Few investigators have explored the relationships of these variables in a comprehensive fashion. Although the current study was an exploration of these associations, findings can inform future research designed to examine these associations, assist clinicians in treating obesity and depression for the family, and inform policies that support mother-child health. More importantly, this study is unique to the exploration of depressive symptoms and physical activity self-efficacy in African American children 7-10 years of age. There is an evident lack of information in the sample population.

\section{DISCUSSION OF DEMOGRAPHIC FINDINGS}

In this study a majority of the mothers were single and never married $(73.85 \%)$. However, it is unknown whether or not a male companion resided in their homes. Approximately $77 \%$ of the mothers had completed a high school diploma or a GED. These statistics are slightly lower than the 2009 national averages for adults 25 years and older that had completed a high school diploma (85\%) (U.S. Census Bureau, 2012). In addition, the percentage of African American females who have not completed a high school education has significantly decreased over the last few decades. Currently, only $6 \%$ of African American females between the ages of 16-24 have not attained a high school diploma (National Center for Education Statistics, 2015b). In contrast, 23\% (95\% CI, $12.56 \%-33.60 \%$ ) of mothers in the current study did not have a high school diploma or GED. Recruitment sites were distributed in areas that would promote diversity among the participants. However, a snowball sampling effect on recruitment possibly occurred.

The mean BMI for mothers in the study was characterized as obese $(\mathrm{M}=33.17$, $\mathrm{SD}=6.98$ ) with 57 out of 65 of participants being categorized as overweight or obese ( $95 \% \mathrm{CI}, 31.56 \%-35.10 \%)$. However, this proportion is comparable to the national average indicating that $82 \%$ of African American women are overweight or obese (Ogden et al., 2014). Cutler and Lleras-Muney (2010) examined whether increases in years of education would improve weight outcomes in adults. Their findings implicated with each year of education increase the chances of being obese decreased by $1.4 \%$ and decreased more quickly for individuals who had attained over 12 years of education. Research also indicates that attainment of at least a Bachelor's degree has the potential to double an individual's lifetime earnings in comparison to only completing a high school diploma (The Hamilton Project, 2015). Increased education and higher yearly incomes have the potential to positively influence food-buying practices, thus potentially decreasing obesity, especially in minorities and women (Drewnowski, 2009). Though the percentage of obese mothers in the current study was relatively high, 33.85\% (95\% CI, $22.03 \%-45.66 \%$ ) had completed a bachelor's degree or higher, which is numerically 
higher than the current national average of adults 25 years and older with a Bachelor's degree or higher (29\%) (United States Census Bureau, 2015).

Similarly, African American children nationally are confronted with disparities in education, reduced access to healthier food, and lower socioeconomic status compared to other racial groups (Fiscella \& Kitzman, 2009; Flores \& Tomany-Korman, 2008; Walker, Keane, \& Burke, 2010). The percentages of girls (52.31\%, 95\% CI: 39.83\%-64.78\%) and boys (47.69\%, participating in this study were very similar (female, $47.69 \%$ male). Although $70.77 \%$ of children had no medical conditions, $18.46 \%$ had a current diagnosis of asthma. BMI Z-scores of the children were normally distributed.

\section{DISCUSSION OF RESEARCH FINDINGS}

\section{Child Depressive Symptoms}

As predicted, CDI 2 total score for child depressive symptoms were positively associated with BMI Z-scores in African American children $(p=.137)$. Depressive symptoms categorized as functional problems and interpersonal problems were also positively correlated with BMI Z-scores for the child $(\mathrm{p}=.136, \mathrm{p}=.060)$. It has been documented that apparent associations between depressive symptoms and obesity are

evident in both pediatric and adult populations. Goodman and Whitaker (2002) found that depressed mood in adolescents who were not obese at baseline predicted obesity at the follow-up period. In contrast, they found that obesity at baseline did not predict depression at the follow-up. Similarly, in a study examining the predictive value of depressive symptoms for obesity in African American and Caucasian adolescents, aged 16 and 18, researchers found that depressive symptoms at baseline predicted the future occurrence of obesity and increased BMI by the age of 21 (Franko, Striegel-Moore, Thompson, Schreiber, \& Daniels, 2005). Reeves et al. (2008) have documented how several childhood depressive symptoms parallel those of obesity. In both conditions the child can present with sleep disturbances, increases in appetite, and decreases in physical activity (Reeves et al., 2008). Results from this study link increased functional problems, which can include a reduction in grades and difficulties getting along with family or peers due to associated irritability, to increased BMI Z-score in children (Kovacs \& MultiHealth Systems, 2011).

No associations were found between child depressive symptoms and maternal BMI. This finding can be attributed to a relatively small sample size with minimal variation in maternal BMI. Instead, maternal depressive symptoms were positively associated with higher overall depressive symptoms, emotional problems, and negative $\operatorname{mood} /$ physical symptoms among their children $(\mathrm{p}=.127, \mathrm{p}=.049, \mathrm{p}=.010)$. These results were expected because previous research has identified links between maternal depressive symptoms and negative affect and negative behavior in their children (S. H. Goodman et al., 2011). However, in a study of 77 African American mothers, researchers did not find a significant relationship between the severity of maternal depressive 
symptoms and child depressive symptoms in children 8-14 years of age (Boyd \& Waanders, 2013). The child's age at exposure to maternal depressive symptoms also has a relationship to child depressive symptoms. Several, studies have indicated that children exposed to maternal depressive symptoms early in life, have a higher risk for exhibiting negative psychopathy when compared to children who are exposed to maternal depressive symptoms in late childhood (Connell \& Goodman, 2002; S. H. Goodman et al., 2011). This study plays an integral role by informing new findings with young African American children.

Lower, overall physical activity self-efficacy was associated with greater ineffectiveness symptoms in children $(\mathrm{p}=.199)$. Lower support seeking physical activity behaviors of the child was associated with increased functional problems and interpersonal problems $(\mathrm{p}=0.174, \mathrm{p}=.050)$. These findings are to be expected because children with functional and interpersonal problems have difficulties connecting with their family and friends (Kovacs \& Multi-Health Systems, 2011). Positive alternatives to physical activity were decreased as the child reported higher overall depressive symptoms $(\mathrm{p}=.193)$ and interpersonal problems $(\mathrm{p}=.088)$ Surprisingly, results indicated that children with increased depressive symptoms, emotional problems, negative selfesteem, and interpersonal problems all reported fewer barriers to physical activity ( $\mathrm{p}=$ $.158, \mathrm{p}=.070, \mathrm{p}=.012, \mathrm{p}=.644$, respectively). This finding may be attributed to the fact that many participating children lacked a proper understanding of the terminology of being physically active. One participant equated being physically active as sitting outside on her porch playing with toy dolls. To date there are no studies that explore the relationships between depressive symptoms and physical activity self-efficacy in African American children 7-10 years of age.

\section{Child BMI Z-Score}

Unlike the findings of previous research, this study did not find a significant association between child BMI Z-score and maternal BMI or maternal depressive symptoms. There was little variation within the sample of maternal BMI. Surprisingly, children with higher BMI Z-scores reported having higher physical activity self-efficacy $(\mathrm{p}=.045)$, support seeking behaviors $(\mathrm{p}=.056)$, and fewer barriers to being physically active $(\mathrm{p}=.045)$. These results contradict past research findings that African American children complete more vigorous physical activity when they are able to overcome barriers to self-efficacy (Trost, Kerr, Ward, \& Pate, 2001). Future studies should incorporate a method to measure physical activity in conjunction with self-reports in younger children to increase accuracy.

\section{Physical Activity Self-Efficacy}

There were no significant associations between maternal BMI and the child's physical activity self-efficacy. However, results did indicate that as maternal depressive symptoms increased, children had less support seeking physical activity behaviors ( $\mathrm{p}=$ 
.109. From the questionnaire, these questions indicated that children were less likely to ask their parent to be physically active with them, buy them the equipment they needed to physically active, or enroll them in a sports program. This is not uncommon, because research has found that depressed mothers are less involved and have decreased interactions with their children (Barth, 2009; Field, 2010).

\section{IMPLICATIONS AND RECOMMENDATIONS}

In previous years, millions of African American families were uninsured, because they were unemployed and not afforded the opportunity to purchase health care insurance through an employer. Additionally, millions of low-income workers could not afford the costs of private insurance or they were ineligible for public insurance due to unaffordability or state ineligibility (Kaiser Family Foundation, 2015). However, with the recent passage of the Affordable Care Act (ACA) the chasm between uninsured and insured African Americans has substantially closed. According to recent statistics the number of uninsured African Americans has decreased by $6.8 \%$. Furthermore, as 23 million adults ages 18-64 have gained health care coverage, six out of ten uninsured African Americans now qualify for Medicaid, Children's Health Insurance Plan (CHIP), or a reduction in their monthly premiums for their healthcare coverage (U.S. Department of Health \& Human Services, 2015).

Though the rates of uninsured have consistently been on a downward trend, multiple disparities for access to proper healthcare in the African American community nevertheless persist. Historically, larger percentages of African Americans do not seek treatment for mental health conditions in comparison to Caucasians, which can be attributed to several factors. To begin, many of those with health care coverage do not specifically seek treatment for their mental health conditions or they are reluctant to seek treatment because of a lack of knowledge and misunderstanding of the disease process and corresponding symptoms (National Alliance on Mental Illness, 2016a). Research has found that African American women with depression are less likely to desire treatment due to the stigma associated with being depressed (Nadeem et al., 2007). African Americans also underreport affective depressive symptoms, yet more frequently report somatic symptoms (Iwata et al., 2002; Zhang \& Gary, 2013).

\section{Church Partnerships}

It has also been reported that African Americans heavily rely on their church and their religious beliefs as an immediate form of support or a support system in comparison to Caucasians (Blank, Mahmood, Fox, \& Guterbock, 2002). On average African Americans attend church services, read religious materials, and pray more frequently than Caucasians, subsequently, providing them with hope and mechanisms to cope with stressful crises (Ellison \& Flannelly, 2009). Studies have also shown that individuals report lower levels of depression, when they regularly subscribe to a particular religion 
and view their religious support as beneficial (Ellison \& Flannelly, 2009; Hill \& Pargament, 2008).

Understanding that African Americans rely heavily on their religious support as a protective factor, healthcare providers and schools of nursing can utilize this information to their benefit. The creation of a church-clinician partnership can better address and assist the mental health needs of the African American community. This partnership would entail private screening for depressive symptoms during community health fairs hosted by churches and providing proper referral information to those who are identified with moderate to severe depressive symptoms. Moreover, screening the children of mothers who present with increased depressive symptoms would be beneficial considering results of this study that indicate higher depressive symptoms were associated with child personal and behavioral characteristics. It would be essential for healthcare providers and nursing schools to build lasting relationships with the congregational leaders. This continuity would provide the opportunity to speak to churches about the stigmatizing beliefs surrounding depression, educate the clergy on depressive symptoms, and provide information to church members on where to seek specific treatment in hopes of bridging the gap in mental health care.

\section{Primary Care Partnerships}

Steadily increasing is the percentage of individuals with a mental illness, especially those of lower incomes, who are more likely to present to their primary care provider with symptoms of depression rather than to pursue a specialty mental health care setting (Kaltman, Pauk, \& Alter, 2011). Again, this can be attributed to a misunderstanding of symptoms and a lack of knowledge in regards to treatment modalities and appropriate facilities. An integration of primary care and mental health into one setting can increase provider knowledge of mental health, increase collaborative efforts amongst various health care professions, and promote favorable patient outcomes to assist in combating this problem (World Health Organization, 2008). Mergl et al. (2007) found that over $20 \%$ of primary care patients suffer from a depressive disorder. Unfortunately, this statistic may be lower than actuality due to lack of widespread screening and diagnosing of depression in primary care settings. Integration of the two entities in which a mental health provider located within a primary care facility provides an immediate assessment of a patient, after they have a positive screening for mental health complication, fosters better patient outcomes and satisfaction (Zeiss \& Karlin, 2008). In this model of care patients can be treated holistically at one location, eliminating the wait time for referrals and increasing their likelihood of obtaining treatment. Providers can also incorporate systematic screenings for mental health conditions at well patient visits (Thielke, Vannoy, \& Unützer, 2007).

Screening for childhood depressive symptoms in a variety of settings can assist in identifying more children with mental health problems. Primary care settings, especially those that specifically treat childhood obesity, can be instrumental in examining children for depressive symptoms. Properly training health care providers to identify depressive 
symptoms in children can aid in early detection of depressive symptoms in children (Asarnow, Jaycox, \& Anderson, 2002). Results from this study indicate that children with increased depressive symptoms have higher BMI percentiles. Unfortunately, many children are not diagnosed with a depressive disorder because their parents do not recognize the relevant symptoms, considering these vary with age and gender (Cash, 2004).

\section{Implications for Schools}

Similar to educating health care providers, teachers and school counselors should participate should be current with latest information with regards to identifying depressive symptoms in children, because depressive symptoms can interfere with the child's academics and social life (Association for Supervision and Curriculum Development, 2016). It has been well documented that there is a positive association between obesity and bullying in children, which can lead to increased depressive symptoms later in life (Barth, 2009; Lumeng et al., 2010; Ttofi et al., 2011). Educators can combat bullying by creating an environment that is supportive of learning for a diverse group of students (Teaching Tolerance, 2016). School nurses should also play a key role in recognizing the signs of bullying to aid in suicide prevention (Cooper, Clements, \& Holt, 2012).

Though BMI Z-scores for child participants were normally distributed in this study, it is possible that the concept of physical activity self-efficacy was misunderstood. Those with higher BMI Z-scores reported higher physical activity self-efficacy (0.045). It is important that children perceive themselves as being confident to make healthy food choices and be physically active to reduce the risk for obesity (Matthews et al., 2015). In a study of girls in elementary school (predominantly African American), researchers found that implementing a group physical activity intervention assisted in increasing participants' self-efficacy and physical activity after participating in the program (Bean, Miller, Mazzeo, \& Fries, 2012). The development of curricula that increase student exposure to physical activity and incorporates physical activity with classroom lectures can assist children with making better choices to be more physically active in their daily lives (Centers for Disease Control and Prevention, 2013).

\section{Implications for Policy}

Increased political involvement is compulsory in order to combat continual increases in depressive symptoms and obesity within the African American community. Policy has the ability to increase research-funding in minority populations, support the creation of community-based assistive organizations, ensure that medical treatments are accessible and affordable with insurance, and create specific guidelines for healthcare workers to abide by in order to safeguard the rights of their patients (National Institutes of Health, 2011; The White House, 2016, and Epstein, 2015 \#676). Currently, Medicaid will pay for a limited number of mental health inpatient visits for an individual, and some 
private insurance companies offer very little benefits for mental health treatments (National Alliance on Mental Illness, 2016c). Changes in these policies will increase the availability of mental health treatment options to those in need, especially pediatric populations.

To decrease the prevalence of childhood and adult obesity, changes to policy can reduce the number of advertisements of foods with low nutritional status, specifically targeting African American children, and replacing them with ads that promote healthier food and beverage options (State of Obesity, 2014). Additionally, the government's Supplemental Nutrition Assistance Program (SNAP) offers monetary support to lowincome families for the purchase of food and beverages at acceptable locations (Ratcliffe, McKernan, \& Zhang, 2011). Unfortunately, the majority of the resources to assist these families in making better nutritional food purchases are exclusively online; without Internet access, families fail to benefit from this information. Mailing a monthly newsletter that includes a healthy shopping list and recipe for a nutritious and affordable meal can encourage healthier buying practices for SNAP families. Providing monthly SNAP incentives, such as adding an extra $30 \notin$ for every healthy food purchase, can encourage healthier buying practices (Shenkin \& Jacobson, 2010).

Lastly, neighborhood resources can influence residents to become more physically active. Changes in local policies have the ability to increase the number of functional sidewalks and parks within inner city and low-income areas. Though minor, the addition of complete sidewalks in areas that are not conducive to walking, are monumental in encouraging daily physical activity for children and adults (Khan, Sobush, Keener, \& Goodman). Assuring proper street lighting and safety measures when crossing a street were researched and found to aid in increasing physical activity within the community (Heath et al., 2006). Daily increases in physical activity can potentially reduce and prevent childhood and adult obesity (Centers for Disease Control and Prevention, 2015f, 2015g).

\section{Implications for Theoretical Framework}

The framework presented in the Social Cognitive Theory (SCT) guided the theoretical framework for this study. Though the SCT explains how triadic reciprocal relationships between personal factors, environmental factors, and behavioral factors are modifiable, this study specifically examined the associations between environmental and personal factors. However, the concept of self-efficacy was incorporated into the model with a behavioral component of physical activity for the children. Expectations were that environmental factors (maternal depressive symptoms and BMI) are associated with the child's personal factors (depressive symptoms and BMI Z-score) and physical activity self-efficacy.

Correlations were found between maternal depressive symptoms and the child's depressive symptoms and physical activity self-efficacy, which were supported by the theory. It can be expected that interventions to decrease maternal depression will have an 
effect on their child's depressive symptoms and physical activity self-efficacy, but not the child's BMI Z-score. Unfortunately, the reciprocal relationship was not studied. The notion that positive changes to the child's depressive symptoms, BMI Z-score and physical activity self-efficacy would decrease the mother's depressive symptoms or BMI cannot be suggested. That reciprocal component of the SCT is not supported in this study.

Also, maternal BMI was not significantly correlated with the child's depressive symptoms, BMI Z-score, or physical activity self-efficacy. In part, the sample was small and lacked substantial variability in maternal BMI. Future studies with a larger sample may report a correlation between these variables. However, the study does indicate that positively modifying the child's interpersonal problems would increase their self-efficacy support seeking behaviors and positive alternatives to being physically active. This is finding reinforces the theory's concept of self-efficacy and its role in positive behavioral changes.

\section{LIMITATIONS}

Multiple limitations for this study were identified. The study consisted of a small sample size ( $\mathrm{n}=65$ dyads). The magnitude of several correlations were small, thus recommendations must be made cautiously. Although recruitment strategies were developed and attempts were made to diversify the sample by recruiting from a variety of networks, the majority of the mothers were overweight to obese, which substantially decreased the variability of maternal BMIs. However, it was not uncommon to recruit higher frequencies of overweight and obese women, because in 2011, approximately 45\% of women residing in Shelby County were obese (Institute for Health Metrics and Evaluation, 2015). Demographic information did not inquire about the total number of occupants living within the home. Participants were also recruited during the summer months and for a one-week period during the winter. Future studies should recruit for a twelve-month period to assure that depressive symptoms are not influenced by seasonal affects. The term physical activity was unfamiliar to several younger children; the researcher recognized this and had to explain the term before children could answer the physical activity self-efficacy questionnaire. The behavioral factor of being physically active was not directly measured. Moving forward researchers should employ the use of pedometers in young children to quantify their level of physical activity. Children who had a current diagnosis of asthma were not questioned about the potential use of steroids for treatment.

\section{CONCLUSION}

Positive associations between African American children's depressive symptoms and their BMI Z-score are apparent. Likewise, positive associations exist between child depressive symptoms, the child's physical activity self-efficacy, and their mother's depressive symptoms. Previous research on African American children with depressive symptoms, living with mothers who also have depressive symptoms, is understudied. 
This study found that children and women with depressive symptoms were more prevalent than previously reported in the literature. The occurrence of maternal depressive symptoms significantly increases emotional problems, negative mood, and physical symptoms of depression in their children. Children of mothers with higher reported depressive symptoms also indicated that they were less likely to seek support to be physically active from their parent. It is important that depression screening tools can appropriately capture depressive symptoms in African American women and children, thus increasing the chance for a proper diagnosis. Depression preventative measures should be further researched to identify possible strategies and interventions that can reduce the risk of depression in the African American mother-child dyad. The mothers in this study with elevated depressive symptoms stated they never sought mental health treatment for their symptoms before participation. Children with depressive symptoms had not received treatment for their symptoms either. Though a small correlation was found between the child's BMI Z-score and interpersonal problems, future research with a larger sample size might find a stronger association between the two. This study was significant in adding information to the literature on preadolescent African American children with depressive symptoms sampled from an urban community setting. 


\section{LIST OF REFERENCES}

Abrams, S. M., Field, T., Scafidi, F., \& Prodromidis, M. (1995). Newborns of depressed mothers. Infant Mental Health Journal, 16(3), 233-239.

Ahima, R. S. (2008). Revisiting leptin's role in obesity and weight loss. The Journal of clinical investigation, 118(7), 2380-2383.

Alliance for a Healthier Generation. (2016). About childhood obesity. Retrieved from https://www.healthiergeneration.org/about childhood obesity/get informed/

American Heart Association. (2014a). Overweight in children. Retrieved from http://www.heart.org/HEARTORG/GettingHealthy/HealthierKids/ChildhoodObes ity/Overweight-in-Children UCM 304054 Article.jsp

American Heart Association. (2014b). What is childhood obesity? Retrieved from https://www.heart.org/HEARTORG/GettingHealthy/HealthierKids/ChildhoodObe sity/What-is-childhood-obesity UCM_304347_Article.jsp

American Psychiatric Association. (2000). Diagnostic and statistical manual-of mental disorders (4th ed.). Washington, DC: American Psychiatric Publishing

American Psychiatric Association. (2013). Diagnostic and statistical manual of mental disorders (5th ed.). Washington, DC: American Psychiatric Publishing.

Anxiety and Depression Association of America. (2015). Anxiety and depression in children. Retrieved from http://www.adaa.org/living-withanxiety/children/anxiety-and-depression

Asarnow, J. R., Jaycox, L. H., \& Anderson, M. (2002). Depression among youth in primary care: Models for delivering mental health services. Child and Adolescent Psychiatric Clinics of North America, 11(3), 477-497.

Association for Supervision and Curriculum Development. (2016). Responding to a student's depression Retrieved from http://www.ascd.org/publications/educationalleadership/oct10/vol68/num02/Responding-to-a-Student's-Depression.aspx

Bandura, A. (1982). Self-efficacy mechanism in human agency. American Psychologist, $37(2), 122$.

Bandura, A. (1989). Human agency in social cognitive theory. American Psychologist, 44(9), 1175.

Bandura, A. (1994). Self-efficacy: The exerciese of control. New York: Freeman.

Bandura, A. (2001). Social cognitive theory: An agentic perspective. Annual Review of Psychology, 52(1), 1-26.

Bandura, A. (2005). The primacy of self-regulation in health promotion. Applied Psychology, 54(2), 245-254.

Bandura, A., Pastorelli, C., Barbaranelli, C., \& Caprara, G. V. (1999). Self-efficacy pathways to childhood depression. Journal of Personality and Social Psychology, $76(2), 258$.

Bandura, A., Ross, D., \& Ross, S. A. (1963). Imitation of film-mediated aggressive models. The Journal of Abnormal and Social Psychology, 66(1), 3.

Barbeau, P., Johnson, M. H., Howe, C. A., Allison, J., Davis, C. L., Gutin, B., \& Lemmon, C. R. (2007). Ten months of exercise improves general and visceral adiposity, bone, and fitness in black girls. Obesity, 15(8), 2077-2085. 
Barth, R. P. (2009). Preventing child abuse and neglect with parent training: Evidence and opportunities. The Future of Children, 19(2), 95-118.

Bean, M., Miller, S., Mazzeo, S., \& Fries, E. (2012). Social cognitive factors associated with physical activity in elementary school girls. American Journal of Health Behavior, 36(2), 265-274.

Beck, A., Steer, R., \& Brown, G. (1996). Beck Depression Inventory-Second Edition (2nd ed.). San Antonio, TX: Pearson.

Belmaker, R., \& Agam, G. (2008). Major depressive disorder. New England Journal of Medicine, 358(1), 55-68.

Beydoun, M. A., \& Wang, Y. (2010). Pathways linking socioeconomic status to obesity through depression and lifestyle factors among young US adults. Journal of Affective Disorders, 123(1), 52-63.

Blank, M. B., Mahmood, M., Fox, J. C., \& Guterbock, T. (2002). Alternative mental health services: The role of the Black church in the South. American Journal of Public Health, 92(10), 1668-1672.

Boyd, R. C., \& Waanders, C. (2013). Protective factors for depression among African American children of predominantly low-income mothers with depression. Journal of child and family studies, 22(1), 85-95.

Bradlee, M. L., Singer, M. R., Qureshi, M. M., \& Moore, L. L. (2010). Food group intake and central obesity among children and adolescents in the Third National Health and Nutrition Examination Survey (NHANES III). Public Health Nutrition, 13(06), 797-805.

Brennan, P. A., Hammen, C., Andersen, M. J., Bor, W., Najman, J. M., \& Williams, G. M. (2000). Chronicity, severity, and timing of maternal depressive symptoms: relationships with child outcomes at age 5. Developmental Psychology, 36(6), 759.

Brietzke, E., Stertz, L., Fernandes, B. S., Kauer-Sant'Anna, M., Mascarenhas, M., Vargas, A. E., . . Kapczinski, F. (2009). Comparison of cytokine levels in depressed, manic and euthymic patients with bipolar disorder. Journal of Affective Disorders, 116(3), 214-217.

Buckley, N. A., Dawson, A. H., \& Isbister, G. K. (2014). Serotonin syndrome. British Medical Journal, 348, 1626.

Burdette, H. L., Whitaker, R. C., Harvey-Berino, J., \& Kahn, R. S. (2003). Depressive Symptoms in Low-Income Mothers and Emotional and Social Functioning in Their Preschool Children. Ambulatory Pediatrics, 3, 288-294. doi:10.1367/15394409(2003)003<0288:DSILMA > 2.0.CO;2

Caprio, S., Daniels, S. R., Drewnowski, A., Kaufman, F. R., Palinkas, L. A., Rosenbloom, A. L., . . Kirkman, M. S. (2008). Influence of race, ethnicity, and culture on childhood obesity: implications for prevention and treatment. Obesity, 16(12), 2566-2577.

Cash, E. R. (2004). Depression in young children: Information for parents and educators. Retrieved from http://www.nasponline.org/communications/spawareness/depressyc ho.pdf

Centers for Disease Control and Prevention. (2010a). Current depression among adults--United states, 2006 and 2008. Morbidity and Mortality Weekly Report, 59(38), 1229. 
Centers for Disease Control and Prevention. (2010b). Medical complications of obesity Retrieved from http://www.cdc.gov/vitalsigns/AdultObesity/infographic.html

Centers for Disease Control and Prevention. (2013). Make a difference at your school. Retrieved from http://digitalcommons.hsc.unt.edu/disease/31/?utm_source=digitalcommons.hsc.u nt.edu\%2Fdisease $\% 2$ F31\&utm medium=PDF\&utm campaign=PDFCoverPages

Centers for Disease Control and Prevention. (2014a). Childhood obesity facts. Retrieved from http://www.cdc.gov/obesity/data/childhood.html

Centers for Disease Control and Prevention. (2014b). Facts about physical activity. Retrieved from http://www.cdc.gov/physicalactivity/data/facts.html

Centers for Disease Control and Prevention. (2014c). The obesity epidemic and memphis students. Retrieved from http://www.cdc.gov/healthyyouth/yrbs/pdf/obesity/memphis_obesity combo.pdf

Centers for Disease Control and Prevention. (2014d). Youth risk behavior surveillanceUnited states, 2013. Morbidity and Mortality Weekly Report, 63(4), 157-159.

Centers for Disease Control and Prevention. (2015a). About adult BMI. Retrieved from http://www.cdc.gov/healthyweight/assessing/bmi/adult bmi/index.html

Centers for Disease Control and Prevention. (2015b). About child \& teen BMI. Retrieved from http://www.cdc.gov/healthyweight/assessing/bmi/childrens_bmi/about_childrens bmi.html

Centers for Disease Control and Prevention. (2015c). Adult obesity facts Retrieved from http://www.cdc.gov/obesity/data/adult.html

Centers for Disease Control and Prevention. (2015d). Black or african american populations Retrieved from http://www.cdc.gov/minorityhealth/populations/REMP/black.html

Centers for Disease Control and Prevention. (2015e). Childhood obesity facts Retrieved from http://www.cdc.gov/obesity/data/childhood.html

Centers for Disease Control and Prevention. (2015f). How much physical activity do adults need? Retrieved from https://www.cdc.gov/physicalactivity/basics/adults/index.htm

Centers for Disease Control and Prevention. (2015g). How much physical activity do chrilden need? Retrieved from https://www.cdc.gov/physicalactivity/basics/children/index.htm

Centers for Disease Control and Prevention. (2015h). Prevalence of self-reported obesity among non-hispanic black adults by state and territory, BRFSS, 2012-2014. Retrieved from http://www.cdc.gov/obesity/data/table-non-hispanic-black.html

Centre for Effective Practice. (2007). Patient self-management: A discussion paper. Retrieved from http://www.effectivepractice.org/site/ywd_effectivepractice/assets/pdf/4a_SelfManagement - Discussion Paper.pdf

Chen, L. P., Murad, M. H., Paras, M. L., Colbenson, K. M., Sattler, A. L., Goranson, E. N., ... Prokop, L. J. (2010). Sexual abuse and lifetime diagnosis of psychiatric disorders: systematic review and meta-analysis. Paper presented at the Mayo Clinic Proceedings. 
Cohen, J. (1988). Statistical Power Analysis for the Behavioral Sciences. 2nd edn. Hillsdale, New Jersey: L: Erlbaum.

Cohen, J. (1992). A power primer. Psychological Bulletin, 112(1), 155.

Coleman, M. T., \& Newton, K. S. (2005). Supporting self-management in patients with chronic illness. American Family Physician, 72(8), 1503-1510.

Connell, A. M., \& Goodman, S. H. (2002). The association between psychopathology in fathers versus mothers and children's internalizing and externalizing behavior problems: a meta-analysis. Psychological Bulletin, 128(5), 746.

Coogan, P. F., Cozier, Y. C., Krishnan, S., Wise, L. A., Adams-Campbell, L. L., Rosenberg, L., \& Palmer, J. R. (2010). Neighborhood Socioeconomic Status in Relation to 10-Year Weight Gain in the Black Women's Health Study. Obesity, 18(10), 2064-2065.

Cooper, G., Clements, P., \& Holt, K. (2012). Examining childhood bullying and adolescent suicide: implications for school nurses. Journal of School Nursing, 28(4), 275-283.

Cutler, D. M., \& Lleras-Muney, A. (2010). Understanding differences in health behaviors by education. Journal of Health Economics, 29(1), 1-28.

Cutrona, C. E., Russell, D. W., Brown, P. A., Clark, L. A., Hessling, R. M., \& Gardner, K. A. (2005). Neighborhood Context, Personality, and Stressful Life Events as Predictors of Depression Among African American Women. Journal of Abnormal Psychology, 114(1), 3-15.

Daniels, S. (2009). Complications of obesity in children and adolescents. International Journal of Obesity, 33, S60-S65.

Davis, \& Stevenson. (2006). Racial socialization experiences and symptoms of depression among Black youth. Journal of Child and Family Studies, 15(3), 293307.

Davis, Young, Davis, \& Moll. (2011). Parental depression, family functioning, and obesity among African American children. ABNF Journal, 22(1), 4.

Davis, M., Young, L., Davis, S., \& Moll, G. (2007). Parental depression, family functioning and obesity among African American children. Journal of Cultural Diversity, 15(2), 61-65.

de Ruyter, J. C., Olthof, M. R., Seidell, J. C., \& Katan, M. B. (2012). A trial of sugar-free or sugar-sweetened beverages and body weight in children. The New England Journal of Medicine 367, 1397-1406.

Delavega, E. (2014). 2014 Memphis poverty factsheet [Fact sheet]. Retrieved from http://www.memphis.edu/socialwork/pdfs/fact_sheets/2014povertyfactsheet.pdf

Department of Health. (2009). Incorporating self-managment support into primary care Retrieved from http://www.health.vic.gov.au/pch/downloads/factsheet09.pdf

Dishman, R. K., Motl, R. W., Sallis, J. F., Dunn, A. L., Birnbaum, A. S., Welk, G. J., . . Jobe, J. B. (2005). Self-management strategies mediate self-efficacy and physical activity. American Journal of Preventive Medicine, 29(1), 10-18.

Dowlati, Y., Herrmann, N., Swardfager, W., Liu, H., Sham, L., Reim, E. K., \& Lanctôt, K. L. (2010). A meta-analysis of cytokines in major depression. Biological Psychiatry, 67(5), 446-457.

Drewnowski, A. (2009). Obesity, diets, and social inequalities. Nutrition Reviews, 67(suppl 1), S36-S39. 
Duarte, C. S., Shen, S., Wu, P., \& Must, A. (2012). Maternal depression and child BMI: longitudinal findings from a US sample. Pediatric Obesity, 7(2), 124-133.

Dunton, G. F., Kaplan, J., Wolch, J., Jerrett, M., \& Reynolds, K. D. (2009). Physical environmental correlates of childhood obesity: a systematic review. Obesity Reviews, 10(4), 393-402.

Ebbeling, C. B., Pawlak, D. B., \& Ludwig, D. S. (2002). Childhood obesity: publichealth crisis, common sense cure. The Lancet, 360(9331), 473-482.

Elgar, F. J., Mills, R. S., McGrath, P. J., Waschbusch, D. A., \& Brownridge, D. A. (2007). Maternal and paternal depressive symptoms and child maladjustment: The mediating role of parental behavior. Journal of Abnormal Child Psychology, 35(6), 943-955.

Ellison, C. G., \& Flannelly, K. J. (2009). Religious involvement and risk of major depression in a prospective nationwide study of African American adults. The Journal of nervous and mental disease, 197(8), 568-573.

Ertel, K., Koenen, K., Rich-Edwards, J., \& Gillman, M. (2010). Antenatal and postpartum depressive symptoms are differentially associated with early childhood weight and adiposity. Paediatric and Perinatal Epidemiology, 24(2), 179-189.

Feldman, R., Granat, A., Pariente, C., Kanety, H., Kuint, J., \& Gilboa-Schechtman, E. (2009). Maternal depression and anxiety across the postpartum year and infant social engagement, fear regulation, and stress reactivity. Journal of the American Academy of Child and Adolescent Psychiatry, 48(9), 919-927.

Field, T. (2010). Postpartum depression effects on early interactions, parenting, and safety practices: a review. Infant Behavior and Development, 33(1), 1-6.

Field, T., Diego, M., \& Hernandez-Reif, M. (2009). Infants of depressed mothers are less responsive to faces and voices: A review. Infant Behavior \& Development, 32(3), 239.

Fiscella, K., \& Kitzman, H. (2009). Disparities in academic achievement and health: the intersection of child education and health policy. Pediatrics, 123(3), 1073-1080.

Flegal, K. M., Carroll, M. D., Kit, B. K., \& Ogden, C. L. (2012). Prevalence of obesity and trends in the distribution of body mass index among US adults, 1999-2010. JAMA, 307(5), 491-497.

Flores, G., \& Tomany-Korman, S. C. (2008). Racial and ethnic disparities in medical and dental health, access to care, and use of services in US children. Pediatrics, 121(2), e286-e298.

Franko, D., Striegel-Moore, R., Thompson, D., Schreiber, G., \& Daniels, S. (2005). Does adolescent depression predict obesity in black and white young adult women? Psychological Medicine, 35(10), 1505.

Fried, E. I., \& Nesse, R. M. (2014). The impact of individual depressive symptoms on impairment of psychosocial functioning. PloS One, 9(2), e90311.

Galea, S., Ahern, J., Nandi, A., Tracy, M., Beard, J., \& Vlahov, D. (2007). Urban neighborhood poverty and the incidence of depression in a population-based cohort study. Annals of Epidemiology, 17(3), 171-179.

Galvez, M. P., Hong, L., Choi, E., Liao, L., Godbold, J., \& Brenner, B. (2009). Childhood obesity and neighborhood food-store availability in an inner-city community. Academic Pediatrics, 9(5), 339-343. 
Gao, Z. (2012). Urban Latino school children's physical activity correlates and daily physical activity participation: A social cognitive approach. Psychology, Health \& Medicine, 17(5), 542-550.

Gao, Z., Lochbaum, M., \& Podlog, L. (2011). Self-efficacy as a mediator of children's achievement motivation and in-class physical activity. Perceptual and Motor Skills, 113(3), 969-981.

Garaulet, M., Ordovas, J. M., \& Madrid, J. A. (2010). The chronobiology, etiology and pathophysiology of obesity. International Journal of Obesity, 34(12), 1667-1683.

Gavin, A. R., Walton, E., Chae, D. H., Alegria, M., Jackson, J. S., \& Takeuchi, D. (2010). The associations between socio-economic status and major depressive disorder among Blacks, Latinos, Asians and non-Hispanic Whites: findings from the Collaborative Psychiatric Epidemiology Studies. Psychological Medicine, 40(01), 51-61.

Golan, M., \& Crow, S. (2004a). Parents are key players in the prevention and treatment of weight-related problems. Nutrition Reviews, 62(1), 39-50.

Golan, M., \& Crow, S. (2004b). Targeting Parents Exclusively in the Treatment of Childhood Obesity: Long-Term Results. Obesity Research, 12(2), 357-361.

Goodman, E., \& Whitaker, R. C. (2002). A prospective study of the role of depression in the development and persistence of adolescent obesity. Pediatrics, 110(3), 497504.

Goodman, S., Rouse, M., Connell, A., Broth, M., Hall, C., \& Heyward, D. (2011). Maternal depression and child psychopathology: A meta-analytic review. Clinical Child and Family Psychology Review, 14(1), 1-27.

Goodman, S. H., Rouse, M. H., Connell, A. M., Broth, M. R., Hall, C. M., \& Heyward, D. (2011). Maternal depression and child psychopathology: A meta-analytic review. Clinical Child and Family Psychology Review, 14(1), 1-27.

Greenberg, P. E., Fournier, A.-A., Sisitsky, T., Pike, C. T., \& Kessler, R. C. (2015). The economic burden of adults with major depressive disorder in the United States (2005 and 2010). The Journal of clinical psychiatry, 76(2), 1,478-162.

Gross, R. S., Velazco, N. K., Briggs, R. D., \& Racine, A. D. (2013). Maternal Depressive Symptoms and Child Obesity in Low-Income Urban Families. Academic Pediatrics, 13(4), 356-363.

Guénard, F., Deshaies, Y., Cianflone, K., Kral, J. G., Marceau, P., \& Vohl, M.-C. (2013). Differential methylation in glucoregulatory genes of offspring born before vs. after maternal gastrointestinal bypass surgery. Proceedings of the National Academy of Sciences, 110(28), 11439-11444.

Halfon, N., Larson, K., \& Slusser, W. (2013). Associations between obesity and comorbid mental health, developmental, and physical health conditions in a nationally representative sample of US children aged 10 to 17. Academic Pediatrics, 13(1), 6-13.

Hamer, M., Stamatakis, E., \& Mishra, G. (2009). Psychological distress, television viewing, and physical activity in children aged 4 to 12 years. Pediatrics, 123(5), 1263-1268.

Han, J. C., Lawlor, D. A., \& Kimm, S. Y. (2010). Childhood obesity. The Lancet, 375(9727), 1737-1748. 
Harvard Medical School. (2011). Depression and cardiovascular risk in women. Harvard Women's Health Watch, 19(4), 1-2.

Heath, G. W., Brownson, R. C., Kruger, J., Miles, R., Powell, K. E., Ramsey, L. T., \& Services, T. F. o. C. P. (2006). The effectiveness of urban design and land use and transport policies and practices to increase physical activity: a systematic review. Journal of Physical Activity \& Health, 3, S55.

Hernandez-Reif, M., Field, T., Diego, M., Vera, Y., \& Pickens, J. (2006). Happy faces are habituated more slowly by infants of depressed mothers. Infant Behavior and Development, 29(1), 131-135.

Hicken, M. T., Lee, H., Mezuk, B., Kershaw, K. N., Rafferty, J., \& Jackson, J. S. (2013). Racial and Ethnic Differences in the Association Between Obesity and Depression in Women. Journal of Women's Health (15409996), 22(5), 445-452. doi:10.1089/jwh.2012.4111

Hill, P. C., \& Pargament, K. I. (2008). Advances in the conceptualization and measurement of religion and spirituality: Implications for physical and mental health research.

Hinkle, S. N., Sharma, A. J., \& Dietz, P. M. (2010). Gestational weight gain in obese mothers and associations with fetal growth. The American journal of clinical nutrition, 92(3), 644-651.

Hinkley, T., Crawford, D., Salmon, J., Okely, A. D., \& Hesketh, K. (2008). Preschool children and physical activity: a review of correlates. American Journal of Preventive Medicine, 34(5), 435-441. e437.

Ho, M., Garnett, S. P., Baur, L. A., Burrows, T., Stewart, L., Neve, M., \& Collins, C. (2013). Impact of dietary and exercise interventions on weight change and metabolic outcomes in obese children and adolescents: a systematic review and meta-analysis of randomized trials. JAMA pediatrics, 167(8), 759-768.

Institute for Health Metrics and Evaluation. (2015). US county profile: Shelby county, tennessee. Retrieved from http://www.healthdata.org/sites/default/files/files/county_profiles/US/County_Re port Shelby County_Tennessee.pdf

Iwata, N., Turner, R. J., \& Lloyd, D. A. (2002). Race/ethnicity and depressive symptoms in community-dwelling young adults: A differential item functioning analysis. Psychiatry Research.

Jaquet, D., Swaminathan, S., Alexander, G. R., Czernichow, P., Collin, D., Salihu, H. M., ... Levy-Marchal, C. (2005). Significant paternal contribution to the risk of small for gestational age. BJOG: An International Journal of Obstetrics and Gynaecology, 112(2), 153-159. doi:10.1111/j.1471-0528.2004.00313.x

Jiménez-Pavón, D., Kelly, J., \& Reilly, J. J. (2010). Associations between objectively measured habitual physical activity and adiposity in children and adolescents: Systematic review. International Journal of Pediatric Obesity, 5(1), 3-18.

Kaiser Family Foundation. (2015). Key facts about the uninsured population Retrieved from http://files.kff.org/attachment/fact-sheet-key-facts-about-the-uninsuredpopulation

Kaltman, S., Pauk, J., \& Alter, C. L. (2011). Meeting the Mental Health Needs of LowIncome Immigrants in Primary Care: A Community Adaptation of an EvidenceBased Model. American Journal of Orthopsychiatry, 81(4), 543-551. 
Kendler, K. S., Kessler, R. C., Walters, E. E., MacLean, C., Neale, M. C., Heath, A. C., \& Eaves, L. J. (2010). Stressful life events, genetic liability, and onset of an episode of major depression in women. Focus.

Khan, L. K., Sobush, K., Keener, D., \& Goodman, K. Recommended community strategies and measurements to prevent obesity in the United States.

Kim, I. J., Ge, X., Brody, G. H., Conger, R. D., Gibbons, F. X., \& Simons, R. L. (2003). Parenting behaviors and the occurrence and co-occurrence of depressive symptoms and conduct problems among african american children. Journal of Family Psychology, 17(4), 571.

Kistner, J. A., David-Ferdon, C. F., Lopez, C. M., \& Dunkel, S. B. (2007). Ethnic and sex differences in children's depressive symptoms. Journal of Clinical Child and Adolescent Psychology, 36(2), 171-181.

Klohe-Lehman, D. M., Freeland-Graves, J., Clarke, K. K., Cai, G., Voruganti, V. S., Milani, T. J., . . Bohman, T. M. (2007). Low-income, overweight and obese mothers as agents of change to improve food choices, fat habits, and physical activity in their 1-to-3-year-old children. Journal of the American College of Nutrition, 26(3), 196-208.

Kneipp, S. M., Kairalla, J. A., Stacciarini, J., \& Pereira, D. (2009). The Beck Depression Inventory II factor structure among low-income women. Nursing Research, 58(6), 400-409.

Kopelman, P. (2007). Health risks associated with overweight and obesity. Obesity Reviews, 8(s1), 13-17.

Kovacs, M., \& Multi-Health Systems. (2011). Children's depression inventory 2nd Edition (2nd ed.). Toronto, Canada: MHS.

Kubik, M. Y., Lytle, L. A., Birnbaum, A. S., Murray, D. M., \& Perry, C. L. (2003). Prevalence and correlates of depressive symptoms in young adolescents. American Journal of Health Behavior, 27(5), 546-553.

Lakshman, R., Elks, C. E., \& Ong, K. K. (2012). Childhood obesity. Circulation, 126(14), 1770-1779.

Lampard, A. M., Franckle, R. L., \& Davison, K. K. (2014). Maternal depression and childhood obesity: A systematic review. Preventive Medicine, 59(0), 60-67. doi:http://dx.doi.org/10.1016/j.ypmed.2013.11.020

Legrand, F. D. (2014). Effects of exercise on physical self-concept, global self-esteem, and depression in women of low socioeconomic status with elevated depressive symptoms. Journal of Sport \& Exercise Psychology, 36(4), 357-365.

Li, C., Ford, E. S., Mokdad, A. H., \& Cook, S. (2006). Recent trends in waist circumference and waist-height ratio among US children and adolescents. Pediatrics, 118(5), e1390-e1398.

Liu, L. L., Lawrence, J. M., Davis, C., Liese, A. D., Pettitt, D. J., Pihoker, C., . . Kahn, H. S. (2010). Prevalence of overweight and obesity in youth with diabetes in USA: the SEARCH for Diabetes in Youth study. Pediatric Diabetes, 11(1), 4-11.

Lorig, K. R., \& Holman, H. R. (2003). Self-management education: history, definition, outcomes, and mechanisms. Annals of Behavioral Medicine, 26(1), 1-7.

Lovasi, G. S., Hutson, M. A., Guerra, M., \& Neckerman, K. M. (2009). Built environments and obesity in disadvantaged populations. Epidemiologic Reviews, $\operatorname{mxp} 005$. 
Lucan, S. C., Barg, F. K., \& Long, J. A. (2010). Promoters and barriers to fruit, vegetable, and fast-food consumption among urban, low-income African Americans-a qualitative approach. American Journal of Public Health, 100(4), 631-635.

Luke, S., Salihu, H. M., Alio, A. P., Mbah, A. K., Jeffers, D., Berry, E. L., \& Mishkit, V. R. (2009). Risk factors for major antenatal depression among low-income African American women. Journal of Women's Health, 18(11), 1841-1846.

Lumeng, J. C., Forrest, P., Appugliese, D. P., Kaciroti, N., Corwyn, R. F., \& Bradley, R. H. (2010). Weight status as a predictor of being bullied in third through sixth grades. Pediatrics, $125(6)$, e1301-e1307.

Malik, V. S., Pan, A., Willett, W. C., \& Hu, F. B. (2013). Sugar-sweetened beverages and weight gain in children and adults: a systematic review and meta-analysis. The American journal of clinical nutrition, 98(4), 1084-1102.

Mather, M. (Producer). (2010). U.S. children in single-mother families Retrieved from http://www.prb.org/pdf10/single-motherfamilies.pdf

Matthews, T. D., O'Neill, E., Kostelis, K. T., Jaffe, D., Vitti, S., Quinlan, M., \& Boland, M. (2015). Physical Activity and Self-efficacy in Physical Activity and Healthy Eating in an Urban Elementary Setting. American Journal of Health Education, 46(3), 132-137. doi:10.1080/19325037.2015.1023476

McGuffin, P., Rijsdijk, F., Andrew, M., Sham, P., Katz, R., \& Cardno, A. (2003). The heritability of bipolar affective disorder and the genetic relationship to unipolar depression. Archives of General Psychiatry, 60(5), 497-502.

McLaren, L. (2007). Socioeconomic status and obesity. Epidemiologic Reviews, 29(1), 29-48.

McLeod, B. D., Weisz, J. R., \& Wood, J. J. (2007). Examining the association between parenting and childhood depression: A meta-analysis. Clinical Psychology Review, 27(8), 986-1003.

Mergl, R., Seidscheck, I., Allgaier, A. K., Möller, H. J., Hegerl, U., \& Henkel, V. (2007). Depressive, anxiety, and somatoform disorders in primary care: prevalence and recognition. Depression and Anxiety, 24(3), 185-195.

Merikangas, K. R., He, J.-p., Burstein, M., Swanson, S. A., Avenevoli, S., Cui, L., . . Swendsen, J. (2010). Lifetime prevalence of mental disorders in US adolescents: results from the National Comorbidity Survey Replication-Adolescent Supplement (NCS-A). Journal of the American Academy of Child and Adolescent Psychiatry, 49(10), 980-989.

Miller, S. T., Marolen, K. N., \& Beech, B. M. (2010). Perceptions of physical activity and motivational interviewing among rural African-American women with type 2 diabetes. Women's Health Issues, 20(1), 43-49.

Mistry, K. B., Minkovitz, C. S., Strobino, D. M., \& Borzekowski, D. L. (2007). Children's television exposure and behavioral and social outcomes at 5.5 years: does timing of exposure matter? Pediatrics, 120(4), 762-769.

Mitchell, S. J., \& Ronzio, C. R. (2011). Violence and other stressful life events as triggers of depression and anxiety: What psychosocial resources protect African American mothers? Maternal and child health journal, 15(8), 1272-1281. 
Moore, L. L., Lombardi, D. A., White, M. J., Campbell, J. L., Oliveria, S. A., \& Ellison, R. C. (1991). Influence of parents' physical activity levels on activity levels of young children. The Journal of pediatrics, 118(2), 215-219.

Murphy, N., MacIntyre, K., Stewart, S., Hart, C., Hole, D., \& McMurray, J. (2006). Long-term cardiovascular consequences of obesity: 20-year follow-up of more than 15000 middle-aged men and women (the Renfrew-Paisley study). European Heart Journal, 27(1), 96-106.

Nadeem, E., Lange, J. M., Edge, D., Fongwa, M., Belin, T., \& Miranda, J. (2007). Does stigma keep poor young immigrant and US-born black and Latina women from seeking mental health care? Psychiatric Services.

National Alliance on Mental Health. (2014). Depression in children and teens. Retrieved from

http://www.nami.org/Template.cfm?Section=By_Illness\&template=/ContentMan agement/ContentDisplay.cfm\&ContentID $=88551$

National Alliance on Mental Illness. (2016a). African american mental health Retrieved from https://www.nami.org/Find-Support/Diverse-Communities/AfricanAmericans

National Alliance on Mental Illness. (2016b). Depression. Retrieved from https://www.nami.org/Learn-More/Mental-Health-Conditions/Depression

National Alliance on Mental Illness. (2016c). Mental health reform. Retrieved from https://www.nami.org/Learn-More/Public-Policy/Mental-Health-Reform

National Center for Chronic Disease Prevention and Health Promotion. (2014).

Overweight and obesity. Retrieved from

http://www.cdc.gov/nccdphp/dnpao/state-local-programs/profiles/pdfs/tennesseestate-profile.pdf

National Center for Education Statistics. (2015a). Children living in povert. Retrieved from https://nces.ed.gov/programs/coe/pdf/coe cce.pdf

National Center for Education Statistics. (2015b). Fast Facts. Retrieved from https://nces.ed.gov/fastfacts/display.asp?id=16

National Institues of Health. (2012). How are overweight and obesity treated. Retrieved from http://www.nhlbi.nih.gov/health/health-topics/topics/obe/treatment

National Institute of Mental Health. (2014a). Major depression among adults. Retrieved from http://www.nimh.nih.gov/health/statistics/prevalence/major-depressionamong-adults.shtml

National Institute of Mental Health. (2014b). Major deprssion among adults. Retrieved from http://www.nimh.nih.gov/health/statistics/prevalence/major-depressionamong-adults.shtml

National Institute of Mental Health. (2015). Major depression among adolescents. Retrieved from http:/www.nimh.nih.gov/health/statistics/prevalence/majordepression-among-adolescents.shtml

National Institute of Mental Health. (n.d.). Depression in children and adolescents [Fact sheet]. Retrieved from http://www.nimh.nih.gov/health/publications/depressionin-children-and-adolescents/index.shtml 
National Institutes of Health. (2011). Inclusion of minorities and women in study populations- questions and answers. Retrieved from

https://www.nhlbi.nih.gov/research/funding/human-subjects/include-womenminorities-qa

National Institutes of Health. (2015). What is physical activity? Retrieved from https://www.nhlbi.nih.gov/health/health-topics/topics/phys

National Institutes of Health. (n.d.). BMI tools. Retrieved from https://www.nhlbi.nih.gov/health/educational/lose wt/bmitools.htm

National Institutes of Health, \& Department of Health and Human Services. (n.d.). Retrieved from http://www.nhlbi.nih.gov/health/educational/lose wt/BMI/bmicalc.htm

Natsuaki, M. N., Ge, X., Brody, G. H., Simons, R. L., Gibbons, F. X., \& Cutrona, C. E. (2007). African American children's depressive symptoms: The prospective effects of neighborhood disorder, stressful life events, and parenting. American Journal of Community Psychology, 39(1-2), 163-176.

Nicolaidis, C., Timmons, V., Thomas, M. J., Waters, A. S., Wahab, S., Mejia, A., \& Mitchell, S. R. (2010). "You don't go tell white people nothing": African American women's perspectives on the influence of violence and race on depression and depression care. American Journal of Public Health, 100(8), 1470-1476.

Nolen-Hoeksema, S. (2001). Gender differences in depression. Current Directions in Psychological Science, 10(5), 173-176.

Odoms-Young, A. M., Zenk, S., \& Mason, M. (2009). Measuring food availability and access in African-American communities: implications for intervention and policy. American Journal of Preventive Medicine, 36(4), S145-S150.

Office of Disease Prevention and Health Promotion. (2016). Chapter 3: Active children and adolescents Retrieved from http://health.gov/paguidelines/guidelines/chapter3.aspx

Ogden, C. L., Carroll, M. D., Kit, B. K., \& Flegal, K. M. (2012). Prevalence of obesity and trends in body mass index among US children and adolescents, 1999-2010. JAMA, 307(5), 483-490.

Ogden, C. L., Carroll, M. D., Kit, B. K., \& Flegal, K. M. (2014). Prevalence of childhood and adult obesity in the United States, 2011-2012. JAMA, 311(8), 806-814.

Ørskou, J., Henriksen, T. B., Kesmodel, U., \& Secher, N. J. (2003). Maternal characteristics and lifestyle factors and the risk of delivering high birth weight infants. Obstetrics and Gynecology, 102(1), 115-120. doi:http://dx.doi.org/10.1016/S0029-7844(03)00402-2

Pachter, L. M., Auinger, P., Palmer, R., \& Weitzman, M. (2006). Do parenting and the home environment, maternal depression, neighborhood, and chronic poverty affect child behavioral problems differently in different racial-ethnic groups? Pediatrics, 117(4), 1329-1338.

Pekmezi, D., Marcus, B., Meneses, K., Baskin, M. L., Ard, J. D., Martin, M. Y., . . Demark-Wahnefried, W. (2013). Developing an intervention to address physical activity barriers for African-American women in the deep south (USA). Women's Health, 9(3), 301-312. 
Poston, L., Harthoorn, L. F., \& Van der Beek, E. M. (2011). Obesity in pregnancy: implications for the mother and lifelong health of the child. A consensus statement. Pediatric Research, 69(2), 175-180.

President's Council on Fittness Sports \& Nutrition. (2015). Facts \& statistics Retrieved from http://www.fitness.gov/resource-center/facts-and-statistics/

Ratcliffe, C., McKernan, S.-M., \& Zhang, S. (2011). How much does the Supplemental Nutrition Assistance Program reduce food insecurity? American Journal of Agricultural Economics, aar026.

Reeves, G. M., Postolache, T. T., \& Snitker, S. (2008). Childhood obesity and depression: connection between these growing problems in growing children. International journal of child health and human development: IJCHD, 1(2), 103.

Richardson, L. P., McCauley, E., McCarty, C. A., Grossman, D. C., Myaing, M., Zhou, C., ... Katon, W. (2012). Predictors of persistence after a positive depression screen among adolescents. Pediatrics, 130(6), e1541-e1548.

Ruager-Martin, R., Hyde, M. J., \& Modi, N. (2010). Maternal obesity and infant outcomes. Early Human Development, 86(11), 715-722.

Saunders, R. P., Pate, R. R., Felton, G., Dowda, M., Weinrich, M. C., Ward, D. S., . . Baranowski, T. (1997). Development of questionnaires to measure psychosocial influences on children's physical activity. Preventive Medicine, 26(2), 241-247.

Schulz, A. J., Israel, B. A., Zenk, S. N., Parker, E. A., Lichtenstein, R., Shellman-Weir, S., \& AB, L. K. (2006). Psychosocial stress and social support as mediators of relationships between income, length of residence and depressive symptoms among African American women on Detroit's eastside. Social Science and Medicine, 62(2), 510-522.

Shenkin, J. D., \& Jacobson, M. F. (2010). Using the Food Stamp Program and other methods to promote healthy diets for low-income consumers. American Journal of Public Health, 100(9), 1562-1564.

Smarr, K. L., \& Keefer, A. L. (2011). Measures of depression and depressive symptoms: Beck Depression Inventory-II (BDI-II), Center for Epidemiologic Studies Depression Scale (CES-D), Geriatric Depression Scale (GDS), Hospital Anxiety and Depression Scale (HADS), and Patient Health Questionnaire-9 (PHQ-9). Arthritis Care and Research, 63(S11), S454-S466.

Smith, J., Cianflone, K., Biron, S., Hould, F., Lebel, S., Marceau, S., . . Kral, J. (2009). Effects of maternal surgical weight loss in mothers on intergenerational transmission of obesity. The Journal of Clinical Endocrinology \& Metabolism, 94(11), 4275-4283.

State of Obesity. (2014). Obesity prevention in black communities. Retrieved from http://stateofobesity.org/disparities/blacks/

Steinberg, D. M., Askew, S., Lanpher, M. G., Foley, P. B., Levine, E. L., \& Bennett, G. G. (2014). The effect of a "maintain, don't gain" approach to weight management on depression among Black women: results from a randomized controlled trial. American Journal of Public Health, 104(9), 1766-1773.

Teaching Tolerance. (2016). Bullying Basis Retrieved from http://www.tolerance.org/bullying-basics

The Children's Hospital of Philadelphia. (2016). Pediatric Z-score Calculator Retrieved from http://stokes.chop.edu/web/zscore/ 
The Hamilton Project. (2015). Increasing education: What it will and will not do for earnings and earnings inequalty. Retrieved from http://www.hamiltonproject.org/papers/increasing_education_what it_will and will_not_do for_earnings inequal

The White House. (2016). About the healthcare law. Retrieved from https://www.whitehouse.gov/healthreform/healthcare-overview - consumer-rights

Thielke, S., Vannoy, S., \& Unützer, J. (2007). Integrating mental health and primary care. Primary care, 34(3), 571-592, vii.

Thompson, A. L. (2013). Intergenerational impact of maternal obesity and postnatal feeding practices on pediatric obesity. Nutrition Reviews, 71 Suppl 1, S55-S61. doi:10.1111/nure.12054

Topham, G. L., Page, M. C., Hubbs-Tait, L., Rutledge, J. M., Kennedy, T. S., Shriver, L., \& Harrist, A. W. (2010). Maternal depression and socio-economic status moderate the parenting style/child obesity association. Public Health Nutrition, 13(08), 1237-1244.

Townsend, M. C. (2014). Psychiatric mental health nursing: Concepts of care in evidence-based practice (8th ed.). Philadelphia, PA: F.A. Davis Company.

Trost, S. G., Kerr, L., Ward, D. S., \& Pate, R. R. (2001). Physical activity and determinants of physical activity in obese and non-obese children. International Journal of Obesity and Related Metabolic Disorders, 25(6).

Trost, S. G., Pate, R. R., Saunders, R., Ward, D. S., Dowda, M., \& Felton, G. (1997). A prospective study of the determinants of physical activity in rural fifth-grade children. Preventive Medicine, 26(2), 257-263.

Trust for America's Health, \& Robert Wood Johnson Foundation. (2014). Racial and ethnic disparities in obesity. Retrieved from http://stateofobesity.org/disparities/

Trust for Americas Health and Robert Wood Johnson Foundation. (2015). Adult obesity in the united states. Retrieved from http://stateofobesity.org/adult-obesity/

Ttofi, M. M., Farrington, D. P., Lösel, F., Ttofi, M. M., Farrington, D. P., Lösel, F., \& Loeber, R. (2011). Do the victims of school bullies tend to become depressed later in life? A systematic review and meta-analysis of longitudinal studies. Journal of Aggression, Conflict and Peace Research, 3(2), 63-73.

Tzanetakou, I. P., Katsilambros, N. L., Benetos, A., Mikhailidis, D. P., \& Perrea, D. N. (2012). "Is obesity linked to aging?": adipose tissue and the role of telomeres. Ageing research reviews, 11(2), 220-229.

U.S. Census Bureau. (2011). Living arrangements of children:2009. Washington, DC Retrieved from https://www.census.gov/prod/2011pubs/p70-126.pdf.

U.S. Census Bureau. (2012). Educational attainment in the United States: 2009. Retrieved from http://www.census.gov/prod/2012pubs/p20-566.pdf

U.S. Department of Health \& Human Services. (2015). The ACA is working for the african-american community. Retrieved from http://www.hhs.gov/healthcare/facts-and-features/fact-sheets/aca-workingafrican-american-community/

U.S. Department of Health and Human Services, \& National Institutes of Mental Health. (2015). Depression. Retrieved from http://www.nimh.nih.gov/health/publications/depression-what-you-need-to-know12-2015/depression-what-you-need-to-know-pdf_151827.pdf 
U.S. Department of Health and Human Services Office of Minority Health. (2013). Obesity and african americans Retrieved from http://minorityhealth.hhs.gov/omh/browse. aspx?lvl=4\&lvlid=25

United States Census Bureau. (2015). Quick facts. Retrieved from http://www.census.gov/quickfacts/table/PST045215/00

United States Department of Agriculture. (2015). Physical Activity Retrieved from https://www.choosemyplate.gov/physical-activity-what-is

University of Maryland Medical Center. (2016). Depression. Retrieved from http://umm.edu/health/medical/reports/articles/depression

Waite, R., \& Killian, P. (2008). Health beliefs about depression among African American women. Perspectives in Psychiatric Care, 44(3), 185-195.

Walker, R. E., Keane, C. R., \& Burke, J. G. (2010). Disparities and access to healthy food in the United States: a review of food deserts literature. Health \& Place, 16(5), 876-884.

Wang, L., Anderson, J. L., Dalton III, W. T., Wu, T., Liu, X., Zheng, S., \& Liu, X. (2013). Maternal depressive symptoms and the risk of overweight in their children. Maternal and child health journal, 17(5), 940-948.

Wethington, H., Pan, L., \& Sherry, B. (2013). The Association of Screen Time, Television in the Bedroom, and Obesity Among School-Aged Youth: 2007 National Survey of Children's Health. Journal of School Health, 83(8), 573-581. doi:10.1111/josh. 12067

Whisman, M. A., Judd, C. M., Whiteford, N. T., \& Gelhorn, H. L. (2013). Measurement invariance of the Beck Depression Inventory-Second Edition (BDI-II) across gender, race, and ethnicity in college students. Assessment, 20(4), 419-428.

Wight, R. G., Aneshensel, C. S., Botticello, A. L., \& Sepúlveda, J. E. (2005). A multilevel analysis of ethnic variation in depressive symptoms among adolescents in the United States. Social Science and Medicine, 60(9), 2073-2084.

Williams, H. G., Pfeiffer, K. A., O'neill, J. R., Dowda, M., McIver, K. L., Brown, W. H., $\&$ Pate, R. R. (2008). Motor skill performance and physical activity in preschool children. Obesity, 16(6), 1421-1426.

World Health Organization. (2008). Integrating mental health into primary care: a global perspective: World Health Organization.

World Health Organization. (2012). Depression [Fact sheet]. Retrieved from http://www.who.int/mediacentre/factsheets/fs369/en/

World Health Organization. (2015a). Depression. Retrieved from http://www.who.int/mediacentre/factsheets/fs369/en/

World Health Organization. (2015b). Obesity and overweight [Fact sheet]. Retrieved from http://www.who.int/mediacentre/factsheets/fs311/en/

World Health Organization. (2016a). Facts and figures on childhood obesity Retrieved from http://www.who.int/end-childhood-obesity/facts/en/

World Health Organization. (2016b). Obesity and overweight [Fact Sheet]. Retrieved from http://www.who.int/mediacentre/factsheets/fs311/en/

XiaoXia, S., Ping, X., McBride, R. E., JiLing, L., \& Thornton, M. A. (2016). At-risk boys' social self-efficacy and physical activity self-efficacy in a summer sports camp. Journal of Teaching in Physical Education, 35(2), 159-168. 
Yach, D., Stuckler, D., \& Brownell, K. D. (2006). Epidemiologic and economic consequences of the global epidemics of obesity and diabetes. Nature Medicine, $12(1), 62-66$.

Zeiss, A. M., \& Karlin, B. E. (2008). Integrating mental health and primary care services in the Department of Veterans Affairs health care system. Journal of Clinical Psychology in Medical Settings, 15(1), 73-78.

Zhang, A. Y., \& Gary, F. (2013). Discord of measurements in assessing depression among african americans with cancer diagnoses. International Journal of Culture and Mental Health, 6(1), 58-71.

Zhao, Goldberg, J., \& Vaccarino, V. (2013). Promoter methylation of serotonin transporter gene is associated with obesity measures: a monozygotic twin study. International Journal of Obesity, 37(1), 140-145.

Zhao, \& Grant. (2011). Genetics of childhood obesity. Journal of Obesity, 2011. 
APPENDIX A. PHYSICAL ACTIVITY SELF-EFFICACY SCALE

\section{Physical Activity Self-Efficacy Tool}

Name:

Date of Birth:

Grade:

Today's Date: ________ Circle One: Male or Female

Directions: Please put a check by "Yes" or "No" for each of the following sentences. "Yes" means that you agree with the sentence. "No" means that you do not agree with the sentence. Remember that physical activity can be any play, game, sport, or exercise that gets you moving and breathing harder. There are no wrong answers.

1. I think I can be physically active most days after school. Yes No

2. I think I can ask my parent or other adult to do physically active things with me.

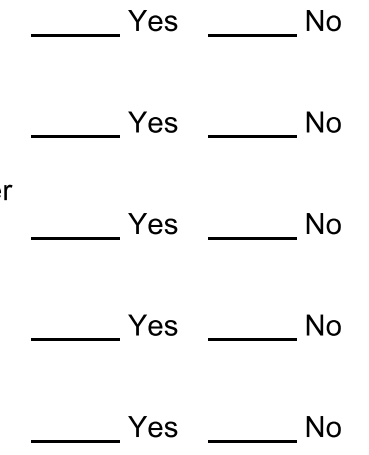

6. I think I can ask my parent or other adult to sign me up for a sport, dance, or other physical activity program. Yes No

7. I think I can be physically active even if it is very hot or cold outside.

Yes No

8. I think I can ask my best friend to be physically active with me.

Yes No 
9. I think I can ask my parent or other adult to get me the equipment I need to be physically active.

Yes No

10. I think I can be physically active no matter how tired I may feel. Yes

11. I think I can ask my parent or other adult to take me to a physical activity or sport practice Yes No

12. I think I can be physically active, even if I have a lot of homework.

Yes No

13. I think I can be physically active even if I have to stay at home.

Yes — No

14. I think I can be physically active even if my friends don't want me to.

Yes No

15. I think I have the skills I need to be physically active.

Yes No

16. I think I can be physically active no matter how busy my day is.

Yes No

17. I think I can be physically active at least three times a week for the next 2 weeks.

Yes No 


\section{APPENDIX B. DEMOGRAPHIC PROFILE QUESTIONNAIRE}

\section{Demographic Profile Questionnaire}

Please answer each question listed below about you and your child. All answers will be used for research purposes only.

Section 1: Questions regarding the Mother.

1. What are your age and your birthdate in month, day, and year?

$$
\text { Example: } 30 \text { years January } 14,1986
$$

a.

2. What is your ethnicity?
a. Black
b. Black/Biracial

3. What is the highest level of education that you have completed as of today? (Please circle just one answer choice)
a. Some high school
b. High school diploma or GED
c. Associates degree
d. Bachelors degree e. Masters Degree
f. Doctorate Degree

4. Have you had weight loss/reduction surgery, such as gastric banding, gastric bypass, or biliopancreatic diversion?
a. Yes, I have
b. No, I have not

5. Are you currently enrolled in a weight loss program? For example Weight Watchers, Jenny Craig, or other.
a. Yes, I am
b. No, I am not

*If you answered yes, please indicate which:

6. What is your current marital status?
a. Single
b. Married
c. Divorced
d. Widowed

7. What is the address of where you live?

Street:

Apt \#: 
City:

State:

8. Are you currently taking an antidepressant medication, such as Prozac, Celexa,

Zoloft, etc.?
a. Yes
b. No

\section{Section 2: Questions regarding the Child.}

1. What is your child's gender?
a. Boy
b. Girl

2. What is your child's age and birthdate in month, day, and year?

$$
\text { Ex: } 7 \text { years January } 14,2008
$$

a.

b.

3. What is your child's ethnicity?
a. Black
b. Black/Biracial

4. What grade in school is your child? (If answered during the summer, list the grade your child will enter in the fall)

a.

5. Is your child currently taking an antidepressant medication, such as Prozac, Celexa, Zoloft, etc.?
a. Yes
b. No

6. What is your child's physical address if different from yours? Street:

Apt \#:

City:

State:

7. Has your child ever been diagnosed with any of the following conditions? *Please circle either Yes or No
a. High Blood Pressure
Yes No

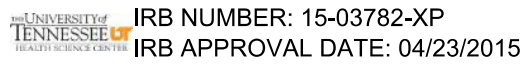



b. Asthma
Yes No
c. Anxiety Disorder
Yes No
d. Depression
Yes No
e. Bipolar Disorder
Yes No
f. Type II Diabetes
Yes No
g. Attention Deficit Hyperactivity Disorder (ADHD) Yes No
h. Other:

IRB NUMBER: 15-03782-XP

TENNESEEE IRB APPROVAL DATE: 04/23/2015 


\section{APPENDIX C. TELEPHONE SCREENING}

Hello,

Yes, this is Y'Esha Weeks. (Caller states they obtained my contact information from the flyer and they would like to receive more information about the study).

"Thank you for showing interest. This study involves comparing Body Mass Index and depressive symptoms of black mothers and their child. If you qualify to be a participant I would collect height and weight information from you and child in order to calculated your Body Mass Index. This measurement indicates whether a person in underweight, normal weight, overweight, or obese for their specific height and weight. There is a written component where you and your child will complete a depressive symptom questionnaire. Lastly, children will complete a physical activity questionnaire. This entire process will all take about 45 minutes to complete."

"To assure that you meet the criteria for my study do you mind telling me the grade and age of your child? Do you and your child self-identify ethnically as black? Can you give me an approximation of how tall and how much you and your child weigh? Are you and your child both able to stand up straight without any assistance such as a prosthetic limb, walker, cane, or crutch? Are you or your child currently taking a prescribed antidepressant medication? Lastly, are you currently pregnant? Thank you for your responses."

"You have met the basic prescreen requirements via telephone. Would you be interested in participating within the study? Do you have an email address because I would like to send you the demographic profile questionnaire, consent form, and assent form (if applicable) to provide you with more information about the study? If you decide to participate after you have met all inclusion criteria we will move forward with scheduling a date and time for you and your child to complete the study. Thank you for your time and interest in participation. I look forward to speaking with you in the near future." 


\section{APPENDIX D. MAIN CONSENT AND ASSENT FORMS}

Main Consent Form

THEUNIVERSITYof

TENNESSEE

2. PROCEDURES TO BE FOLLOWED:

All procedures performed are for research purposes only.

Children (35 minutes):

- The study staff will obtain and record height and weight measurements for BMI calculation.

- Children will complete the Children's Depression Inventory II and the Physical Activity Self-Efficacy Tool. The Children's Depression Inventory II is a 28-item, multiple choice, self-report screening tool used to assess symptoms of depression in children and adolescents. The child will choose one of three items that best explains their feelings in the past two weeks. Mothers will be notified if a child displays moderate to severe depression symptoms. Follow-up with the child's health care provider will also be recommended.

- The Physical Activity Self-Efficacy Tool is a 17-item questionnaire that assesses support seeking behaviors, barriers and positive alternatives in relation to physical activity in children.

Mothers (15 minutes):

- Mothers will complete the demographic profile questionnaire while the child is completing their questionnaires.

- The study staff will obtain and record height and weight measurements for BMI calculations

- Mothers will complete the Beck's Depression Inventory II that consists of 21-items that assess for depression symptoms such agitation, poor concentration and loss of energy in adolescents and adults. Mothers with moderate to severe depression symptoms will be notified and recommended to follow-up with their primary care provider.

All the procedures described in this consent form are for research purposes only.

\section{RISKS ASSOCIATED WITH PARTICIPATION:}

There is the potential risk of loss of confidentiality. Every effort will be made to keep your information confidential; however, this cannot be guaranteed.

The research may involve risks to you, which are currently unforeseeable. You will be told about any new information that might change your decision to be in this study. You may be asked to sign a new consent form if this occurs.

Questionnaires/Surveys:

[May 7, 2015]

Page 2 of 8

Subject or Parent/Legally Authorized Representative Initials

IRB NUMBER: 15-03782-XP

IRB APPROVAL DATE: 06/02/2015

IRB EXPIRATION DATE: 03/18/2016 
Completion of the depressive symptom questionnaires may make you feel uncomfortable or cause troublesome feelings or emotions. You may refuse to answer any of the questions and you may take a break at any time during the study.

\section{BENEFITS ASSOCIATED WITH PARTICIPATION:}

You will not receive any benefits from being in this study. This study has the potential to expand the current knowledge of depression and obesity in black women and children. The results of this study may help people with obesity or depression in the future by integrating family centered care in primary care settings.

\section{ALTERNATIVES TO PARTICIPATION:}

You do not have to participate in this study. You will not have to undergo the following procedures if you do not take part in this study:

- Assessment of height and weight information (mother and child)

- Complete a self-report depression inventory (mother and child)

- Complete a physical activity self-efficacy scale (child only)

\section{CONFIDENTIALITY:}

\section{Research records}

All your paper research records will be stored in locked file cabinets and will be accessible only to research personnel.

All your electronic research records will be computer password protected and accessible only to research personnel.

\section{Medical Records}

Information about your participation in this study or the results of procedures performed in this study will not be placed in your medical record; as such, this information will not be made available to your employer or insurer.

\section{Presentations/Publications}

You will not be identified in any presentations or publications based on the results of this research study.

Authorization to Use and Disclose Information for Research Purposes 
Under federal privacy regulations, you have the right to decide who can review and copy your personal health information (called "protected health information" or PHI). PHI collected in this study may include information such as:

- Past and present medical records

- Records about your study visits

- Records about phone calls made as part of this research

- Research records

By signing this consent form, you are giving your permission for the study staff at the University of Tennessee to get your PHI from your doctor and/or facilities where you have received health care. They may also share your PHI with:

- The Institutional Review Board (IRB) at the University of Tennessee Health Science Center

- UT Le Bonheur Pediatric Specialists, Inc.

Your PHI will only be used and/or given to others:

- To do the research

- To study the results

- To see if the research was done correctly

Your PHI will be used until the study is completed.

You may withdraw or take away your permission to use and disclose your PHI at any time. You do this by sending written notice to the study staff. If you withdraw your permission, you will not be able to stay in the study.

When you withdraw your permission, no new PHI will be gathered after that date. However, information that has already been gathered may still be used and given to others. The federal regulations allow you to review or copy your PHI that is used in this study.

\section{COMPENSATION AND TREATMENT FOR INJURY:}

You are not waiving any legal rights or releasing the University of Tennessee, UT Le Bonheur Pediatric Specialists, Inc., or the agents of either, from liability for negligence. In the event of physical injury resulting from research procedures, the University of Tennessee and UT Le Bonheur Pediatric Specialists, Inc. do not have funds budgeted for compensation for medical treatment. Therefore, the University of Tennessee and UT Le Bonheur Pediatric Specialists, Inc. do not provide for treatment or reimbursement for such injuries.

[May 7, 2015]

Page 4 of 8

Subject or Parent/Legally Authorized Representative Initials

IRB NUMBER: 15-03782-XP

IRB APPROVAL DATE: 06/02/2015

IRB EXPIRATION DATE: 03/18/2016 
If you are injured or get sick as a result of being in this study, you and/or your insurance will be billed for the costs associated with this medical treatment. The study doctor will provide acute medical treatment, and will provide you with a subsequent referral to appropriate health care facilities.

No compensation will be available to you for any extra expenses that you may have as the result of research related physical injuries, such as additional hospital bills, lost wages, travel expenses, etc.

No compensation will be available to you for any non-physical injuries that you may have as a result of research participation, such as legal problems, problems with your finances or job, or damage to your reputation.

\section{QUESTIONS:}

Contact Y'Esha Weeks at 662-832-4983 if you have questions about your participation in this study, or if you have questions, concerns, or complaints about the research.

If you feel you have had a research-related injury contact Y'Esha Weeks at 662-832-4983, which is a cell phone number.

You may contact Terrence F. Ackerman, Ph.D., UTHSC IRB Chairman, at 901-448-4824, or visit the IRB website at http://www.uthsc.edu/research/research_compliance/IRB/participant_complaint.php if you have any questions about your rights as a research subject, or if you have questions, concerns, or complaints about the research.

\section{PAYMENT FOR PARTICIPATION:}

You and your child will each receive $\$ 10$ cash at the completion of the study. The child's $\$ 10$ cash payment will be given to the mother for their use.

However, if you are an employee of the University of Tennessee, you will not receive cash; your payment for participation will be added to your paycheck and will be subject to the standard taxes.

\section{COSTS OF PARTICIPATION:}

There are no costs to you for participating in this study.

[May 7, 2015]

Page 5 of 8

Subject or Parent/Legally Authorized Representative Initials

IRB NUMBER: 15-03782-XP

IRB APPROVAL DATE: 06/02/2015

IRB EXPIRATION DATE: 03/18/2016 
Main Consent Form

\section{VOLUNTARY PARTICIPATION AND WITHDRAWAL:}

Your participation in this research study is voluntary. You may decide not to participate or you may leave the study at any time. Your decision will not result in any penalty or loss of benefits to which you are entitled.

If you are a student of the University of Tennessee Health Science Center, participating or not participating in this study will in no way influence your grade in any course. If you are an employee of University of Tennessee Health Science Center, participating or not participating in this study will not affect your employment status.

If you decide to stop being part of the study, you should tell the study researcher, and any information that you have already provided will be kept in a confidential manner.

The researcher may stop your participation in this research study without your consent for any of the following reasons:

- If you or your child does not show up for the study visit.

- If you or your child does not complete the BMI assessment.

- If you or your child does not complete the questionnaire(s).

- If you or your child has a change in physical structure such as broken bones that require cast placement, or the inability to stand up straight. 
Main Consent Form

\section{CONSENT OF SUBJECT:}

You have read or have had read to you a description of the research study as outlined above. The investigator or his/her representative has explained the study to you and has answered all the questions you have at this time. You knowingly and freely choose to participate in the study. A copy of this consent form will be given to you for your records.

Signature of Research Subject - Parent $(18$ years +$)$

Date

Date

Date

Date
Signature of Legally Authorized Representative

Printed Name of Legally Authorized Representative

Relationship of Legally Authorized Representative
Date

Time

In my judgment, the subject or the legally authorized representative has voluntarily and knowingly given informed consent and possesses the legal capacity to give informed consent to participate in this research study.

\begin{tabular}{lc}
${ } }$ & Date \\
\hline$[$ May 7,2015$]$ & Page 7 of 8 \\
& IRB NUMBER: 15-03782-XP \\
& IRB APPROVAL DATE: 06/02/2015 \\
TENNESSEEG & IRB EXPIRATION DATE: $03 / 18 / 2016$
\end{tabular}




\section{A. Assent Obtained:}

The assent discussion was initiated on

(date) at (time).

The information was presented in age-appropriate terms

Minor Subject's Printed Name

Minor Subject's Signature (8-10 years)

\section{Minor Subject's Date of Birth}

$\overline{\text { Date }} \quad \overline{\text { Time }}$

* Please note that the parent(s)/legally authorized representative(s) must sign the consent signature page.

I hereby certify that I have discussed the research project with the minor subject and/or his/her parent(s)/legally authorized representative(s). I have explained all the information contained in the informed consent document, including any risks that may be reasonably expected to occur. I further certify that the research subject was encouraged to ask questions and that all questions were answered.

\section{Printed Name of Person Obtaining Assent}

B. Assent Not Obtained, but Minor Subject was Enrolled:

Assent of the minor subject was NOT obtained for the following reason:

$\square$ Minor is cognitively or emotionally unable to participate in an assent discussion (e.g., minor has either a psychiatric or developmental disorder; minor received narcotics within the last 4 hours; minor is sedated; etc.).

$\square$ Minor refused to provide assent; however, the intervention or procedure involved in the research holds out a prospect of direct benefit that is important to the health or well being of the minor and is available only in the context of the research [45 CFR 46.408(a)].

C. Assent Was Obtained, but Minor Subject was Unable to Sign:

$\square$ The minor assented to participation, but has an incapacity that prevents applying a signature (e.g., the subject's dominant hand is incapacitated, the subject is illiterate, etc.) The assenting subject's inability to sign the assent document has been duly noted in the research record. 


\section{APPENDIX E. IRB LETTER OF APPROVAL}

\begin{tabular}{lr}
\hline THE UNIVERSITY OF TENNESSEE \\
Health Science Center
\end{tabular}

April 23, 2015

Y'Esha V Weeks, MSN, RN

UTHSC - CON - Nursing- Academic Programs

547920 Madison Building

920 Madison Avenue

Memphis, TN 38163-2275

Re: 15-03782-XP

Study Title: Relationships between Depressive Symptoms, Body Mass Index, and Physical Activity Self-Efficacy in Mother-Child Dyads

Dear Dr. Weeks:

The Administrative Section of the UTHSC Institutional Review Board (IRB) has received your written acceptance of and/or response dated 04/22/2015 07:43:24 PM CDT to the provisos outlined in our correspondence of 3/30/2015 and 4/22/2015 concerning the above referenced project. The IRB determined that your application is eligible for expedited review under $45 \mathrm{CFR}$ 46.110(b)(1), categories (4), (5) and (7). The use of children as subjects is approved under 45 CFR 46.404. The IRB has reviewed these materials and determined that they do comply with proper consideration for the rights and welfare of human subjects and the regulatory requirements for the protection of human subjects. Therefore, this letter constitutes full approval by the IRB of your application (version 1.3) as submitted including:

- Protocol dated 4/20/2015;

- Telephone Prescreen Script dated 4/22/2015;

- Flyer dated 4/22/2015;

- Demographic profile questionnaire;

- Children's Depression Inventory II;

- Self-Efficacy Scale to the child;

- Beck's Depression Inventory II, and

- Consent form dated 4/20/2015 (stamped IRB approved 4/23/2015). The UTHSC IRB stamped-approved consent form must be used to enroll prospective subjects in the study.

Approval of this study will be valid from April 23, 2015 to 03/18/2016. 
The IRB has determined that the informed consent form, incorporating the authorization of subjects to use their protected health information in research, complies with the federal privacy regulations as specified in 45 CFR 160 and 45 CFR 164.

In addition, the request for waiver of HIPAA authorization to identify potential subjects, and to recruit potential subjects from the telephone-screening interview is approved.

In the event that subjects are to be recruited using solicitation materials, such as brochures, posters, web-based advertisements, etc., these materials must receive prior approval of the IRB. Any revisions in the approved application must also be submitted to and approved by the IRB prior to implementation. In addition, you are responsible for reporting any unanticipated serious adverse events or other problems involving risks to subjects or others in the manner required by the local IRB policy.

Finally, re-approval of your project is required by the IRB in accord with the conditions specified above. You may not continue the research study beyond the time or other limits specified unless you obtain prior written approval of the IRB.

Sincerely,

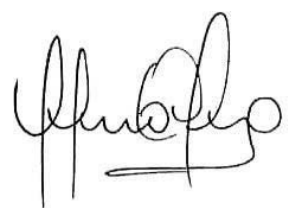

Signature applied by Virginia D Calvo Torres on 04/23/2015 12:47:33 PM CDT

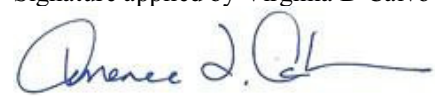

Signature applied by Terrence F Ackerman on 04/23/2015 12:48:26 PM CDT

Virginia Calvo-Torres, BS, CCRP, CIM

IRB Compliance Advisor

UTHSC IRB

Terrence F. Ackerman, Ph.D

Chairman

UTHSC IRB 


\section{VITA}

Ms. Y'Esha Williams was born in Clarksdale, MS, in 1986. Currently, she is a student in the Nursing Science PhD program at the University of Tennessee Health Science Center (UTHSC) College of Graduate Health Sciences. During her undergraduate program at The University of Mississippi she became interested in research and conducted a study entitled "The Effects of Carbon Dioxide Absorbed in Sea Water on Aiptasia pallida and its Symbiotic Zooxanthellae." After the completion of her Bachelor's degree she taught Biology I, Biology II, and Human and Anatomy and Physiology at Greenwood High School. She was awarded Teacher of the Year for the 2009-2010 academic school year. In 2012 she attained her MSN degree at the University of Tennessee Health Science Center and was inducted into Sigma Theta Tau International, The Honor Society of Nursing. Shortly after enrolling into the $\mathrm{PhD}$ program in 2012 she began working as a Graduate Teaching Assistant for $1^{\text {st }}$ and $2^{\text {nd }}$ year MSN-CNL students at UTHSC. She also gained experience in coordinating mentorship, community service, and leadership activities for MSN-CNL students awarded the Robert Wood Johnson Foundation Scholarship. From 2013-2016, she received the Southern Regional Educational Board State Doctoral Scholarship. Y'Esha worked as a charge nurse at a mental and behavioral health hospital before joining the faculty at the University of Memphis. At present her research interests include examining associations between depressive symptoms, body mass index (BMI), and physical activity selfefficacy in African American mothers and their children. In the near future she would like to explore self-management strategies and quality of life in adolescent populations diagnosed with type II diabetes and obesity. 